Copyright

by

Travis Zhi-Rong Wicks

2013 
The Thesis Committee for Travis Zhi-Rong Wicks Certifies that this is the approved version of the following thesis:

\section{The Use of $\delta^{13} \mathrm{C}$ Values of Leporid Teeth as Indicators of Past \\ Vegetation}

\section{APPROVED BY SUPERVISING COMMITTEE:}

Supervisor:

Timothy M. Shanahan

Co-Supervisor:

Christopher J. Bell

Daniel O. Breecker 


\title{
The Use of $\delta^{13} \mathrm{C}$ Values of Leporid Teeth as Indicators of Past Vegetation
}

\author{
by
}

\section{Travis Zhi-Rong Wicks, B.S.}

\author{
Thesis \\ Presented to the Faculty of the Graduate School of \\ The University of Texas at Austin \\ in Partial Fulfillment \\ of the Requirements \\ for the Degree of
}

Master of Science in Geological Sciences

The University of Texas at Austin

May 2013 


\section{Dedication}

This thesis is dedicated to my parents

who have influenced every part of who I am today. 


\section{Acknowledgements}

I hate to start off with an apology, but as a disclaimer, I am sorry for the omission of anyone who deserves acknowledgement. Though I may have forgotten to include you in the acknowledgements, know that I am fully appreciative of the assistance you have provided me.

I would like to express my deepest appreciation for all the support my family has

given me. My parents, Dr. Charles W. Wicks, Jr. III, and Jackie C. Wicks and my brothers, Cody Z. Wicks and Jamison Z. Wicks have provided a tremendous amount of intellectual, financial, and especially moral support. Without the support of each one of these people, whom I love dearly, I undoubtedly would have been incapable of finishing this work.

Additionally, none of this would have been conceived without the support of my committee. Though I was the one to carry out this project, Dr. Tim Shanahan and Dr. Chris Bell were the ones who conceived the project and provided tremendous guidance every step of the way. I can only hope that they feel I have done this project justice. Dr. Dan Breecker was incredibly flexible throughout this ordeal, and was always willing to sit down and talk shop when I wanted to.

The members, past and present, of the Shanahan lab were critical in the execution of every step of my project. From coring to extraction to writing to just helping me keep my sanity and sense of self-worth at reasonable levels, Veronica Anderson, Vera Stoynova, Curtis Bixler, Kyra Kim and John Swartz never seemed to not be willing to help. 
Throughout all of this, Dr. Ernie Lundelius was the source of sage advice on everything from Hall's Cave to leporid teeth to cave sedimentology to who to call for bail should I end up in prison. Aside from connections, equipment, and methodological know-how, Ernie provided copious amounts of inspiration, motivation, laughter, and color (and not just blue) to my master's experience.

The help of Dr. Terry Quinn, his students, Kaustubh Thirumalai, Chris Maupin, and Meaghan Gorman, and lab tech, Dorinda Ostermann, was absolutely indispensable. The entire tooth portion of this study would have been feasible without their help.

I extend my deepest thanks to Billie Hall for allowing me onto her property to sample for bulk carbon analyses. I can safely say that Mrs. Hall was always welcoming and open to whatever we had to do. I only hope I can pay her generosity forwards someday to an aspiring scientist.

Actually obtaining samples was the work of a number of people. Without the help of Roger Gary, I would not have come up with a functional sampling protocol. Madison Ball, Chad Baber, Will Gelnaw, and Robert Burroughs were terrific field assistants, and hopefully the sore muscles, bumps, bruises, and the "goat lung" was at least partially compensated for by all the fun we had in Goat Crap Hall's Cave.

The actual access to the teeth was only allowed with authorization from Dr. Tim Rowe, whom I also need to thank for being the only reason I was accepted to the program in the first place. Matt Brown and Dr. Chris Sagebiel were a huge help in dealing with the collections and how I should deal with the bureaucratic aspect of destructive sampling. I have to additionally thank Allison Honea for enthusiastically going through several metric craploads of Hall's Cave matrix with me in search of elusive leporid teeth. Lastly, I need to acknowledge the tremendous work of Dr. Rick Toomey, without whom I would have no incredible Hall's Cave record to sample in the first place. 
There are also a number of people I need to recognize for their instrumental, climatological, geophysical, or botanical knowhow. In no particular order I greatly appreciate this help from Dr. Toti Larson, Dorinda Ostermann, Dr. Jack Holt, Kevin Befus, Isaac Smith, Dr. Lisa Boucher, and Adam Bowerman, my go-to climatologist.

I also need to thank the folks who provided me with the many employment opportunities I took on to keep myself financially afloat during all of this. Dr. Julia Clarke, Dr. Chris Bell, and Dr. Mary Poteet are the reasons I was able to gain teaching experience here and truly discover my passion for it. Dr. Ann Molineux was my summer support, and the rest of the NPL crew, especially Angie Thompson, made great company in the shelter of the lab during blistering Austin summers.

Funding for this project was provided by the Jackson School of Geosciences, Tim Shanahan, Chris Bell, and the Lundelius Scholarship. I certainly would not have been able to pay for this on my own, and am incredibly thankful that others were so giving.

I would like to thank my fellow UT paleontology students and associates for more reasons than I can possibly list here. In no particular order, this includes Rachel Simon, Robert Burroughs, Will Gelnaw, Alicia Kennedy, Michelle Stocker, James Profitt, Lauren English, Ashley Latimer, Natasha Vitek, Josh Lively, Zhiheng Li, Adam Marsh, Zachary Morris, Felicia Kulp, Katie Brown, Gerard Wallace, Dr. Sterling Nesbitt, Dr. Matthew Colbert, Katherine Criswell, Dr. Jennifer Olori, Christian George, Drew Eddy, and Kyle Womack.

Lastly, I would like to thank Aubri Kottek, who supported me in all the intangible ways a human could. She was my main source of happiness during these years, and is the one who could pull me out of the pit of self-loathing and depression I would occasionally slip into. 


\begin{abstract}
The Use of $\delta^{13} \mathrm{C}$ Values of Leporid Teeth as Indicators of Past Vegetation

Travis Zhi-Rong Wicks, M.S.

The University of Texas at Austin, 2013
\end{abstract}

Supervisor: Timothy M. Shanahan

Co-Supervisor: Christopher J. Bell

Records of change of $\delta^{13} \mathrm{C}$ values in vertebrate teeth offer an opportunity to gain insight into changes in past vegetation. Increasingly, teeth from small mammals are used for such purposes, but because their teeth grow very rapidly, seasonal changes in vegetation potentially provide a large source of variability in carbon isotope composition, complicating interpretations of small mammal tooth isotope data. To investigate the controls of seasonality on the stable isotope composition of fossil teeth, we constructed a Monte-Carlo-based model to simulate the effects of changes in the seasonal pattern of diet in leporid lagomorphs (rabbits and hares) on the distribution of $\delta^{13} \mathrm{C}$ values in random populations of leporid teeth from the Edwards Plateau in central Texas. Changes in mean-state, seasonal vegetation range, and relative season length manifest themselves in predictable ways in the median, standard deviation, and skewness of simulated tooth $\delta^{13} \mathrm{C}$ populations, provided sufficient numbers of teeth are analyzed. This Monte Carlo model was applied to the interpretation of a 20,000 year record of leporid tooth $\delta^{13} \mathrm{C}$ values from Hall's Cave on the Edwards Plateau in central Texas. Variations in the $\delta^{13} \mathrm{C}$ viii 
values of teeth deposited at the same time (standard deviation $=1.69 \%$ ) are larger than changes in the mean vegetation composition reconstructed from bulk organic carbon $\delta^{13} \mathrm{C}$, indicating the influence of short-term variability, making it difficult to assess changes in mean $\mathrm{C}_{3} / \mathrm{C}_{4}$ vegetation from the tooth $\delta^{13} \mathrm{C}$ data. However, populations of teeth from different climate intervals (e.g., the late Glacial, Younger Dryas, and the Holocene) display changes in the shape of the tooth $\delta^{13} \mathrm{C}$ distributions. Interpretation of these changes as shifts in seasonal vegetation patterns that are based upon results from our model are consistent with hypothesized climatic changes. An increase in the standard deviation of the tooth population between the late Glacial and the Younger Dryas Holocene is consistent with an increase in seasonality. Furthermore, a shift to more $\mathrm{C}_{3^{-}}$ dominated vegetation in the tooth $\delta^{13} \mathrm{C}$ distribution during the Younger Dryas is accompanied by a more skewed population - indicative of not only wetter conditions but an increase in the duration in the $\mathrm{C}_{3}$ growing season. However, late Holocene changes in vegetation are not clear in the tooth data, despite the evidence from bulk organic carbon $\delta^{13} \mathrm{C}$ values for an increase in $\% \mathrm{C}_{3}$ vegetation of $57 \%$. Small mammal teeth can potentially provide unique insights into climate and vegetation on seasonal and longer timescales that complement other data, but should be interpreted with a careful consideration of local conditions, taxon ecology and physiology, and the dominant timescales of isotope variability. 


\section{Table of Contents}

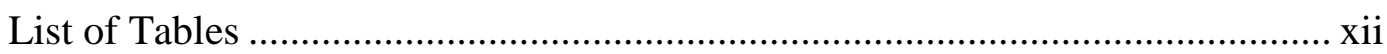

List of Figures ........................................................................................ xiii

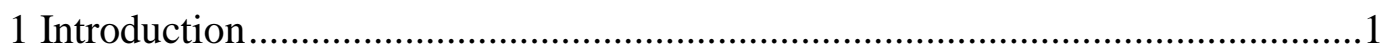

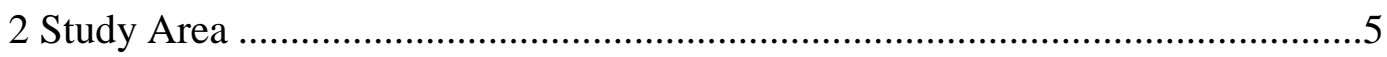

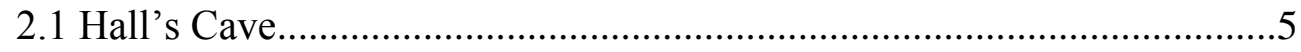

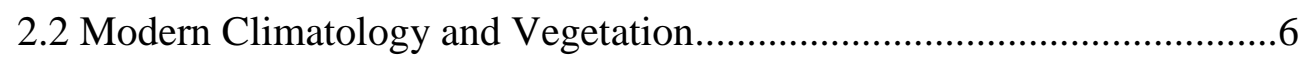

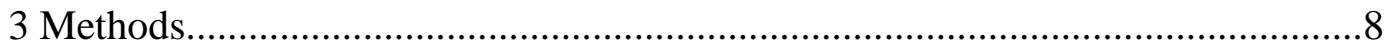

3.1 Modeling the effect of intra-annual variability on leporid tooth isotopic

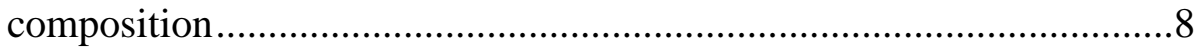

3.1.1 Establishing the Seasonal Cycle in Leporid Tooth $\delta^{13} \mathrm{C}$ Values...9

3.1.2 Modeling variations in vegetation seasonality.............................12

3.2 Sediment Sampling ...........................................................................

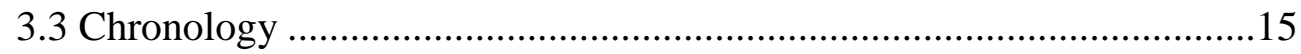

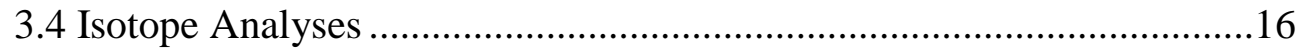

3.4.1 Bulk Organic Carbon ...............................................................16

3.4.2 Leporid Enamel Carbon ...........................................................17

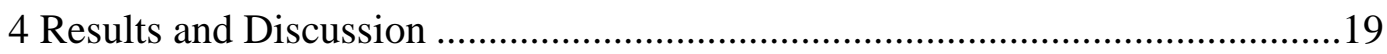

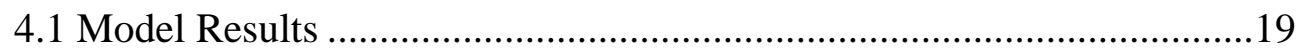

4.1.1 Mean-State Shift .....................................................................19

4.1.2 Change in Seasonal Range .........................................................20

4.1.3 Change in Relative Season Length ..............................................21

4.1.4 Inferring Changes in the Seasonal Cycle from Distribution Changes . .22

4.1.5 Error and Testing for Significance..............................................24

4.2 Variability on Longer Time Scales .......................................................27

4.3 Variations in Leporid Teeth $\delta^{13} \mathrm{C}$ Values from Hall's Cave...................29

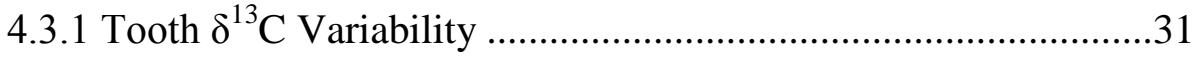


4.3.2 Offset in $\mathrm{C}_{3} / \mathrm{C}_{4}$ Vegetation.......................................................3

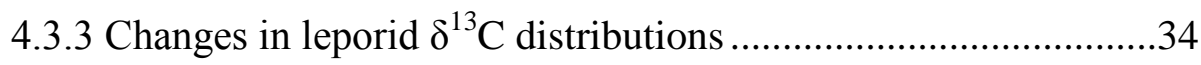

4.3.4.1 Late Glacial Variability...................................................34

4.3.4.2 Younger Dryas Variability and Median............................35

4.3.4.3 Lack of Holocene Change..................................................37

5 Implications for Interpreting $\delta^{13} \mathrm{C}$ values of Small Mammal Teeth ....................40

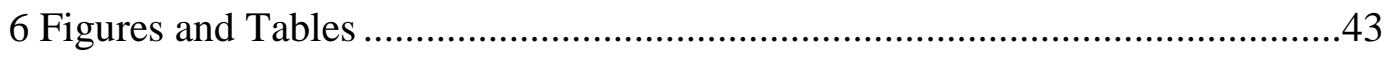

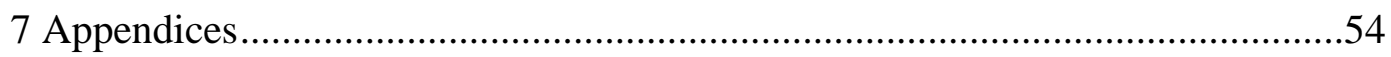

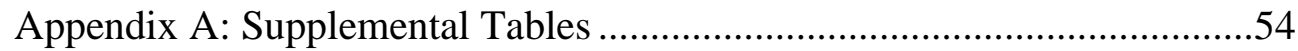

Appendix B: Matlab Modeling Scripts ..........................................................73

Script 1: Distribution change with relative season length ....................73

Script 2: Distribution change with amplitude …………………….......77

Script 3: Precision change with sample size ..........................................81

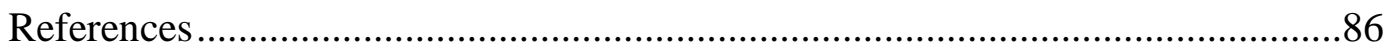




\section{List of Tables}

Table 1: $\quad$ Probabilities of detection . ............................................................53

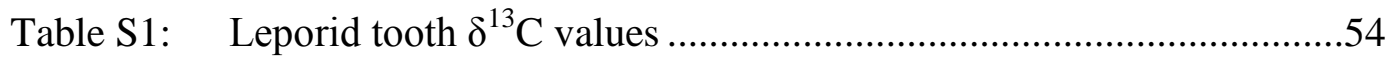

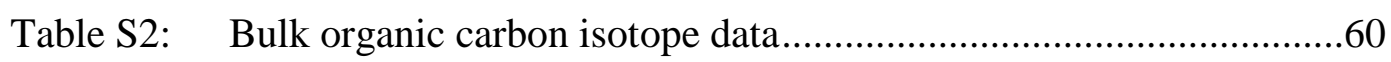

Table S3: $\quad$ Radiocarbon dates as published by Cooke et al. (2003).................67

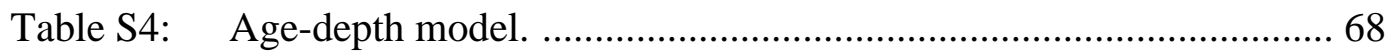




\section{List of Figures}

Figure 1: Modern climate and vegetation of Texas.......................................43

Figure 2: $\quad$ Modern seasonal climate and vegetation of the study area...............44

Figure 3: Anatomy of and possible changes to intra-annual changes in

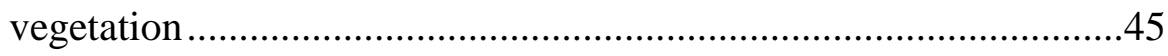

Figure 4: Age model of Hall's Cave deposit ..............................................46

Figure 5: Contour plots representing changes in median ............................47

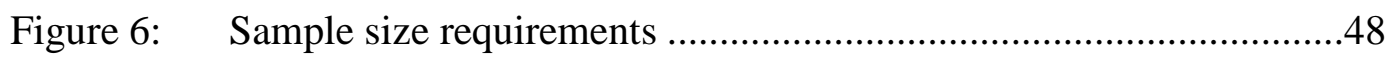

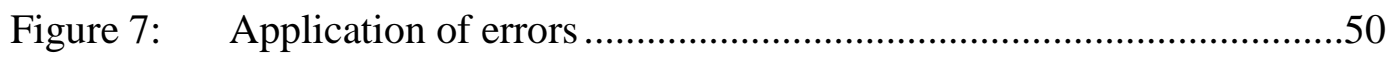

Figure 8: $\quad$ Summary of enamel carbon isotope measurements ........................52 


\section{Introduction}

Reconstructions of past vegetation are important for understanding past ecosystem dynamics and climate variability. Carbon isotope variations in vertebrate teeth are widely used as tools for reconstructing past vegetation (e.g., Lee-Thorp and Beaumont, 1995; MacFadden et al., 1996; Cerling et al., 1997; Koch et al., 2004; Forbes et al., 2010; Bedaso et al., 2013), particularly in regions such as central Texas, where there are few well-resolved and long-term records of past vegetation change. Because the stable carbon isotopic compositions of herbivore teeth are determined largely by the diet of the animal, offset by a predictable magnitude as a result of physiological processes (DeNiro and Epstein, 1978; Cerling and Harris, 1999), the $\delta^{13} \mathrm{C}$ values of herbivore teeth can be used to reconstruct changes in the relative abundance on the landscape of $\mathrm{C}_{3}$ and $\mathrm{C}_{4}$ photosynthetic plants, assuming no dietary preference.

To date, most stable isotope studies of herbivore teeth have focused on the teeth of large, herbivorous mammals because the enamel is both easy to sample and its isotopic composition integrates diet over at least a year (Cerling and Sharp, 1996; Hoppe et al., 2004; Feranec et al., 2009). Though they are less well studied, small mammals are increasingly being used to tackle questions about paleoenvironmental change (e.g., Rogers and Wang, 2002; Feranec et al., 2010; McLean and Emslie, 2012; Hynek et al., 2012). The use of small mammals confers several advantages over large mammals, such as the greater relative abundance of small mammals in the fossil record (e.g., Hibbard 1949). Small mammals also are typically non-migratory, ensuring that $\delta^{13} \mathrm{C}$ values do not 
reflect a mixed signal associated with changes in the isotopic composition of vegetation across regional climate gradients. For example, leporid lagomorphs (rabbits and hares) typically spend their lives in areas 0.4-200 ha in size (McNab 1963; Chapman and Willner 1978), but large mammals such as Bison have modern home ranges several orders of magnitude larger (Larter and Gates, 1994), and are known to migrate long distances (Morgan, 1980; Feranec et al., 2009). Leporids also often are generalist herbivores (Feldhamer et al., 2003), so their teeth reflect a more representative proportion of the extant vegetation, namely low lying herbaceous plants, than large, grazing herbivores, such as Bison and Equus, which primarily consume grasses (Feldhamer et al., 2003). Another common feature of small, herbivorous mammals is hypselodont (evergrowing) dentition (Ungar 2010). When sampled from adults, these teeth are less likely to reflect the nursing period, which can result in a carbon isotope value that is $(0-5.1 \%)$ lighter than expected from the adult diet (Hobson and Sease 1998; Jenkins et al., 2001).

However, hypselodont small mammal teeth are fast-growing (0.6-1.6 mm/day) (Podlesak et al., 2008), resulting in tooth isotopic compositions that are drawn from half to one month of the animal's diet. Any isotopic measurements of these teeth will therefore represent snapshots of vegetation consumed by the animal 2-4 weeks prior to death. This can result in variations in tooth $\delta^{13} \mathrm{C}$ values depending on the time of the year the tooth stopped growing. Because seasonal changes in $\mathrm{C}_{3} / \mathrm{C}_{4}$ composition in arid regions can be large (e.g., a seasonal range of $25 \%$ to $100 \% \mathrm{C}_{3}$ vegetation on the Edwards Plateau, see Fig. 2c), these variations are as large as the changes in landscape $\mathrm{C}_{3} / \mathrm{C}_{4}$ biomass being reconstructed. As a result, it may be difficult, if not impossible, to 
gain useful information on past vegetation changes using long-term variations in the $\delta^{13} \mathrm{C}$ values of individual small mammal teeth.

An alternative approach is to study changes in the distributions of $\delta^{13} \mathrm{C}$ values from populations of small mammal teeth over time. Provided sufficient number of teeth are sampled to characterize the statistics of the tooth populations, changes in these statistics should reflect not only changes in the mean vegetation growing on the landscape, but also changes in the seasonality of vegetation. Such an approach was recently suggested for interpreting the $\delta^{18} \mathrm{O}$ values of rodent dentition (Royer et al., 2013).

A similar approach has been used with to reconstruct sea surface temperature variability using the $\delta^{18} \mathrm{O}$ values of single foraminifera (SST; Koutavas et al., 2006; Leduc et al., 2009; Koutavas and Joanides, 2012). In the single-foram approach, populations of single foraminifera $\delta^{18} \mathrm{O}$ values from discrete intervals of sedimentation are generated, and changes in the standard deviations of these distributions are interpreted as reflecting changes in the magnitude of SST variability associated with the El Nino Southern Oscillation (ENSO). Recently, several models were created to investigate how sample size and long-term climate trends affect the resulting distribution of measured isotopic values, as well as to aid in the interpretation of paleoclimate reconstructions based on single-foram analyses (Leduc et al., 2009; Thirumalai et al., pers. comm.). These exercises have demonstrated the need for modeling approaches in order to properly understand and interpret the controls on changes in single-foram populations. 
In the present study, we investigate the utility of using a similar approach to understand and interpret the $\delta^{13} \mathrm{C}$ values of populations of individual, fast-growing, fossil leporid teeth as indicators of past seasonal variability in vegetation. Methods similar to those developed for single-foraminifera are used to simulate how changes in the $C_{3} / C_{4}$ seasonal cycle affect populations of leporid $\delta^{13} \mathrm{C}$ values, and synthetic leporid $\delta^{13} \mathrm{C}$ populations are sub-sampled to examine the relationship between sample size and ability to approximate characteristics of the total population. Changes in the seasonal characteristics of the vegetation available to leporids are modeled, and the results are used to understand how changes in seasonality manifest themselves in changes in the in the distributions of leporid tooth $\delta^{13} \mathrm{C}$ values. Those results are then applied to the contruction of vegetation changes from leporid tooth $\delta^{13} \mathrm{C}$ data from the sediments of Hall's Cave, a continuous record of past sedimentation on the Edwards Plateau spanning the last 20,000 years. 


\section{Study Area}

\subsection{Hall's CAVE}

Hall's Cave is located in central Texas near the center of the Edwards Plateau, a large, karstified, limestone plateau $\left(30^{\circ} 8^{\prime} 0.53^{\prime \prime} \mathrm{N} 99^{\circ} 32^{\prime} 15.30^{\prime \prime} \mathrm{W}\right)$ at $695 \mathrm{~m}$ elevation above sea level (Fig. 1c). The cave currently consists of a single chamber approximately $30 \mathrm{~m} \times 55 \mathrm{~m}$ in the Segovia Member of the Lower Cretaceous Edwards Limestone (Toomey 1993). The floor is covered by up to $3.7 \mathrm{~m}$ of well-stratified, fossiliferous sediment (Toomey 1993). Excavations in the northern portion of the cave approximately $10 \mathrm{~m}$ from the entrance were carried out in multiple pits, now collectively called Composite Pit I. The majority of that pit was excavated by Rick Toomey at $5 \mathrm{~cm}$ intervals from 1986-1993, and the fossils removed from the site currently reside at the Vertebrate Paleontology Laboratory at the University of Texas at Austin (Toomey 1993).

The current entrance to the cave is a talus slope located in the northeastern corner, and sediments are washed into the cave during precipitation events. Sediments are primarily fine-grained clays, soils, and sands, with limestone and chert cobbles present as well as occasional boulders. Considerable biological contributions to the deposit also are present in the form of guano, feathers, charcoal, plant macrofossils, and bone. The majority of vertebrate skeletal material was deposited via owl pellet accumulation, though occasional large mammal remains were likely deposited through a different mechanism (Toomey 1993). Currently, we know of no modern owl species on the Edwards Plateau that is both migratory and large enough to eat an adult leporid 
(Johnsgard, 2002), leading us to hypothesize that any seasonal component to adult leporid deposition was minimal.

\subsection{Modern Climatology and Vegetation}

The climate of the region surrounding Hall's Cave is subtropical and subhumid (Larkin and Bomar, 1983) with a mean annual temperature of $18.4^{\circ} \mathrm{C}$, and monthly mean temperatures range from $8.3^{\circ} \mathrm{C}$ (January) to $27.4^{\circ} \mathrm{C}$ (August) (Fig. 2a), based on 30-year climate normals from Kerrville from the National Climate Data Center (Arguez et al., 2012). Mean annual precipitation is $814 \mathrm{~mm}$ and monthly precipitation totals range between $40 \mathrm{~mm}$ in January and $102 \mathrm{~mm}$ in May (Durre et al., 2012). The majority of that moisture comes from the Gulf of Mexico, with input from occasional storms from the east Pacific (Bomar 1995). The area experiences two maxima in precipitation during the late spring/early summer and the early fall, with little precipitation occurring in the winter and summer (Fig. 2b). Much of the precipitation that falls during the late spring and summer comes in the form of nocturnal thunderstorms that are driven by a low-level southerly flow from the Gulf of Mexico called the Great Plains low-level jet (Means, 1952; Mitchell et al., 1995).

The vegetation surrounding Hall's Cave is characterized as oak savanna and is largely composed of $\mathrm{C}_{4}$ summer grasses and evergreen $\mathrm{C}_{3}$ shrubs and trees (Fowler and Dunlap, 1986). $\mathrm{C}_{3}$ forbs grow in significant abundance during spring months, and one species of $\mathrm{C}_{3}$ grass, Nassella leucotricha, grows during the fall, winter, and spring months. CAM phosotynthesizers, such as Opuntia and other succulents, appear on the 
landscape year-round in small numbers. These seasonal patterns of growth result in large changes in $\mathrm{C}_{3} / \mathrm{C}_{4}$ biomass through the year with $\mathrm{C}_{4}$ biomass dominating the late spring through fall (Fig. 2c). $\mathrm{C}_{3}$ vegetation is highest in relative abundance during the winter and early spring, and maintains a noticeable presence throughout the rest of the year as woody plants and a few species of perennial forb species (Correll and Johnston, 1970; Fowler and Dunlap, 1986). Because of these seasonal changes in $\mathrm{C}_{3} / \mathrm{C}_{4}$ abundance, changes in seasonal climate patterns have the potential to affect the overall proportion of $\mathrm{C}_{3} / \mathrm{C}_{4}$ plants. This is evident in the correlation between $\mathrm{C}_{4}$ abundance and the proportion of precipitation occurring during the summer, the primary $\mathrm{C}_{4}$ growing season (Paruelo and Lauenroth 1996).

Gradients in vegetation and climate across the Edwards Plateau are characteristic of those exhibited across the state of Texas. The modern climatology is largely defined by a strong east-to-west precipitation gradient and a latitudinal temperature gradient (Fig. 3a,b). Spatial differences in mean annual precipitation (MAP) exert a strong effect on the composition of vegetation with higher amounts of tree cover occurring in portions of the state with greater MAP (Fig. 3c). This is expected because MAP has been shown to correlate with tree cover in subtropical and tropical grasslands and savannas (Sankaran, 2005; Bond, 2008). Because trees are $C_{3}$ photosynthesizers (Sage et al., 2011), and the vast majority of grasses on the Edwards Plateau are $C_{4}$ plants (Smeins et al., 1976; Fowler and Dunlap 1986), changes in the proportion of tree cover on the landscape will manifest itself as changes in the proportion of $\mathrm{C}_{3} / \mathrm{C}_{4}$ plants and the biomass-weighted mean $\delta^{13} \mathrm{C}$ value of the vegetation. 


\section{Methods}

\subsection{MODELING THE EFFECT OF INTRA-ANNUAL VARIABILITY ON LEPORID TOOTH ISOTOPIC COMPOSITION}

Because many small mammals, like leporids, growth their teeth very rapidly, the stable isotope signal in these teeth reflects at most a few weeks to a month of time. As a result, the isotopic signal in small mammal teeth is strongly affected by seasonal variations in vegetation availability. In places like the Edwards Plateau, where seasonal vegetation changes are large, this effect imparts significant variation on the signal contained in individual teeth. However, if populations of individual teeth can be analyzed from discrete time intervals, the distribution of tooth $\delta^{13} \mathrm{C}$ values within this population can potentially provide additional information about the variations in vegetation composition within that sampling interval. Furthermore, if the total range in the seasonal cycle of vegetation is large, the seasonal cycle could potentially dominate the isotope signal and tooth population data will provide insights into changes in seasonality.

To better understand these processes, and to provide a framework for interpreting leporid tooth population data, we developed a Monte-Carlo model for simulating the production of teeth from a synthetic population of leporids living on the Edwards Plateau with the modern seasonal cycle of vegetation. By sampling the synthetic "true" population of teeth produced under these conditions, and by altering the seasonal vegetation cycle, this approach offers a means of investigating how changes in vegetation

manifest themselves in tooth $\delta^{13} \mathrm{C}$ distributions and allows us to set guidelines for 
estimating the number of teeth needed to characterize the population and the influence of sample size on the robustness of our data interpretations.

\subsubsection{Establishing the Seasonal Cycle in Leporid Tooth $\delta^{13} \mathrm{C}$ Values}

To model the incorporation of seasonal vegetation changes into leporid tooth $\delta^{13} \mathrm{C}$ values, it is necessary to understand the seasonal cycle in $\mathrm{C}_{3} / \mathrm{C}_{4}$ vegetation, how that vegetation is sampled by leporids, and how that signal is incorporated into tooth $\delta^{13} \mathrm{C}$ values. First, existing data on the relative abundances of different species of plants on the Edwards Plateau were gathered (Fowler and Dunlap, 1986), and each species of plant was designated as utilizing the $\mathrm{C}_{3}$ or $\mathrm{C}_{4}$ photosynthetic pathway (Van Auken, 1997; Christin et al., 2008; Besnard et al., 2009; Sage, 2011). Growing season ranges for each plant species (Correll and Johnston, 1970) were then applied, allowing us to construct a synthetic monthly record of $\mathrm{C}_{3} / \mathrm{C}_{4}$ vegetation changes on the Edwards Plateau (Fig. $2 \mathrm{c}$ ). The data exhibit a period of $\mathrm{C}_{3}$ dominance in the winter and $\mathrm{C}_{4}$ dominance in the summer and fall, with transitional periods occurring in the early winter/late fall and spring. This general cycle of increased $\mathrm{C}_{4}$ growth during warmer portions of the year and $\mathrm{C}_{3}$ dominance during cooler portions is consistent with observations reported elsewhere (Ode and Tieszen, 1980; Tieszen et al., 1980).

Estimated $\mathrm{C}_{3} / \mathrm{C}_{4}$ vegetation percentages were converted into mean landscape $\delta^{13} \mathrm{C}$ values assuming mean values for $\mathrm{C}_{3}\left(-27 \%\right.$ ) and $\mathrm{C}_{4}(-13 \%$ ) plants (Boutton et al., 1998). Though plants with the same photosynthetic pathway will have different isotopic composition due to species differences (Cerling and Harris, 1999), the $\delta^{13} \mathrm{C}$ value of $\mathrm{CO}_{2}$ 
(Keeling et al., 2005), changes in irradiance (Ehleringer et al., 1986; Zimmerman and Ehleringer, 1990), water stress (Ehleringer, 1993), and even the structure of the surrounding vegetation (Medina et al., 1986), they provide reasonable estimates which, when applied to our estimates of $\mathrm{C}_{3} / \mathrm{C}_{4}$ percentages from modern vegetation data, allow us to create a general estimate of the seasonal cycle in plant $\delta^{13} \mathrm{C}$ on the Edwards Plateau. Furthermore, for the purposes of this model, the numerical $\delta^{13} \mathrm{C}$ value of consumed vegetation is less important than how changes in the proportion of $\mathrm{C}_{3} / \mathrm{C}_{4}$ vegetation are manifested in $\delta^{13} \mathrm{C}$ values and as a result in the distribution of teeth produced by leporids consuming this vegetation.

Modelling of the incorporation of this idealized seasonal vegetation signal into leporid teeth necessitates a consideration of the possible sources of differences in carbon isotope composition between leporid teeth and vegetation on the landscape. These include seasonal changes in diet, dietary preferences, carbon isotope fractionation during metabolism and tooth production, and individual, random variability due to a combination of plant selection and microenvironments. Leporids are expected to consume vegetation which reflects the seasonal pattern in $\mathrm{C}_{3} / \mathrm{C}_{4}$ plant abundance that is present on the landscape. As leporids are not obligate drinkers, they largely consume vegetation according to moisture content (Dalke and Sime, 1941; Turkowski, 1975; Brewer, 2006; Ugan and Coltrain, 2011). Plants contain highest moisture content when growing, so we expect leporid diet during a given time to be largely dependent on what is actively growing on the landscape. Because they also do not store food or hibernate, leporids sample the vegetation year-round (Vander Wall, 1971; Feldhamer et al., 2003). 
However, the absolute proportion of $\mathrm{C}_{3} / \mathrm{C}_{4}$ consumed is not expected to match precisely that in the environment because leporids have a tendency to favor certain plant types over others. For example, woody plant material is rarely consumed unless other vegetation types are scarce (Schmidly, 1994). Additionally, during the spring on the Edwards Plateau, when both $\mathrm{C}_{3}$ forbs and sedges and $\mathrm{C}_{4}$ grasses are growing (Correll and Johnston, 1970; Fowler and Dunlap, 1986), isotopic analyses reveal that $\mathrm{C}_{3}$ forbs are preferentially consumed (Smith, 2011). Because of this, the proportion of $\mathrm{C}_{3} / \mathrm{C}_{4}$ consumed is likely somewhat offset from the true composition of vegetation on the landscape. Though the direction of the offset will remain the same as vegetation composition changes, the amount of offset will likely change, potentially complicating the interpretations of leporid tooth distributions. Although the magnitude of this effect is unknown, the dietary preference amongst modern leporids is relatively small, so for the purposes of this modeling exercise, we assume that it is small. This is consistent with the limited data from modern leporids, which show variations of $\pm 1.59 \%$ in $\delta{ }^{13} \mathrm{C}$ for animals living at the same time and in the same location (Smith, 2011). This was incorporated into the model as a randomizing element in the generation of simulated tooth $\delta^{13} \mathrm{C}$ values. Additional offsets between the $\delta^{13} \mathrm{C}$ values of the vegetation on the landscape and tooth $\delta^{13} \mathrm{C}$ also reflect the isotope fractionation between the food source and the tooth material. Previous studies on leporids have reported offsets of ca. $+12.8 \%$ (Passey et al., 2005). 


\subsubsection{Modeling variations in vegetation seasonality}

In order to understand better how seasonal changes in vegetation would influence the $\delta^{13} \mathrm{C}$ signal incorporated into leporid teeth, we considered three main avenues by which the vegetation might change on a seasonal basis: (1) a change in the mean-state, (2) a change in the seasonal range, and (3) a change in season length. For simplicity, we first consider these changes individually, and then discuss the influence of combined effects later.

The first of these, a change in the mean-state, is modeled as a shift towards a greater or lower proportion of $\mathrm{C}_{3}$ vegetation, with no direct change in the seasonal cycle. This type of change would be analogous to a situation in which an overall increase or decrease in mean annual temperature or precipitation resulted in an increase or decrease in the proportion of woody plants in the landscape without any change in the seasonal distribution of plants (Fig. 3b). For example, an increase in precipitation during all months might be anticipated to generate a corresponding increase in the relative proportion of $\mathrm{C}_{3}$ plants during all months.

The second possible vegetation change that was considered is a change in the seasonal proportion of $\mathrm{C}_{3} / \mathrm{C}_{4}$ plants (Fig 3c). This type of change might include a change in the composition of plants in the winter with no change in the summer, a change in summer vegetation without any change in winter, differential change in both seasons in the same direction, or a change in both seasons in the opposite direction. End-member conditions for this change would be $100 \% \mathrm{C}_{4}$ in summer and $100 \% \mathrm{C}_{3}$ in winter, or, conversely, a constant vegetation composition thoughout the year. In some cases, these 
changes could result in a shift in the annual average $\mathrm{C}_{3} / \mathrm{C}_{4}$ ratio; in other cases, they would not be associated with a change in the mean-state. Because a change in the meanstate is modeled as a separate condition, only seasonal range changes that do not result in a mean-state shift were considered. These changes in the seasonal range of vegetation composition would be consistent with an increase or decrease in climate seasonality. Because the timing of deciduous/annual plant dormancy/death depends on environmental cues, such as aridity, photoperiod, and temperature (Volaire and Norton, 2006; Rohde and Bhalerao, 2007), changes in the magnitude of climatic seasonality could result in changes in the amount of $\mathrm{C}_{3}$ and $\mathrm{C}_{4}$ plants that grow through the $\mathrm{C}_{4}$ and $\mathrm{C}_{3}$ seasons, respectively. This is evident in the correlation between minimum temperature during the growing season and $\% \mathrm{C}_{4}$ grasses observed in North America today (Teeri and Stowe 1976).

The third possible vegetation change was a shift in the relative lengths of the $C_{3}$ and $\mathrm{C}_{4}$ growing seasons (Fig. 3d). This could include a change in the timing of dormancy termination/germination or dormancy/death of $\mathrm{C}_{3}$ or $\mathrm{C}_{4}$ plants, resulting in the growth of $\mathrm{C}_{3} / \mathrm{C}_{4}$ vegetation during a longer or shorter part of the year. Because relative season lengths that approach $100 \% \mathrm{C}_{4}$ or $100 \% \mathrm{C}_{3}$ growth are unrealistic in our study area, we restricted the possible end-member season lengths to between $20 \%$ and $80 \%$. Such changes could result from changes in the time of year that certain environmental thresholds are crossed. For example, because temperatures play a large role in timing of germination (Angevine and Chabot, 1979; Probert, 2000), lower overall temperatures 
could truncate the amount of the year that $\mathrm{C}_{4}$ plants are capable of growing, shortening the $\mathrm{C}_{4}$ season relative to the $\mathrm{C}_{3}$ season.

\subsection{SEDIMENT SAMPLING}

A continuous record of the upper $2 \mathrm{~m}$ of sediment in Hall's Cave was obtained by coring approximately $10 \mathrm{~cm}$ from the northwest edge of Pit 1d/e (Toomey, 1993) in January, 2012. The bottom meter (2-3 m depth) was not obtained from this portion of the cave due to large limestone clasts inhibiting sediment collection. Instead, the remainder $(\sim 1 \mathrm{~m})$ was obtained by coring approximately $10 \mathrm{~cm}$ from the northeast edge of the same pit during a subsequent trip in July, 2012. Overlap between the two sections was identified using changes in lithostratigraphy and reference nails left in the wall of the pit during the first visit. An unconformity in the sediment was identified at $222-236 \mathrm{~cm}$ by the presence of hair and goat feces indicative of modern sediment. This was likely due to sloughing off of the side of Toomey's original excavation and subsequent backfilling, and the interval was excluded from the analyses. A sudden change in the character of the sediment from red clay to dark brown and black organic materials along with the presence of numerous articulated bat fossils below $287 \mathrm{~cm}$ depth were indicative of a guano deposit. This interval was also excluded from analyses.

Because the cave sediment samples were obtained separately from the fossil tooth samples and associated radiocarbon dates, it was necessary to correlate sample depths between the sediment cores and the depths of the tooth samples as documented by 
Toomey (1993) in order to put them on the same age-depth chronology. To do so, we used a series of reference nails placed in the wall of the pit by Stafford (Cooke et al., 2003 ) at $0,1.0$, and $1.5 \mathrm{~m}$ depth. These depth correlations were confirmed by measuring a plumb line from a level-line extended from a railroad spike datum driven into the wall closest to the pit, also placed by Toomey in 1993. Lithostratigraphic boundaries were used to provide additional ties to Toomey's section.

\subsection{CHRONOLOGY}

The chronologic control of this deposit is based on 23 radiocarbon dates of charcoal, humates, and bone collagen (Fig. 4; Table S3; Cooke et al., 2003). Age modeling was performed using the Bayesian age-depth modeling program BACON

(Table S4; Blaauw and Christen, 2011). ${ }^{14} \mathrm{C}$ dates were converted to calendar ages using the IntCal09 calibration curve (Reimer et al., 2009). BACON uses an assumed probability distribution of sediment accumulation rates and generates a distribution of possible age-depth models considering this accumulation rate probability function and using the non-normal probability distributions for the calibrated radiocarbon ages. The output provides an estimate of both the optimal age depth model and the uncertainty in age model as a function of depth. For the Hall's Cave model, 71, 5-cm-thick sections and a mean accumulation rate of 52 year/cm were utilized. Average uncertainty was \pm 511 Cal. yr BP and ranges from \pm 165 to \pm 960 Cal. yr BP. Despite the wide range in uncertainty, there is no discernible trend with age, and it generally fluctuates between \pm 200 and \pm 700 Cal. yr BP throughout the section. 


\subsection{ISOTOPE ANALYSES}

\subsubsection{Bulk Organic Carbon}

The stable isotopic composition of the bulk organic carbon from Hall's Cave was analyzed continuously at centimeter resolution (equivalent to $59 \pm 49$ years) over the top 3 m. The sediment samples were homogenized with a mortar and pestle and dried either through lyophilization or in an oven at $70^{\circ} \mathrm{C}$ for 48 hours. $2-20 \mathrm{mg}$ of each sample were then placed in silver capsules, and 2-3 drops of sulfurous acid (6.4\%) were applied to each vessel to remove inorganic carbon (Steinbeiss et al., 2008). Samples were again dried at $70^{\circ} \mathrm{C}$ for 48 hours and subsequently combusted in an elemental analyzer (Costech Instruments Elemental Combustion System 4010) connected to an isotope ratio mass spectrometer (Thermo Scientific Delta V Plus). The analytical precision for these data is $\pm 0.24 \%$ based upon repeated measurements of an in-house standard, which was used to correct raw measured values to the VPDB scale. The bulk sediment organic carbon $\delta^{13} \mathrm{C}$ record is interpreted as reflecting the $\delta^{13} \mathrm{C}$ value of the surrounding vegetation at the time of deposition with little to no isotopic enrichment during diagenesis (Balesdent et al., 1993), and provides a record of changes in the relative abundance of $C_{3} / C_{4}$ plants to which we can compare our tooth isotope data. 


\subsubsection{Leporid Enamel Carbon}

Adult leporid cheek teeth were selected from among fossils excavated by Toomey (1993) and currently curated as part of the Texas Natural Science Center at the University of Texas at Austin. Upper cheek teeth were preferentially selected because of the ease of identification to Leporidae and because the thick, smooth enamel band along the mesial surface maximizes the ease of sampling. Because isolated cheek teeth are not identifiable beyond Leporidae, it is likely that multiple species were sampled. However, this problem is somewhat alleviated by the similarity of diet among the different species of leporids present across Texas today (Schmidly, 1994; Feldhamer et al., 2003). Furthermore, teeth were selected to be similar in size $(\sim 1 \mathrm{~cm}$ in length) to minimize the amount of taxonomic mixing among sampled teeth.

Even at the high density of fossils in the deposit, there were not enough teeth at each level to treat each excavation level $(\sim 5 \mathrm{~cm})$ as a distribution. Instead, the bulk organic carbon record was used to identify four key vegetation regimes, and the 136 leporid teeth measured during this study were binned within these intervals (Fig. 7). These intervals were identified as the late Holocene $(\mathrm{LH} ; \mathrm{n}=38)$, early Holocene $(\mathrm{EH} ; \mathrm{n}$ $=35)$, Younger Dryas $(Y D ; n=34)$, and late Glacial $(L G ; n=29) .136$ teeth were selected from levels interspersed throughout these intervals. Prior to sampling, occlusal, mesial, and lingual surfaces were photographed for archival purposes. A fine file was then used to remove contaminants and cementum that may have been on the mesial surface of each tooth. Teeth were mounted to acrylic glass using epoxy and placed on computer-controlled stage which allowed for precise control of drilling location and 
depth. Approximately $0.2 \mathrm{~mm}$ of the mesial enamel band was removed using a carbide dental drill bit (head diameter: $0.25 \mathrm{~mm}$ ) in a rotary tool.

Pretreatment methods were derived from those detailed by Koch et al. (1997). To remove all organic contaminants, powdered samples were treated with $2 \% \mathrm{NaOCl}$ for 24 hrs at $0.4 \mathrm{~mL}$ solution/mg sample. The $\mathrm{NaOCl}$ solution was then decanted, and the powders were rinsed 5 times with $18 \mathrm{M} \Omega$ water. Samples were then soaked in $0.1 \mathrm{M}$ acetic acid for $24 \mathrm{hrs}$ at $0.4 \mathrm{~mL}$ solution/mg sample to remove adsorbed diagenetic carbonate. The acetic acid was decanted and the powders were rinsed 5 times with $18 \mathrm{M} \Omega$ water. Samples were lyophilized and then reacted with phosphoric acid in an evacuated vessel in an automated carbonate preparation system (Thermo Scientific Kiel IV Carbonate Device) attached to an isotope ratio mass spectrometer (Thermo Scientific MAT 253). The analytical precision for these data is $\pm 0.025 \%$ based upon repeated measurements of an in-house standard, which was used to correct raw measured values to the VPDB scale. 


\section{Results and Discussion}

\subsection{MODEl RESUltS}

To establish an interpretive framework for linking changes in the seasonal cycle of consumed $\mathrm{C}_{3} / \mathrm{C}_{4}$ vegetation to changes in leporid tooth $\delta^{13} \mathrm{C}$ distributions, our synthetic populations of tooth $\delta^{13} \mathrm{C}$ values were created using estimated seasonal vegetation patterns and dietary preferences. The distribution of $\delta^{13} \mathrm{C}$ values for each population was characterized using median, standard deviation, and skewness. These three descriptive statistics were tracked as the seasonal dietary pattern was modified through mean-state shifts, changes in seasonal range, and changes in relative season length. The median was used to describe the distribution instead of the mean because it is the more appropriate statistic for describing the skewed distributions (Whitlock and Schluter, 2009).

\subsubsection{Mean-State Shift}

Because shifts in the mean-state move the entire seasonal dietary cycle towards a larger or smaller proportion of $\mathrm{C}_{3}$ to $\mathrm{C}_{4}$ vegetation, these dietary changes are manifested as shifts in tooth $\delta^{13} \mathrm{C}$ distributions towards higher or lower median $\delta^{13} \mathrm{C}$ values. In most cases, the shift in median $\delta^{13} \mathrm{C}$ values will be the same size as that of the mean-state shift.

The potential effect of changes in the mean-state on skewness and standard deviation depend on the seasonal range in $\mathrm{C}_{3} / \mathrm{C}_{4}$ vegetation. If the seasonal range is small enough that neither season is saturated with an end-member, skewness and standard 
deviation generally remain unaffected because most mean-state shifts do not change the shape of the tooth $\delta^{13} \mathrm{C}$ distribution. In contrast, when seasonal range causes a portion of the year to abut against the end-member $\mathrm{C}_{3}$ or $\mathrm{C}_{4}$ vegetation values (e.g., $100 \% \mathrm{C}_{3}$ or $\mathrm{C}_{4}$ ), a portion of the seasonal cycle might not be able to shift because it is already saturated with $\mathrm{C}_{3}$ or $\mathrm{C}_{4}$ vegetation. Because of the limited $\mathrm{C}_{4}$ growing season and consequent $\mathrm{C}_{3}$ dominance of $\mathrm{C}_{3}$ vegetation during the winter, this is the most likely situation for a meanstate shift. This can cause parts of the year to accumulate on one end-member, changing the shape of the seasonal vegetation cycle and tooth $\delta^{13} \mathrm{C}$ distribution. As the distribution shifts towards $100 \% \mathrm{C}_{3}$ or $\mathrm{C}_{4}$ during part of the year, the distribution becomes more asymmetric. The absolute value of skewness increases until a large percentage of the year is saturated with $100 \%$ end-member values, beyond which the absolute value of skewness decreases towards zero. This results in a greater proportion of the year being on the same side of the midpoint as the saturated portion of the year. At the same time, the standard deviation decreases because the overall range of $\delta^{13} \mathrm{C}$ values decreases. This is effectively a mean-state shift driving a simultaneous change in seasonal range and relative season length, the effects of which are discussed below. Median values continue to shift with the mean-state, but no longer track it on a permil basis.

\subsubsection{Change in Seasonal Range}

Shifts in the range of $\delta^{13} \mathrm{C}$ values of vegetation over the seasonal cycle modulate the spread in tooth $\delta^{13} \mathrm{C}$ values. The primary effect of this is to cause a change in the standard deviation of leporid $\delta^{13} \mathrm{C}$ values (Fig. 5b). At the minimum possible seasonal range ( $0 \%$ ), the $\delta^{13} \mathrm{C}$ of consumed vegetation does not change seasonally, and the spread 
in leporid $\delta^{13} \mathrm{C}$ values entirely the result of random variation in tooth values (i.e., 1.59\%o). In contrast, a maximum difference in vegetation $\delta^{13} \mathrm{C}$ changes over the course of a year (14\%o), in which vegetation is $100 \% \mathrm{C}_{3}$ in winter and $100 \% \mathrm{C}_{4}$ in summer can result in a maximum standard deviation of 5.20\%. At equal relative season lengths, changes in seasonal range have no effect on median or skewness (Fig. 5a,c). However, if the lengths of the season are unequal (see below) changes in seasonal range will amplify or dampen the effect of season length (e.g, skew).

\subsubsection{Change in Relative Season Length}

Modifying the relative lengths of the $\mathrm{C}_{3}$ and $\mathrm{C}_{4}$ seasons in the seasonal dietary cycle shifts the probability that a random tooth will represent a portion of the $\mathrm{C}_{3}$ or $\mathrm{C}_{4}$ season. This manifests in the population of leporid $\delta^{13} \mathrm{C}$ values as a change in the relative number of teeth with $\mathrm{C}_{3}$ or $\mathrm{C}_{4}$ season $\delta^{13} \mathrm{C}$ values. This primarily affects the symmetry of the distribution, which can be seen in changes in skewness and median of the distribution (Fig. 5a,c). When the seasons are of equal length, the distribution is symmetric (skewness of zero) and the median $\delta^{13} \mathrm{C}$ value is equal to the annual mean $\delta^{13} \mathrm{C}$ value. However, as one season becomes longer than the other, the asymmetry of the distribution increases, leading to increased absolute values of skewness (more negative for a longer $\mathrm{C}_{4}$ season, and more positive for a longer $\mathrm{C}_{3}$ season) and a shift in the median towards values typical of the longer season.

The effect of unequal season lengths on skewness and median is amplified by an increase in seasonal vegetation range because the seasonal vegetation range dictates the

difference in $\delta^{13} \mathrm{C}$ between the two seasons. At larger seasonal ranges, unequal season 
lengths will result in the production of longer tails in the tooth $\delta^{13} \mathrm{C}$ distribution than at smaller seasonal ranges, resulting in greater absolute skewness in the population. Furthermore, as the seasonal vegetation range increases, the larger differences in the $\delta^{13} \mathrm{C}$ values of the seasons make the median of the distribution more sensitive to changes in relative season length.

\subsubsection{Inferring Changes in the Seasonal Cycle from Distribution Changes}

Though leporid tooth $\delta^{13} \mathrm{C}$ distributions can potentially be influenced by each of those types of changes in the seasonal dietary cycle, the degree of control exerted by each type of change varies, resulting in a unique combination of changes in the leporid $\delta^{13} \mathrm{C}$ distribution. Each statistic used to describe the synthetic populations is predominantly controlled by one or two types of changes to the seasonal cycle. Skewness can be changed through a shift in seasonal range or mean-state shifts under special circumstances, but the largest changes result from shifts in relative season length. The largest modeled change in skewness due to season length was 1.6, whereas seasonal range can at most result in a shift in skewness of 0.8 . Median is potentially susceptible to changes in all three parameters (i.e., relative season length, seasonal range - discussed in 4.1.2 -, and mean state), and as such should be interpreted with caution. In contrast, standard deviation is highly modified by changes in seasonal range $(\leq 3.61 \%)$, but shifts in relative season length result in only small changes in the spread of the tooth $\delta^{13} \mathrm{C}$ values $\left(\leq 0.74 \%\right.$ ). When one season is saturated with one vegetation type (e.g., $100 \% \mathrm{C}_{3}$ or $\mathrm{C}_{4}$ vegetation), mean-state shifts can change standard deviation as well, but this is through effectively changing the seasonal range. 
However, each modeled change in the seasonal dietary cycle does not necessarily occur exclusively. Climate and vegetation dynamics are likely to change in such a way that multiple aspects of the seasonal dietary cycle will shift simultaneously. For example, a decrease in the proportion of $\mathrm{C}_{4}$ vegetation during solely the $\mathrm{C}_{4}$ season will be manifested as a change in both seasonal range and mean-state. Cases such as this one, where multiple aspects of changes in the seasonal cycle occur, can result in changes in tooth $\delta^{13} \mathrm{C}$ distributions that are difficult to interpret. Changes in median, in particular, can prove to be difficult to interpret because median values are susceptible to both changes in relative season length as well as mean-state shifts. Furthermore, these two changes in the seasonal cycle could occur in such a way that they offset one another's modifications to the median. Such a scenario could arise if a shift in the mean-state towards a greater proportion of $\mathrm{C}_{3}$ vegetation was coupled with a decrease in the length of the $\mathrm{C}_{3}$ season. This could be caused by an increase in overall temperature, shortening the $\mathrm{C}_{3}$ season, combined with a decrease in precipitation during the $\mathrm{C}_{4}$ growing season, leading to decreased $\mathrm{C}_{4}$ production and, thus, $\mathrm{C}_{4}$ plant consumption. The mean-state shift would increase the median leporid $\delta^{13} \mathrm{C}$ value, while decreased $\mathrm{C}_{4}$ season length would decrease the median, offsetting changes in the median due to mean-state shifts.

As a result, discerning changes to the seasonal dietary cycle from changes in leporid $\delta^{13} \mathrm{C}$ distributions should rely most heavily on changes in the standard deviation and skewness of the population. Because skewness and standard deviation are predominantly modulated by relative season length and seasonal range, respectively, they provide indicators of these specific types of change to the seasonal cycle. Unambiguous 
identification of a shift in the mean vegetation state, however, can be difficult to detect. The median is the only aspect of a leporid $\delta^{13} \mathrm{C}$ distribution that reliably changes with mean-state shifts, but changes in relative season length present a possible source of interference. The presence of a mean-state shift is only unambiguous when a change in median is not accompanied by a change in skewness or when median and skewness change in opposite directions from that expected from a change in relative season length.

\subsubsection{Error and Testing for Significance}

The ability to test whether changes in the median, standard deviation, and skew of the tooth population data are significant is important for assessing whether patterns in the leporid $\delta^{13} \mathrm{C}$ distributions are meaningful. The first step in testing for significance is to quantify how well a sample leporid tooth $\delta^{13} \mathrm{C}$ distribution approximates aspects of the population from which the sample was drawn. To do so, we used the leporid tooth model presented above to examine the effects of both sample size (i.e., the number of teeth analyzed from a particular interval), and the absolute magnitudes of the changes in seasonal vegetation patterns on the uncertainties in the statistics of the population. This is important in that the number of samples needed to characterize a statistic will differ depending on the magnitude of the vegetation change, the type of change, and the test statistic being used.

In virtually all cases, the median of the population is the most precise statistic for any given sample size. However, the size of the error varies greatly with both seasonal range and relative season length (Fig. 6a). The error is smallest when the combination of seasonal range and relative season length yield populations that have small standard 
deviations, high amounts of skewness, or both. The opposite is true for populations with large standard deviations and symmetrical distributions. For example, when there is no seasonal vegetation change, analysis of 10 teeth would yield an error on the median of less than $0.60 \%$. However, when the seasonal range is maximized $(14 \%)$, the error using the same number of teeth increases to $2.65 \%$. Thus, seasonal range is the primary control on the error in the estimate of the median. Note, however, that at large seasonal vegetation ranges $(>10 \%)$, the relative lengths of the seasons can be more important in controlling the error in the median.

Error in the standard deviation behaves in a similar manner to the error in the median, but the errors are larger for a given sample size (Fig. 6b). If there is no seasonal variation in the vegetation (standard deviation $=1.59 \%$ ), as few as 25 teeth are needed to achieve an error of $25 \%( \pm 0.40 \%)$. However, the error in the estimate of standard deviation of the population is positively correlated with the size of the seasonal range. At seasonal ranges greater than $10 \%$, standard deviation remains positively correlated with seasonal range, but the relative length of the seasons becomes more important, with error minimized in situations where the season lengths are equal.

The error in the estimate of the skewness of the distribution behaves in a manner opposite to that of error of the median, and is the most difficult statistic to quantify. The uncertainty in the estimate of the skew is negatively correlated with the seasonal vegetation range and positively correlated with differences in the lengths of the seasons (Fig. 6c). However, getting precise estimate of the skew is difficult because large numbers of teeth are needed to properly characterize the skewness of a population. For 
example, in a situation with large differences in season length (e.g., equivalent to a skew of 0.8 ), approximately 72 teeth are needed to achieve an error of less than $10 \%$ in the estimate of the skew. This lack of precision is likely due to the vulnerability of this statistic to outliers, and, therefore, skewness is not a useful statistic to use in a quantitative fashion unless large numbers of teeth are available. However, as indicated by modeled changes in distribution, it can provide qualitative information about the relative length of the $\mathrm{C}_{3}$ and $\mathrm{C}_{4}$ seasons.

These results can be used to compare statistics from two sample distributions and evaluate the statistical significance of the differences between these two distributions. To do this, modeled errors are applied to datasets to estimate the uncertainty prior to application of statistical tests. Because error varies primarily with seasonal vegetation range (Fig. 6), error for a given statistic depends on the seasonal vegetation range of the corresponding distribution. The standard deviation of the distribution is used to estimate the seasonal vegetation range and, consequently, the sets of errors this corresponds to. For a particular statistic, the average of the errors is then applied for use in statistical testing.

The approach used here combines published methods on significance detection (Lanzante, 2005) and the Probability of Detection $\left(\mathrm{P}_{\mathrm{d}}\right)$ method (Thirumalai et al., pers. comm.) to evaluate whether changes in the sample statistics are significant. The applied threshold for statistical significance, henceforth referred to as the Lanzante Criterion, is

$$
\left|X_{1}-X_{2}\right| \geq \sqrt{E_{1}^{2}+E_{2}^{2}}
$$


as described by Lanzante (2005), where $\mathrm{X}_{\mathrm{n}}$ refers to a value (median, standard deviation or skewness) with the corresponding errors referred to as $E_{n}$.

To estimate the Probability of Detection, a Monte-Carlo-based uncertainty analysis is performed, utilizing the comparison of simulated distributions $(n=10,000)$ of the statistical parameters (i.e., median, standard deviation, and skew) from each sample derived from the uncertainties in those parameters. All simulated estimates of the statistical parameters from one sample are compared with those from the other sample and tested for significance with the Lanzante Criterion. The Probability of Detection $\left(\mathrm{P}_{\mathrm{d}}\right)$ is then estimated from the percentage of the pairings that are found to be statistically different. Values that are statistically significantly different from one another will have $\mathrm{P}_{\mathrm{d}} \geq 50 \%$.

\subsection{VARIABILITY ON LONGER TIME SCALES}

It is likely, considering the sampling resolution required to obtain sufficient numbers of teeth (at least several hundred to several thousand years), that within individual samples, variability on time scales longer than the seasonal cycle will also play an important role in controlling leporid tooth $\delta^{13} \mathrm{C}$ distributions. Variability on longer time scales is capable of producing changes in the median, standard deviation, and skewness of tooth $\delta^{13} \mathrm{C}$ distributions similar to those modeled using the seasonal changes in vegetation described above. For example, in a conceptual model of single-foram growth, changes in ENSO variability produce changes in median, skewness, and standard 
deviation in a similar manner to that of our modeled changes in the seasonal cycle (Leduc et al., 2009). Although that model only addressed ENSO variability, variability on all time scales can produce similar changes in foram $\delta^{18} \mathrm{O}$ distributions. The effect of longer-term variability can play a role in leporid $\delta^{13} \mathrm{C}$ distributions as well.

An additional potential complication is the presence of long-term trends in $\mathrm{C}_{3} / \mathrm{C}_{4}$ vegetation, which can result in the sampling of teeth spanning a change in the seasonal vegetation cycles. Characteristics of the resulting distribution will not be indicative of one population, but will instead be an amalgamation of all the possible seasonal vegetation distributions within the sampled interval. That distorts the values of the statistics used to characterize the distribution. One such example would be sampling across a mean-state shift. Though each year might have a particular seasonal $\mathrm{C}_{3} / \mathrm{C}_{4}$ range, overlapping multiple years at different mean-states would inflate the $\delta^{13} \mathrm{C}$ range in the resulting tooth $\delta^{13} \mathrm{C}$ distribution. This leads to a higher standard deviation that would result from just the seasonal dietary cycle. If this were compared to another distribution sampled from an interval with relatively stable vegetation, the change in standard deviation might be interpreted as an increase in the seasonal range, when it is just a product of a long-term shift in vegetation.

The effects of long-term changes in vegetation on leporid $\delta^{13} \mathrm{C}$ distributions can be partially mitigated. The most effective strategy for doing so is sampling at high temporal resolution. Because the shape of the leporid $\delta^{13} \mathrm{C}$ distribution can only be influenced by variability that occurs within the time frame of the sampling interval, variability on time scales longer than the sampling interval are eliminated as possible 
explanatory mechanisms. Ideally, each sampling interval would correspond to a single year, completely eliminating interference from processes occurring above the seasonal level. Though annual resolution is unrealistic, sampling at high resolution helps considerably in limiting the number of sources of variability that can play a role in determining the shape of the resulting leporid $\delta^{13} \mathrm{C}$ distributions.

Another consideration is the relative magnitudes of changes in seasonal vegetation versus the changes in vegetation over interannual and longer time scales. When seasonal vegetation changes are much larger than variations that are occurring on longer time scales, seasonal variations in $\delta^{13} \mathrm{C}$ values will dominate the distribution of tooth $\delta^{13} \mathrm{C}$ values. In most locations with a strong seasonal cycle in vegetation, such as the southwestern United States, this will be the case. A potential exception is when the magnitude of the longer-term variations in $\delta^{13} \mathrm{C}$ values approaches the magnitude of the seasonal cycle. In such a scenario, the influence of longer-term variations in vegetation needs to be considered, and will likely be difficult to disentangle from the seasonal cycle. In mid-latitude climates, where there is little seasonality in the proportions of $\mathrm{C}_{3}$ and $\mathrm{C}_{4}$ plants, tooth $\delta^{13} \mathrm{C}$ distributions will reflect mostly long-term changes in vegetation.

\subsection{Variations in Leporid Teeth $\delta^{13}$ C Values from HaLl's CaVe}

To further investigate the utility of leporid tooth $\delta^{13} \mathrm{C}$ distributions for reconstructing vegetation change, we used the leporid tooth $\delta^{13} \mathrm{C}$ model to investigate changes in tooth $\delta^{13} \mathrm{C}$ distributions from Hall's Cave, Texas. Hall's Cave contains a large 
number of fossil leporids throughout, partially mitigating the problems associated with interpreting data from small samples. Additionally, the chronology indicates that the Hall's Cave deposit is a product of relatively continuous deposition over the last 20,000 years, during which large shifts in global climate and vegetation occurred over much of North America (e.g., Overpeck et al., 1992). This time span provides the chance to test the sensitivity of the leporid $\delta^{13} \mathrm{C}$ record to changes in vegetation.

The bulk organic carbon $\delta^{13} \mathrm{C}$ record provides a record of mean $\mathrm{C}_{3} / \mathrm{C}_{4}$ plant biomass (Table S2). This acts as a baseline to which we can compare the leporid $\delta^{13} \mathrm{C}$ record. Long-term shifts in the proportion of $\mathrm{C}_{3} / \mathrm{C}_{4}$ vegetation on the landscape are evident in the bulk organic $\delta^{13} \mathrm{C}$ record, which can be used to divide the bulk carbon record into four distinct vegetation regimes. The first regime, spanning the period between 20 and $14.2 \mathrm{ka} \mathrm{BP}$, is marked by $\mathrm{C}_{4}$ plant dominance and corresponds to the late Glacial (LG). This is followed by a period of increased $C_{3}$ plant abundance from 14 to $11.1 \mathrm{ka}$. Within the uncertainties in the chronology, this corresponds to the Younger Dryas (YD) event. A third vegetation regime, corresponding to the early Holocene (EH; 11 to $5 \mathrm{ka}$.) reflects a return to vegetation similar to that of the late Glacial, with $\mathrm{C}_{4}$ plant dominance. The final vegetation zone, the late Holocene ( $\mathrm{LH})$, is marked by a long-term shift towards increased $\mathrm{C}_{3}$ plant abundance from $5 \mathrm{ka}$ to the present. Leporid teeth were sampled at even spacing throughout each of those vegetation regimes, and replicate teeth were sampled from as many $5 \mathrm{~cm}$ excavation levels as possible. The number of teeth sampled for each of these intervals was limited by the number of suitable teeth present in each interval, but allowed for the sampling of 38 teeth in the LH, 35 teeth in the EH, 34 
teeth in the YD, and 28 teeth in the late Glacial (Table S1). Given these sample size restrictions, error estimates were made using the statistical criterion described previously (Table 1).

\subsubsection{Tooth $\delta^{13} \mathrm{C}$ Variability}

The leporid tooth $\delta^{13} \mathrm{C}$ values exhibit high variability within each interval at Hall's Cave. That variability cannot be explained by the centennial- to millennial-scale $\mathrm{C}_{3} / \mathrm{C}_{4}$ vegetation variability evident in the bulk organic carbon $\delta^{13} \mathrm{C}$ record. The standard deviation of bulk organic $\delta^{13} \mathrm{C}$ values is $1.36 \%$ in the $\mathrm{LG}, 2.23 \%$ in the $\mathrm{YD}$, and $1.35 \%$ o in the EH. In contrast, leporid tooth $\delta^{13} \mathrm{C}$ variability is greater, with $\mathrm{LG}, \mathrm{YD}$, and $\mathrm{EH}$ standard deviation values of $1.78 \%, 2.97 \%$, and $2.36 \%$ during these intervals, respectively. Because each bulk organic carbon $\delta^{13} \mathrm{C}$ value integrates vegetation over 59 \pm 49 years, the spread in $\delta^{13} \mathrm{C}$ values will be due to variability on centennial to millennial time scales. These sources of variability influence tooth $\delta^{13} \mathrm{C}$ values as well, but since each leporid tooth $\delta^{13} \mathrm{C}$ measurement represents 2-4 weeks, the spread in tooth $\delta^{13} \mathrm{C}$ values additionally depends on short-term variability, such as decadal, interannual, and seasonal variability. The total variability in leporid $\delta^{13} \mathrm{C}$ values is a combination of the variability on these different time scales, while variability in bulk organic $\delta^{13} \mathrm{C}$ is the result of only centennial- and millennial-scale variability. Because the variability in tooth $\delta^{13} \mathrm{C}$ values is larger than variability of bulk organic $\delta^{13} \mathrm{C}$ values, variability on centennial to millennial time scale is not capable of explaining the total variability recorded by the tooth $\delta^{13} \mathrm{C}$ record. That means the sub-centennial variability which only the tooth $\delta^{13} \mathrm{C}$ values are subject to is providing a noticeable input. 
In the $\mathrm{LH}$, however, the long-term shift towards greater $\mathrm{C}_{3}$ vegetation results in a standard deviation of bulk organic carbon $\delta^{13} \mathrm{C}$ values of $2.98 \%$, compared to the $\mathrm{LH}$ standard deviation of tooth $\delta^{13} \mathrm{C}$ values of $2.19 \%$. In this case, centennial and millenniallevel variability in mean $\mathrm{C}_{3} / \mathrm{C}_{4}$ biomass, as reconstructed by the bulk organic $\delta^{13} \mathrm{C}$ record, is considerably larger than the variability present in tooth $\delta^{13} \mathrm{C}$ values. This means that, in the spread in the $\mathrm{LH}$ tooth $\delta^{13} \mathrm{C}$ record, the input from the long-term shift in vegetation may be very large, and short-term variability is not necessarily providing substantial input.

The trend of greater variability in tooth $\delta^{13} \mathrm{C}$ than in bulk organic $\delta^{13} \mathrm{C}$ holds true for replicate teeth sampled from individual excavation levels. Because this sampling interval is $295 \pm 211$ years, variability on this time scale is not subject to millennial-level changes. Comparing variability of the two records at this level permits an assessment of the relative contribution of centennial variability to tooth $\delta^{13} \mathrm{C}$ values. For each of the 27 excavation levels from which three teeth were analyzed, excluding those in the LH, the median standard deviation of $\delta^{13} \mathrm{C}$ values is $1.69 \%$ (minimum $=0.41 \%$, maximum $=$ $4.88 \%$ ). However, the median range of bulk organic $\delta^{13} \mathrm{C}$ values from the same levels is $1.07 \%$ (minimum $=0.05 \%$; maximum $=2.96 \%$ ). Similar to the comparison of variability across bins, variability in replicate tooth $\delta^{13} \mathrm{C}$ values is larger than bulk organic $\delta^{13} \mathrm{C}$ variability. This is evidence that vegetation changes on decadal, interannual, and/or seasonal time scales are increasing tooth $\delta^{13} \mathrm{C}$ variability beyond what variability on centennial time scales can produce. 


\subsubsection{Offset in $\mathrm{C}_{3} / \mathrm{C}_{4}$ Vegetation}

For each interval, tooth $\delta^{13} \mathrm{C}$ values indicate lower proportions of $\mathrm{C}_{4}$ vegetation than evident from the bulk organic $\delta^{13} \mathrm{C}$ record, after accounting for isotopic fractionation during production of tooth enamel (Passey et al., 2005). In calculating proportions of $\mathrm{C}_{3} / \mathrm{C}_{4}$ vegetation from pre-industrial samples, end-member $\delta^{13} \mathrm{C}$ values were increased by $1.5 \%$ to compensate for the decrease in the $\delta^{13} \mathrm{C}$ value of atmospheric $\mathrm{CO}_{2}$ over the last 200 years (Friedli et al., 1986). The bulk organic carbon $\delta^{13} \mathrm{C}$ data suggest nearly $100 \%$ $\mathrm{C}_{4}$ plant biomass during the $\mathrm{EH}$ and $\mathrm{LG}$, and reconstruct $64 \%$ and $78 \% \mathrm{C}_{4}$ plant biomass for the LH and YD, respectively. In contrast, median leporid $\delta^{13} \mathrm{C}$ values indicate ca. $25 \% \mathrm{C}_{4}$ plant biomass during the $\mathrm{LG}, 18 \%$ during the $\mathrm{YD}, 29 \%$ during the $\mathrm{EH}$, and $30 \%$ during the LH.

Offsets between the median leporid $\delta^{13} \mathrm{C}$ values and those estimated from bulk organic carbon $\delta^{13} \mathrm{C}$ values beyond that which can be attributed to fractionation may be the result of two processes. First, as discussed previously, dietary bias likely results in some discrepancy between $\mathrm{C}_{3} / \mathrm{C}_{4}$ plants consumed and $\mathrm{C}_{3} / \mathrm{C}_{4}$ plants on the landscape, including the preferences for $C_{3}$ forbs over $C_{4}$ grasses in leporids (Turkowki, 1975; Smith, 2011). Another likely contributor is the limited length of the $\mathrm{C}_{4}$ growing season. Even when $\mathrm{C}_{4}$ vegetation dominates total annual $\mathrm{C}_{3} / \mathrm{C}_{4}$ biomass, $\mathrm{C}_{4}$ grasses do not grow for the entire year (Correll and Johnston, 1970). Because the $\delta^{13} \mathrm{C}$ values of individual teeth represent 2-4 week snapshots of leporid diet, a percentage of $\delta^{13} \mathrm{C}$ measurements of randomly sampled teeth will represent portions of the year when $\mathrm{C}_{4}$ vegetation was not 
growing and, therefore, not consumed by leporids. This results in greater representation of $\mathrm{C}_{3}$ vegetation in leporid $\delta^{13} \mathrm{C}$ values than in total $\mathrm{C}_{3} / \mathrm{C}_{4}$ biomass.

\subsubsection{Changes in leporid $\delta^{13} \mathrm{C}$ distributions}

Errors produced from the model allow for the statistical comparison of tooth $\delta^{13} \mathrm{C}$ distributions, which can provide insight into temporal changes in vegetation dynamics. Comparison of the variability in bulk organic carbon $\delta^{13} \mathrm{C}$ values to the tooth $\delta^{13} \mathrm{C}$ record indicates that short-term variability plays a noticeable role in determining the variability in tooth $\delta^{13} \mathrm{C}$ values. Therefore, short-term variability can provide possible explanations for changes in tooth $\delta^{13} \mathrm{C}$ distributions. Both the median and standard deviation values were statistically compared between bins; however, skewness was only addressed in a qualitative sense because the sample sizes for each bin are not large enough for a robust quantitative assessment.

\subsubsection{Late Glacial Variability}

The standard deviation of leporid $\delta^{13} \mathrm{C}$ values during the LG is significantly lower than during all post-Glacial intervals. At $1.78 \pm 0.23 \%$, the standard deviation in $\delta^{13} \mathrm{C}$ values during the $\mathrm{LG}$ is $40 \%$ lower than that during the $\mathrm{YD}\left(\mathrm{P}_{\mathrm{d}}=98.3 \%\right), 25 \%$ lower than that of the EH $\left(\mathrm{P}_{\mathrm{d}}=75.2 \%\right)$, and $19 \%$ lower than that of the LH $\left(\mathrm{P}_{\mathrm{d}}=60.1 \%\right)$. As indicated by our model, standard deviation in tooth $\delta^{13} \mathrm{C}$ values is positively correlated with the seasonal range in $\delta^{13} \mathrm{C}$ values. Thus, the reconstructed increase in the standard deviation in tooth $\delta^{13} \mathrm{C}$ values from the $\mathrm{LG}$ to the $\mathrm{YD}$ and $\mathrm{EH}$ may reflect an increase in the seasonal range of $\mathrm{C}_{3} / \mathrm{C}_{4}$ plant abundance over that time interval, and is consistent with 
orbitally induced increases in seasonality over that time period, associated with precession of the equinoxes (Fig. 8a; Berger, 1978).

\subsubsection{Younger Dryas Variability and Median}

The YD leporid tooth $\delta^{13} \mathrm{C}$ distribution exhibits the largest standard deviation in the record (2.97\%). Because changes in seasonality modulate changes in the standard deviation of leporid tooth $\delta^{13} \mathrm{C}$ distributions, this suggests that the greatest seasonality of $\mathrm{C}_{3} / \mathrm{C}_{4}$ plant composition in the record occurs during the $\mathrm{YD}$, which cannot be attributed to insolation forcing alone. However, it has been suggested that, in the mid-continent, the YD was characterized by greater temperature seasonality as a result of increased summer advection of warm air masses from the Caribbean (Schiller et al., 1997; Yu and Wright, 2001; Shuman et al., 2002). Because temperature is an important environmental cue for plant life stages (Angevine and Chabot, 1979; Probert, 2000; Volaire and Norton, 2006; Rohde and Bhalerao, 2007), increased seasonality of temperature could result in greater annual extremes in $\mathrm{C}_{3} / \mathrm{C}_{4}$ vegetation on the landscape, resulting in a greater seasonal range of $\mathrm{C}_{3} / \mathrm{C}_{4}$ vegetation consumed by leporids.

The increased variability in leporid tooth $\delta^{13} \mathrm{C}$ values during the $\mathrm{YD}$ is also accompanied by the lowest median $\delta^{13} \mathrm{C}$ value $(-10.24 \pm 0.67), 1.02 \%$ lower than the value for the late Glacial $\left(\mathrm{P}_{\mathrm{d}}=63.9 \%\right), 1.62 \%$ lower than the $\mathrm{EH}\left(\mathrm{P}_{\mathrm{d}}=83.5 \%\right)$, and $1.79 \%$ lower than the $\mathrm{LH}\left(\mathrm{P}_{\mathrm{d}}=89.1 \%\right)$. This is consistent with the shift towards greater proportions of $\mathrm{C}_{3}$ biomass on the landscape apparent in the bulk $\delta^{13} \mathrm{C}$ record, though the magnitudes of the changes evident in the tooth and the bulk $\delta^{13} \mathrm{C}$ records are significantly different. Alternatively, because relative season length modulates the median of leporid 
tooth $\delta^{13} \mathrm{C}$ distributions, these changes could have been caused by an increase in the length of the $\mathrm{C}_{3}$ plant growing season. The peak in skewness during the $\mathrm{YD}$, though not significant, is consistent with this interpretation.

This increase in the length of the $\mathrm{C}_{3}$ plant growing season during the YD could be due to changes in seasonal precipitation patterns, a decrease in spring and fall temperatures, or a rise in atmospheric $\mathrm{pCO}_{2}$. Increases in precipitation on either end of the $C_{3}$ growing season (i.e., spring and fall) could extend the in $C_{3}$ growing season or could allow $\mathrm{C}_{3}$ winter-annuals to become established earlier in the fall. Because a number of $\mathrm{C}_{3}$ annuals grow during the spring, increased precipitation during that season could also result in greater amounts of $\mathrm{C}_{3}$ biomass at this time, effectively extending the $\mathrm{C}_{3}$ season length, and suppressing the growth and establishment of $\mathrm{C}_{4}$ summer grasses (Raynal and Bazzaz, 1975; Abul-Fatih and Bazzaz, 1979; Rathcke and Lacey, 1985; Sherry et al., 2008). Likewise, increased precipitation during the fall could allow winter annuals to reach greater biomass earlier in the year, also resulting in a longer $\mathrm{C}_{3}$ growing season.

Though decreased temperature during from the spring through fall is another possible mechanism for increasing the length of the $\mathrm{C}_{3}$ growing season, changes in standard deviation support the hypothesis that temperatures were likely more seasonal during the YD. Furthermore, to achieve the observed change in $\mathrm{C}_{3}$ growing season length compared with the LG would require temperatures to be lower than during the LG, which is unlikely. Thus, it is unlikely that decreased temperature is the primary driver of 
changing $\mathrm{C}_{3}$ growing season length during the $\mathrm{YD}$, though it may be a secondary factor facilitating these changes.

Likewise, changes in atmospheric $\mathrm{pCO}_{2}$ are capable of changing $\mathrm{C}_{3} / \mathrm{C}_{4}$ abundance, but are unable to completely explain the patter in the YD. Because C3 plants are favored at higher atmospheric concentrations of $\mathrm{CO}_{2}$ (Ehleringer et al., 1997), the increase in $\mathrm{pCO}_{2}$ from the LG to the YD (Petit et al., 1999) could have increased the proportion of the year that favors the growth of $\mathrm{C}_{3}$ plants. This could explain the decrease in the median of leporid tooth $\delta^{13} \mathrm{C}$ values from the LG to the YD. However, this is unable to explain the subsequent increase in median tooth $\delta^{13} \mathrm{C}$ values in the $\mathrm{EH}$, where atmospheric $\mathrm{CO}_{2}$ concentrations were at higher than during the YD (Petit et al., 1999). Instead, the leporid tooth $\delta^{13} \mathrm{C}$ data provide strong support for an increase in precipitation during the spring and/or fall seasons and is consistent with the proxy evidence for wetter conditions across the southwestern United States during the YD, likely as a result of a more southerly mean position of the polar front at that time (Asmerom et al., 2010).

\subsubsection{Lack of Holocene Change}

Standard deviation and median values of leporid $\delta^{13} \mathrm{C}$ distributions do not undergo significant changes between the EH and $\mathrm{LH}$, when shifts might be expected, based on changes in the bulk organic carbon $\delta^{13} \mathrm{C}$ record. $\mathrm{LH}$ standard deviation might be expected to have a similar value to the LG because of similar seasonality of insolation. Instead, the standard deviation in tooth $\delta^{13} \mathrm{C}$ values is significantly greater during the $\mathrm{LH}$. It is possible that this is the result of confounding influences associated with longer-term 
vegetation changes during this time period. Over the late Holocene, bulk organic carbon $\delta^{13} \mathrm{C}$ values decrease by ca. $8 \%$. The magnitude of this change is similar to that of the seasonal cycle, and as a result should have a significant influence on tooth $\delta^{13} \mathrm{C}$ values.

Based on this $\mathrm{LH}$ decrease in bulk organic carbon $\delta^{13} \mathrm{C}$ values, we would expect to see a corresponding decrease in median $\delta^{13} \mathrm{C}$ values for leporid teeth. However, this is not apparent in the tooth $\delta^{13} \mathrm{C}$ record. One possible explanation for the lack of a change in median leporid $\delta^{13} \mathrm{C}$ values is the occurrence of multiple, offsetting changes in the seasonal cycle. For example, the mean-state shift towards more $C_{3}$ vegetation would decrease median tooth $\delta^{13} \mathrm{C}$ values. That might be offset by a decrease in the relative length of the $\mathrm{C}_{3}$ season, which, according to our model, should increase the median values of tooth $\delta^{13} \mathrm{C}$ values. Such a scenario could be caused by an increase in overall temperature, shortening the $\mathrm{C}_{3}$ season, combined with a decrease in precipitation during the $\mathrm{C}_{4}$ growing season, leading to decreased $\mathrm{C}_{4}$ production and, thus, consumption. The decrease in skewness from the $\mathrm{EH}$ to the $\mathrm{LH}$, though not significant, is consistent with this explanation because it indicates a decrease in the relative length of the $\mathrm{C}_{3}$ season.

An alternative explanation is that some or all of the shift in the LH portion of the bulk organic carbon record occurred in aspects of the vegetation that leporid teeth do not sensitively record. One such case would be if the shift occurred due to changes in vegetation rarely consumed by leporids, such as woody plants. If the LH bulk organic carbon shift was solely due to an increase in the amount of woody vegetation relative to $\mathrm{C}_{4}$ grasses, it is unlikely that it would be recorded by leporids. An increase in $\mathrm{C}_{3}$ biomass during the winter is another possible explanation. If leporids already are exclusively 
consuming strictly $\mathrm{C}_{3}$ vegetation during that time of year, a further increase in $\mathrm{C}_{3}$ biomass will not affect leporid $\delta^{13} \mathrm{C}$ values. Additionally, an increase in $\mathrm{C}_{3}$ biomass during the winter rather than spring or fall would likely leave relative season length unaffected. Given the current data, there is no way to discern which explanation or combination thereof is the most probable. 


\section{Implications for Interpreting $\delta^{13} \mathrm{C}$ values of Small Mammal Teeth}

Considering the advantages conferred by small mammal teeth in isotopic studies and their abundance in the fossil record, it is likely that they will continue being used to investigate past changes in vegetation. However, because of their rapid growth, they present a fundamentally different system from those of large mammals, and the differences need to be considered when interpreting stable isotope data from these systems. It is possible to make potentially meaningful interpretations of stable isotope data from small mammal teeth, but this requires a careful consideration of the potential influences of seasonal and longer-term variability on the distribution of tooth isotopic data. However, by using novel approaches, such as characterizing tooth populations from the analysis of large numbers of fast-growing teeth, it is possible to provide additional insights into past variations in vegetation and climate that complement traditional approaches.

Standard deviation, median, and skewness are all aspects of tooth $\delta^{13} \mathrm{C}$ distributions that are capable of providing meaningful information about changes in vegetation and climate variability. Provided that the seasonal changes in vegetation are larger than the changes occurring on interannual and longer time scales, the statistics of tooth $\delta^{13} \mathrm{C}$ values can be interpreted as reflecting changes in the seasonal cycle. Changes in the median tooth $\delta^{13} \mathrm{C}$ values reflect both changes in the mean-state as well as in the relative lengths of the $\mathrm{C}_{3}$ and $\mathrm{C}_{4}$ seasons. Variations in the standard deviation of tooth $\delta^{13} \mathrm{C}$ distributions provide insights into changes in the magnitude of seasonal changes in 
the relative abundance of $\mathrm{C}_{3}$ and $\mathrm{C}_{4}$ plants, and changes in the skewness of tooth $\delta^{13} \mathrm{C}$ distributions provide an indicator of changes in the relative lengths of the $\mathrm{C}_{3}$ and $\mathrm{C}_{4}$ plant growing seasons.

The number of teeth sampled has a significant influence on the ability to properly characterize the tooth population and the ability to distinguish changes in the record. Sampling at small time intervals helps to limit the possible influence of longer-term variability on tooth distributions, but can restrict sample size, which in turn changes the precision of the estimates and the ability to detect meaningful changes. Alternatively, when the sampling interval encompasses a timespan long enough so that the magnitude of non-seasonal $\delta^{13} \mathrm{C}$ variations approach seasonal changes in $\delta^{13} \mathrm{C}$, these two effects cannot be separated, and the interpretation of the $\delta^{13} \mathrm{C}$ data is more ambiguous.

The model generated here specifically focused on leporids - which are abundant in Hall's Cave and across the Edwards Plateau. The stable isotope values in teeth of other taxa with different ecologies and physiologies will potentially reflect changes in vegetation differently. Many rodents, for example, do not have hypselodont cheek teeth (Ungar, 2010), and if this is paired with a distinct breeding season, each tooth might reflect a specific part of the year, creating a bias in the interpretation of the vegetation data. A similar complication applies to hibernating mammals. Animals that store their food are likely to sample the vegetation differently and might not alter their diet seasonally. Other such behaviors and physiological considerations need to be taken into account when interpreting these data. Modeling approaches, like the one presented here, 
provide an interpretive framework for understanding the data generated from these kinds of systems. 


\section{Figures and Tables}
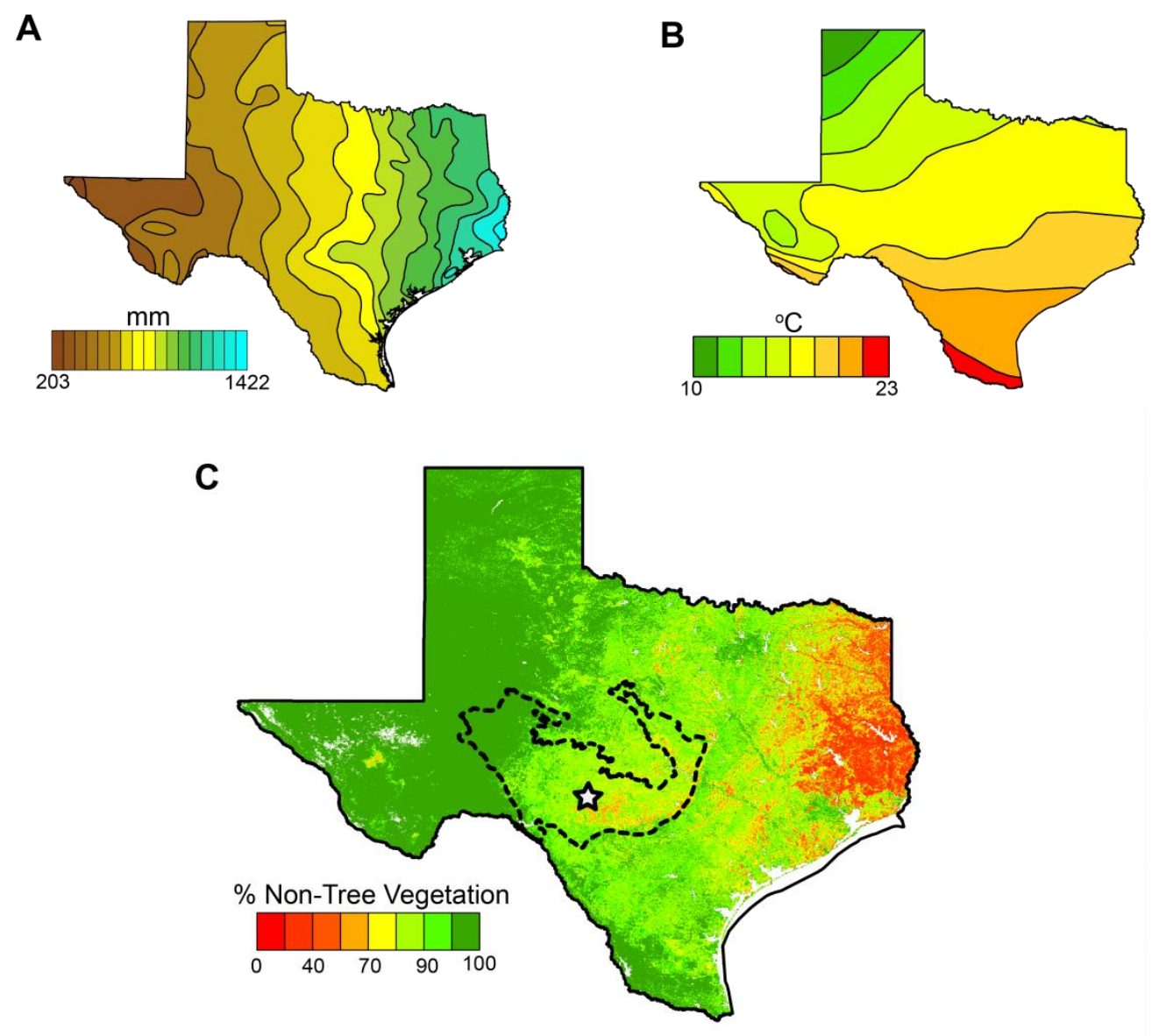

Figure 1: Modern climate and vegetation of Texas. (A) Modern mean annual precipitation in millimeters adapted from the Texas Parks and Wildlife Department. (B) Modern mean annual temperature as interpolated from data provided by NOAA. (C) Percentage of the vegetation that is not trees. Bare ground and water features are white. The star marks the location of Hall's Cave, and the dashed line denotes the boundary of the Edwards Plateau as recognized by the Texas Parks and Wildlife Department. Percentage of non-tree vegetation was calculated from MODIS Vegetation Continuous Fields collection 5 (DiMiceli et al., 2011). 


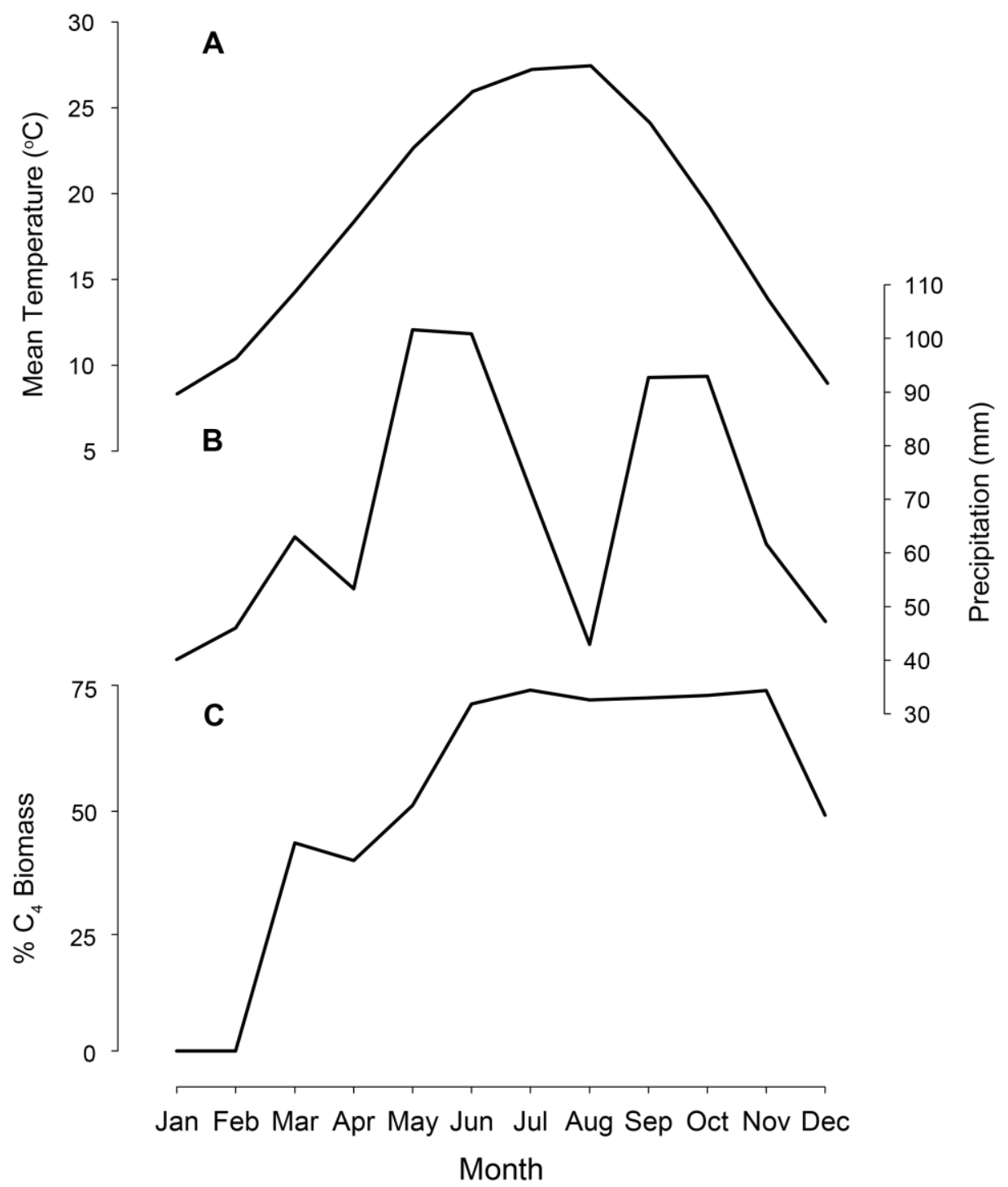

Figure 2: $\quad$ Modern seasonal climate and vegetation of the study area. Mean monthly temperature (A) and mean monthly precipitation $(\mathbf{B})$ are averages from 1981-2010 at the Kerrville 3 NNE weather station (304'28'N 996'31'W). Data were collected from the National Climate Data Center (www.ncdc.noaa.gov). Monthly changes in $\% \mathrm{C}_{4}$ biomass $(\mathbf{C})$ are for sites west of the Balcones Escarpment in Travis, Hays, and Blanco Counties. Relative abundances were calculated using relative abundance data from Fowler and Dunlap (1986) and growing season data from Correll and Johnston (1970). 

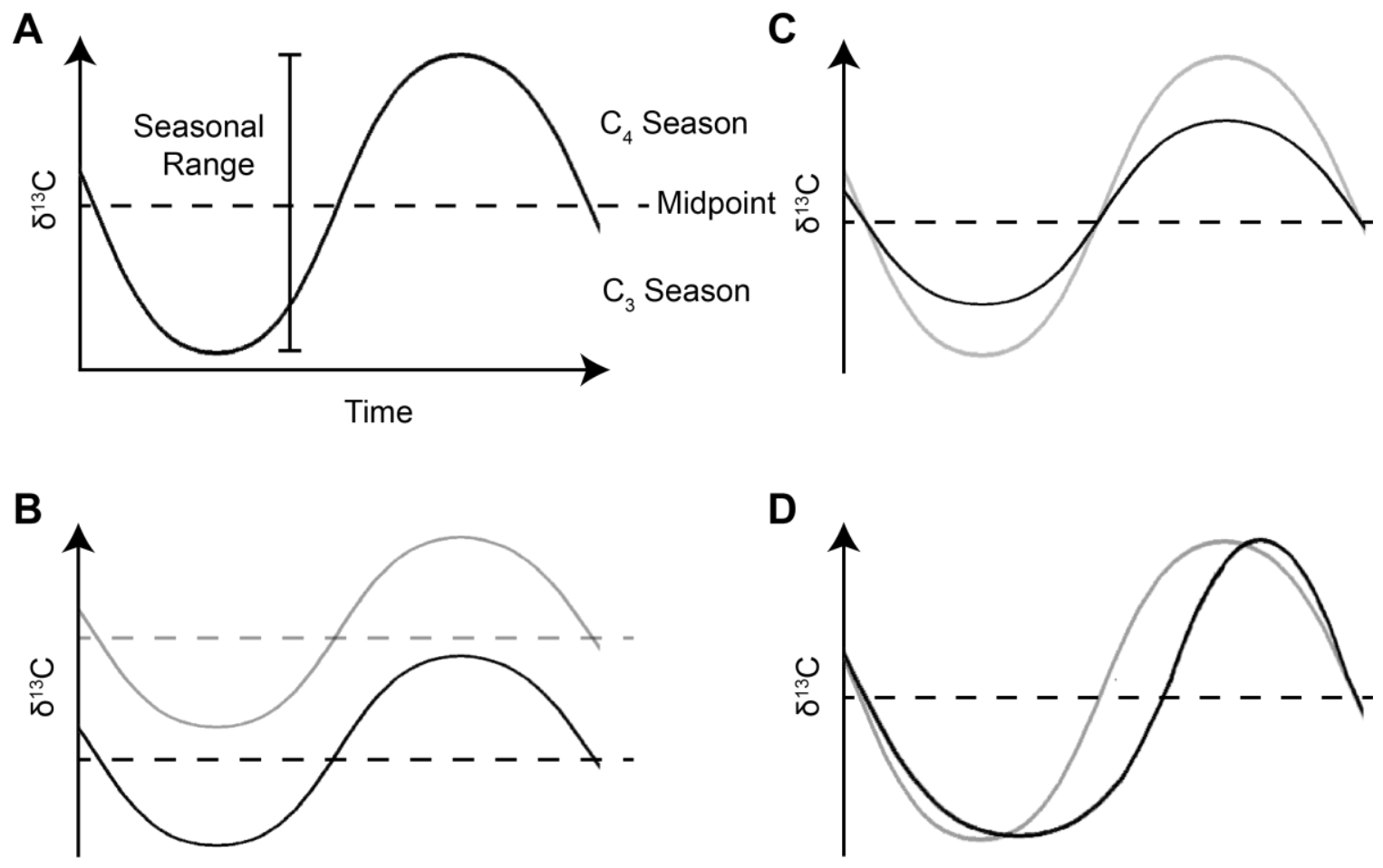

Figure 3: Anatomy of and possible changes to intra-annual changes in vegetation. (A) Terminology used to refer to parts of our model of intra-annual vegetation change. (B, C, D) Illustrations of the effect of mean-state shift, change in amplitude, and change in relative season length, respectively. 


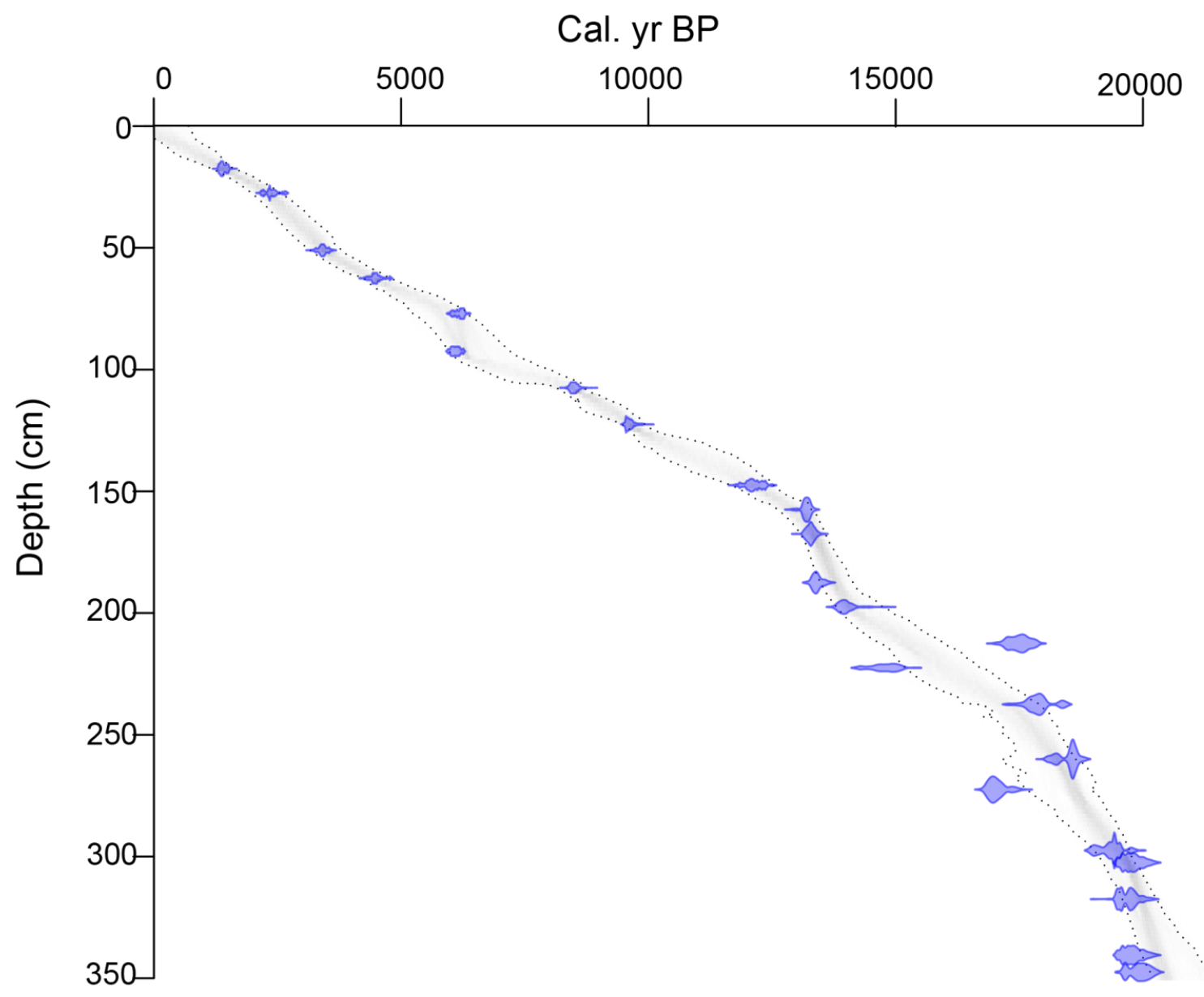

Figure 4: Age model of Hall's Cave deposit. Probability distributions for the calibration of individual radiocarbon dates are indicated, with thicker portions indicating higher probability of correspondence to that age. Dotted lines indicate $95 \%$ probability intervals. Darker shaded areas indicate a greater number of replications. To generate the age model, we used the Rscript BACON (Blaauw and Christen, 2011) with a mean accumulation rate of 52 years $/ \mathrm{cm}$, a $5 \mathrm{~cm}$ sampling window size, and a sample size of 10,000. 


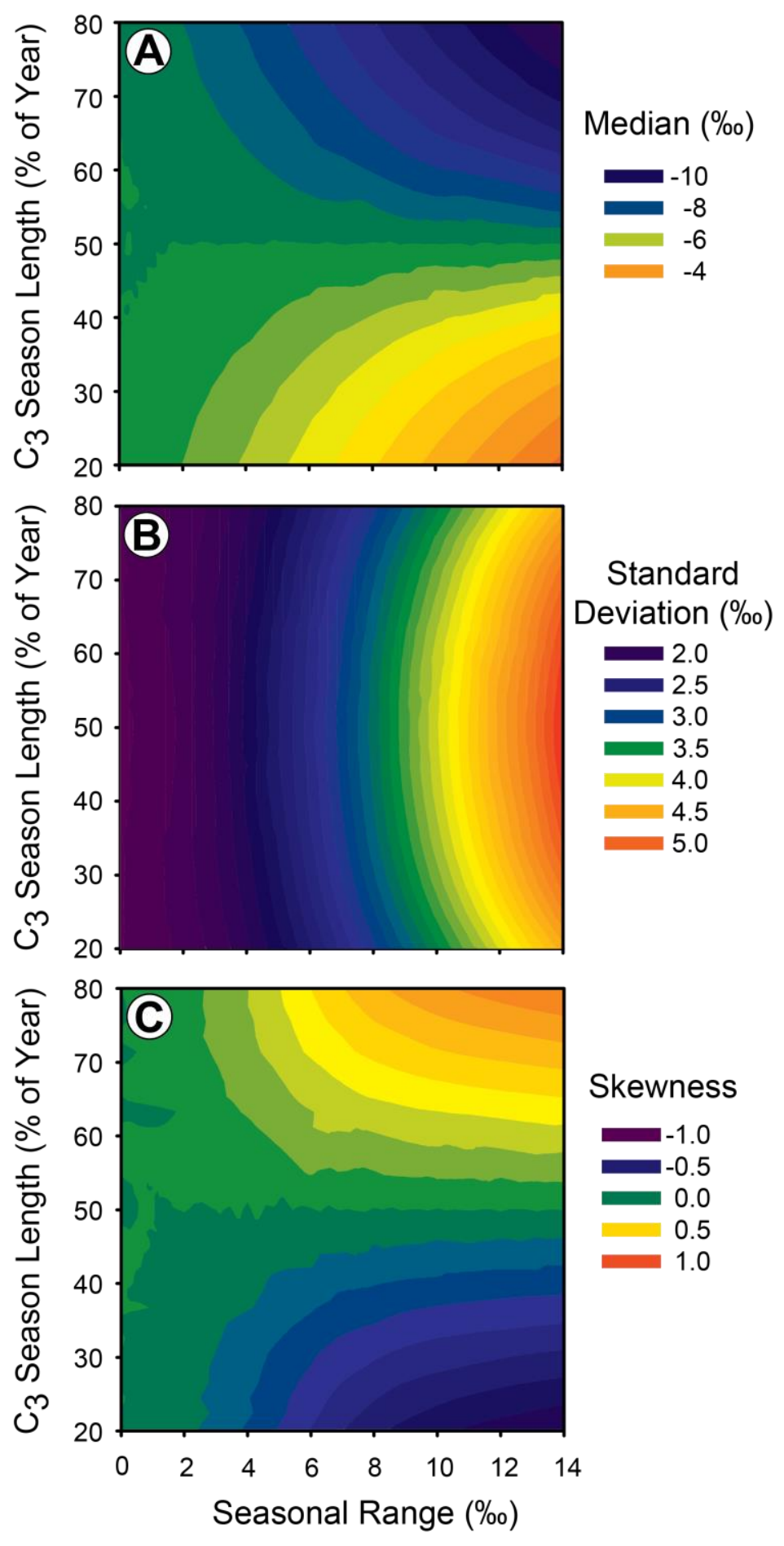

Figure 5: Contour plots representing changes in median (A), standard deviation (B), and skewness $(\mathbf{C})$ as a function of $\mathrm{C}_{3}$ season length and amplitude. For all plots, we set the resting position to $50 \% \mathrm{C}_{3}$ and used synthetic populations of 100,000 teeth in the creation of the plots. 


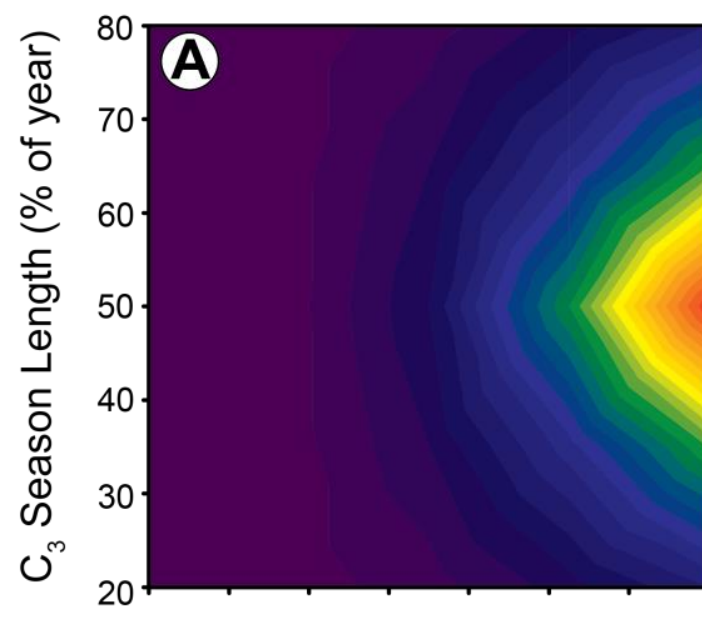

$$
\begin{array}{r}
\text { \# of Teeth } \\
20 \\
40 \\
60 \\
80 \\
100
\end{array}
$$

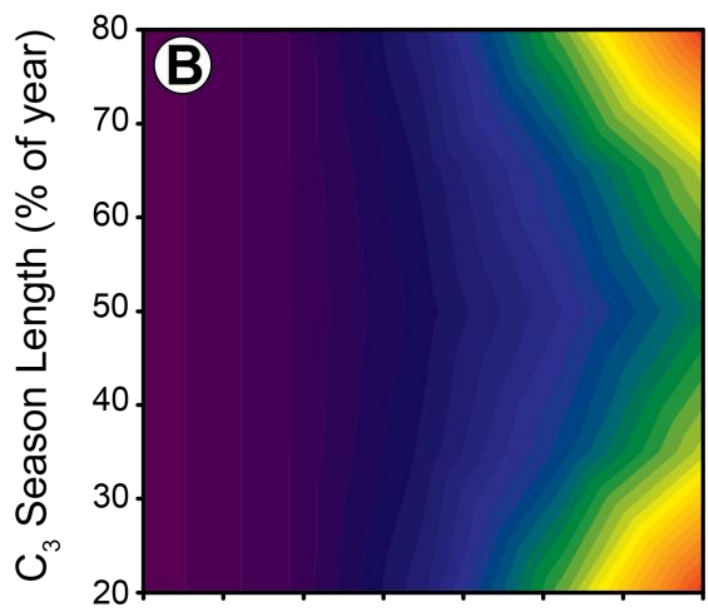

\# of Teeth
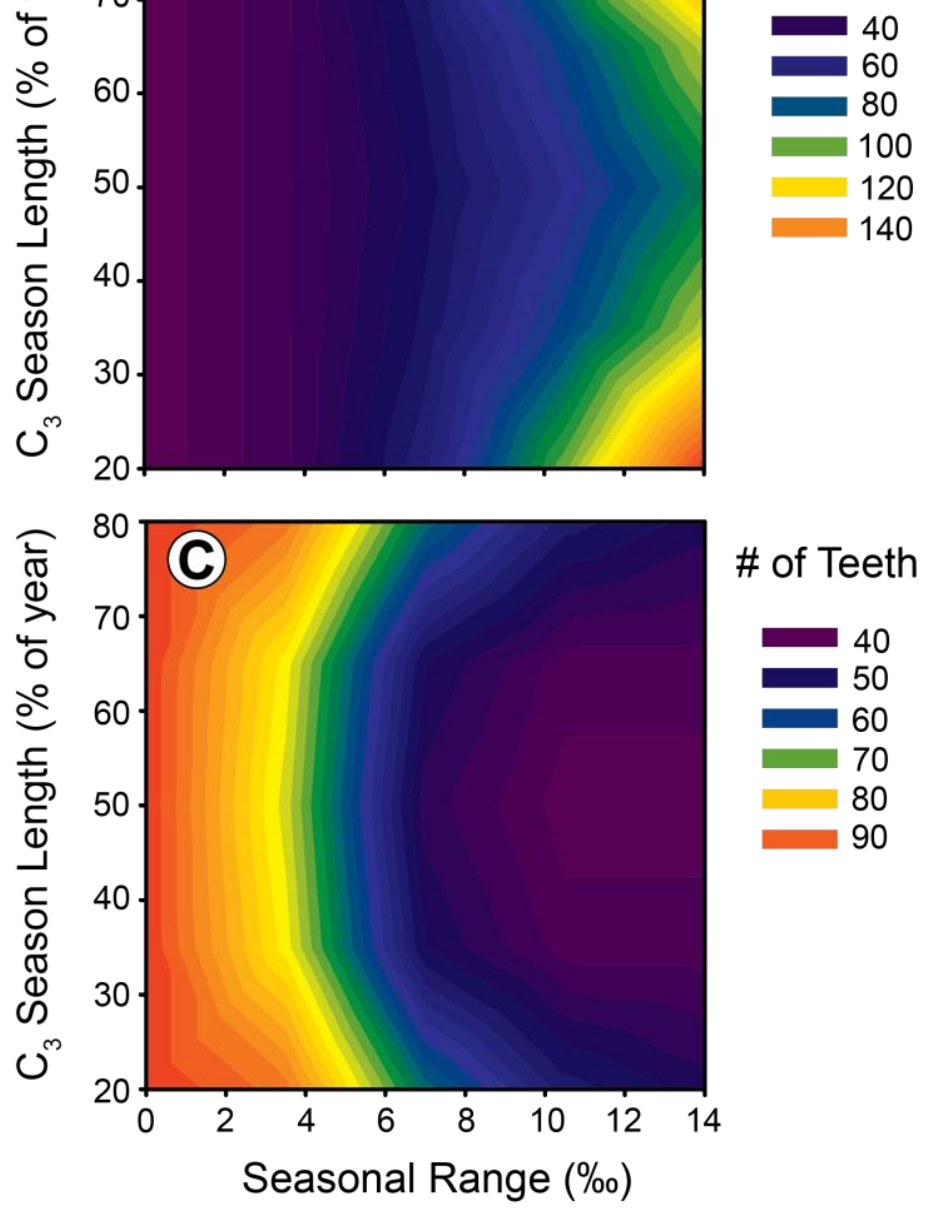

\# of Teeth

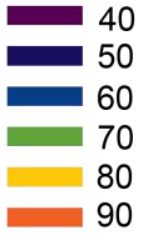


Figure 6: Sample size requirements. (A) The number of teeth required for the error of the median to reach 1\%o. Median is best estimated when standard deviations are small and the distribution is symmetric because those scenarios present cluster the middle values around a small range of $\delta^{13} \mathrm{C}$ values. (B) The number of teeth required for the error of the standard deviation to reach $0.25 \%$. Standard deviation requires more teeth to estimate high variances because under- or overrepresentation of the tails result in a greater difference in $\delta^{13} \mathrm{C}$ values. Very skewed distributions also require more teeth because the long tail represents few teeth but make a large contribution to variance. (C) The number of teeth required for the error of skewness to reach 0.25 . As seasonal range decreases or skewness increases, the distribution becomes more peaked, increasing the $\delta^{13} \mathrm{C}$ range of the tails relative to the rest of the distribution. This makes skewness more difficult to estimate. Each is plotted as a function of amplitude and $\mathrm{C}_{3}$ season length. 10,000 realizations of each sample size were used in error calculation. 


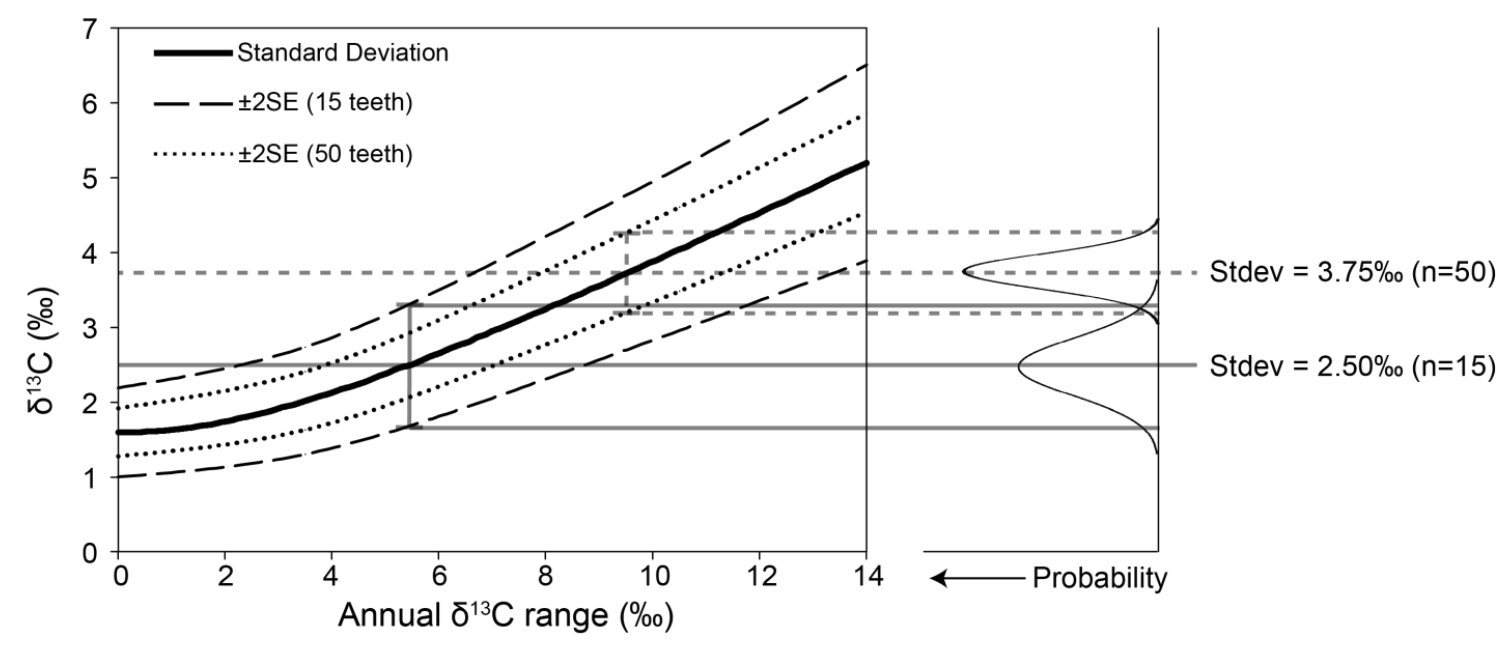

Figure 7: $\quad$ Illustration of how errors are applied to standard deviation using hypothetical datasets indicated on the far right. The depicted relationship between $\delta^{13} \mathrm{C}$ range and standard deviation is for a model with $\mathrm{C}_{3}$ and $\mathrm{C}_{4}$ seasons of equal length. 


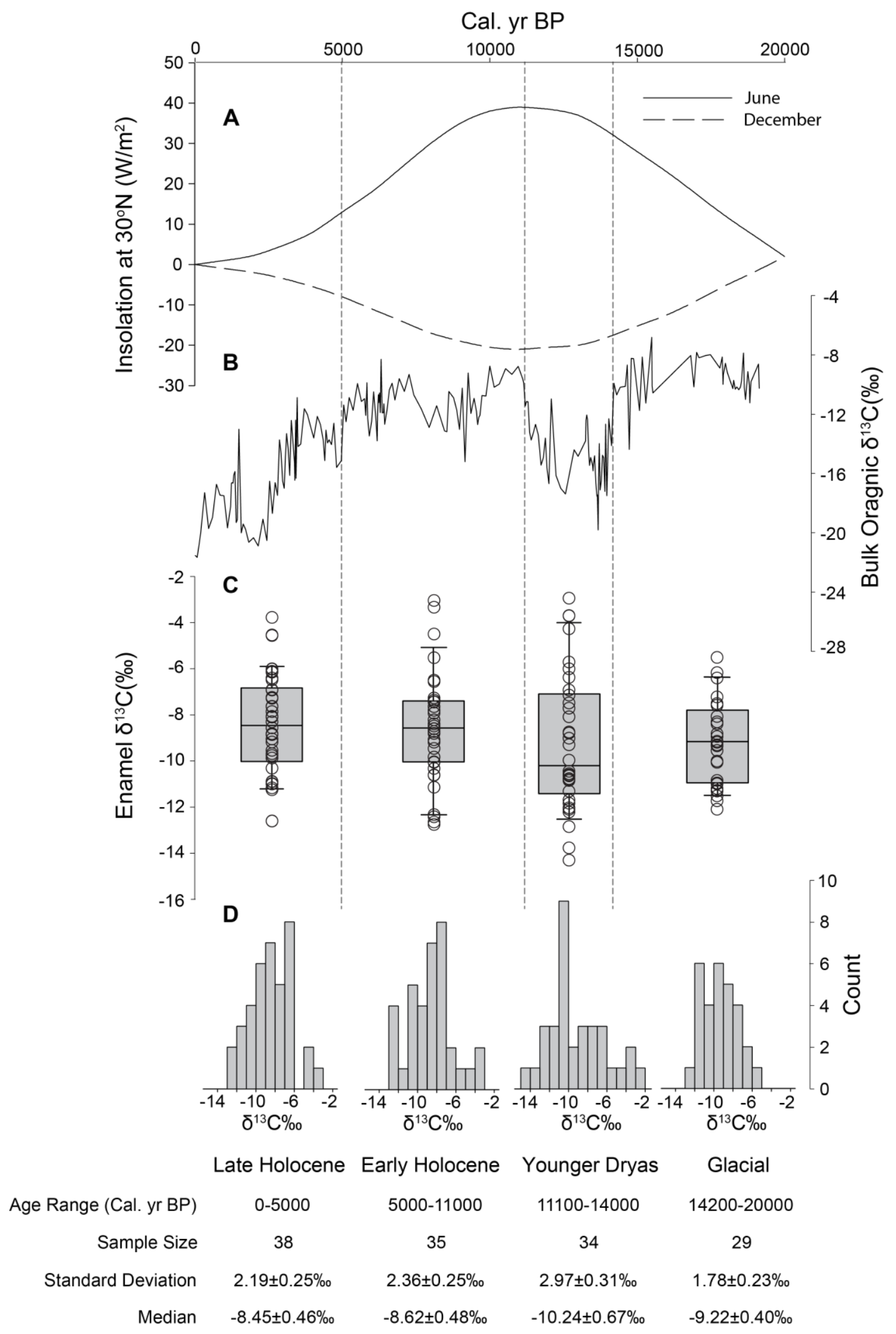


Figure 8: Summary of enamel carbon isotope measurements. (A) Changes in seasonal insolation at $30^{\circ} \mathrm{N}$ over the last 20,000 years (Berger, 1978). (B) Bulk organic stable carbon isotope record. $(\mathbf{C}) \delta^{13} \mathrm{C}$ values for individual teeth plotted (open circles) on top of corresponding 10-90th percentile box plots. Each set of teeth are plotted at their mean age, but individual teeth were sampled from various ages scattered throughout each interval. (D) Histograms of tooth isotope values from each interval with summary statistics below. Dotted lines on $\mathbf{A}-\mathbf{C}$ indicate temporal boundaries between leporid tooth $\delta^{13} \mathrm{C}$ distributions. 


\begin{tabular}{ccccccc} 
& LH-EH & LH-YD & LH-G & EH-YD & EH-G & YD-G \\
\cline { 2 - 7 } SD & - & 88.6 & 60.1 & 77.2 & 75.2 & 98.3 \\
Median & - & 89.1 & 61.7 & 83.5 & - & 63.9
\end{tabular}

Table 1: Probabilities of detection. Column headings indicate the intervals compared. Probabilities are only shown for pairs that are statistically significant according to the criterion detailed by Lanzante (2005). 


\section{Appendices}

\section{APPENDiX A: SuPPlemental TABLES}

Table S1: Leporid tooth $\delta^{13} \mathrm{C}$ values. All isotope values are reported relative to VPDB. Age is that of the midpoint of the depth interval the tooth came from.

\begin{tabular}{|c|c|c|c|c|c|c|c|c|c|}
\hline $\begin{array}{c}\text { Specimen } \\
\text { Number } \\
\end{array}$ & Pit & $\begin{array}{c}\text { Depth } \\
(\mathrm{cm})\end{array}$ & Tooth & Side & $\begin{array}{c}\delta^{13} C \\
(\% o) \\
\end{array}$ & $\begin{array}{c}\delta^{13} \mathrm{C} \\
\text { stdev (\%o) } \\
\end{array}$ & $\begin{array}{c}\delta^{18} O \\
(\% 0) \\
\end{array}$ & $\begin{array}{c}\delta^{18} O \\
\text { stdev (\%o) } \\
\end{array}$ & $\begin{array}{c}\text { Age (Cal. } \\
\text { yr BP) } \\
\end{array}$ \\
\hline TMM 41229-13130 & $1 \mathrm{a}$ & $0-5$ & upper P4 or M1 & right & -4.58 & 0.011 & -1.03 & 0.026 & 105.25 \\
\hline TMM 41229-13134 & $1 \mathrm{a}$ & $0-5$ & upper P4 or M1 & right & -9.07 & 0.011 & -0.03 & 0.021 & 105.25 \\
\hline TMM 41229-13135 & $1 \mathrm{a}$ & $0-5$ & upper P3 & right & -4.56 & 0.013 & 0.97 & 0.036 & 105.25 \\
\hline TMM 41229-13143 & 1 & $5-10$ & upper M2 & left & -8.86 & 0.022 & -1.05 & 0.086 & 652.75 \\
\hline TMM 41229-13144 & $1 \mathrm{a}$ & $5-10$ & upper P4 or M1 & left & -7.65 & 0.013 & 0.05 & 0.022 & 652.75 \\
\hline TMM 41229-13145 & 1 & $5-10$ & upper P4 or M1 & right & -6.42 & 0.023 & -0.41 & 0.021 & 652.75 \\
\hline TMM 41229-13146 & $1 \mathrm{e}$ & $10-15$ & upper P3 & left & -12.62 & 0.011 & -4.36 & 0.022 & 1212.85 \\
\hline TMM 41229-13147 & $1 b$ & $10-15$ & upper P3 & left & -3.80 & 0.017 & 0.42 & 0.023 & 1212.85 \\
\hline TMM 41229-4836 & 1 & $10-15$ & upper P4 or M1 & left & -10.34 & 0.011 & -1.66 & 0.028 & 1212.85 \\
\hline TMM 41229-13148 & 1 & $15-20$ & upper P4 or M1 & left & -11.02 & 0.018 & 0.16 & 0.032 & 1359 \\
\hline TMM 41229-13149 & $1 \mathrm{a}$ & $15-20$ & upper M2 & left & -7.31 & 0.014 & -0.42 & 0.028 & 1359 \\
\hline TMM 41229-13150 & $1 \mathrm{a}$ & $15-20$ & upper P4 or M1 & right & -12.62 & 0.013 & -1.65 & 0.041 & 1359 \\
\hline TMM 41229-13151 & $1 \mathrm{e}$ & $20-25$ & upper M2 & left & -6.03 & 0.019 & -1.92 & 0.025 & 1649.5 \\
\hline TMM 41229-13152 & $1 \mathrm{e}$ & $20-25$ & upper P4 or M1 & left & -9.71 & 0.011 & 0.13 & 0.027 & 1649.5 \\
\hline TMM 41229-13153 & $1 \mathrm{e}$ & $20-25$ & upper P4 or M1 & right & -6.04 & 0.014 & -2.54 & 0.023 & 1649.5 \\
\hline TMM 41229-13154 & $1 \mathrm{e}$ & $25-30$ & upper P4 or M1 & left & -7.66 & 0.011 & 2.17 & 0.021 & 2305.5 \\
\hline TMM 41229-13155 & $1 \mathrm{e}$ & $25-30$ & lower $\mathrm{P} 4, \mathrm{M} 1$, or $\mathrm{M} 2$ & right & -8.58 & 0.010 & 0.48 & 0.017 & 2305.5 \\
\hline TMM 41229-13156 & $1 \mathrm{c}$ & $25-30$ & upper M2 & left & -8.12 & 0.011 & 3.85 & 0.028 & 2305.5 \\
\hline TMM 41229-13157 & $1 \mathrm{a}$ & $30-35$ & upper M2 & left & -6.93 & 0.011 & -1.87 & 0.037 & 2788.35 \\
\hline
\end{tabular}


Table S1 (continued)

\begin{tabular}{|c|c|c|c|c|c|c|c|c|c|}
\hline $\begin{array}{c}\text { Specimen } \\
\text { Number } \\
\end{array}$ & Pit & $\begin{array}{c}\text { Depth } \\
(\mathrm{cm})\end{array}$ & Tooth & Side & $\begin{array}{l}\delta^{13} \mathrm{C} \\
(\% \circ) \\
\end{array}$ & $\begin{array}{c}\delta^{13} \mathrm{C} \\
\text { stdev (\%o) } \\
\end{array}$ & $\begin{array}{c}\delta^{18} O \\
(\% o) \\
\end{array}$ & $\begin{array}{c}\delta^{18} O \\
\text { stdev (\%o) } \\
\end{array}$ & $\begin{array}{c}\text { Age (Cal. } \\
\text { yr BP) } \\
\end{array}$ \\
\hline TMM 41229-13158 & $1 \mathrm{a}$ & $30-35$ & upper P3 & right & -7.26 & 0.016 & 1.19 & 0.023 & 2788.35 \\
\hline TMM 41229-13159 & $1 \mathrm{a}$ & $30-35$ & upper $\mathrm{P} 4, \mathrm{M} 1$ or M2 & right & -6.13 & 0.018 & -0.59 & 0.019 & 2788.35 \\
\hline TMM 41229-13160 & 1 & $35-40$ & upper M2 & left & -9.78 & 0.018 & -0.13 & 0.047 & 3054.6 \\
\hline TMM 41229-13161 & $1 \mathrm{a}$ & $35-40$ & upper M2 & right & -11.27 & 0.012 & -0.63 & 0.030 & 3054.6 \\
\hline TMM 41229-13162 & 1 & $40-45$ & upper P3 & right & -7.88 & 0.007 & 0.19 & 0.012 & 3292.6 \\
\hline TMM 41229-13163 & $1 \mathrm{e}$ & $45-50$ & upper P4 or M1 & right & -8.84 & 0.009 & 0.52 & 0.016 & 3429.6 \\
\hline TMM 41229-13164 & $1 \mathrm{e}$ & $45-50$ & upper P4 or M1 & right & -11.00 & 0.003 & 2.42 & 0.012 & 3429.6 \\
\hline TMM 41229-13165 & 1e & $45-50$ & upper P4 or M1 & right & -11.19 & 0.011 & -1.09 & 0.025 & 3429.6 \\
\hline TMM 41229-13131 & 1 & $50-55$ & possibly upper M1 & right & -8.88 & 0.018 & 0.92 & 0.027 & 3536.4 \\
\hline TMM 41229-13136 & 1 & $50-55$ & possibly upper P4 & left & -10.90 & 0.013 & 0.33 & 0.029 & 3536.4 \\
\hline TMM 41229-13137 & 1 & $50-55$ & possibly upper P4 & right & -8.09 & 0.012 & 1.74 & 0.019 & 3536.4 \\
\hline TMM 41229-13167 & $1 \mathrm{e}$ & $55-60$ & upper P4 or M1 & left & -6.17 & 0.006 & 0.17 & 0.018 & 4074.4 \\
\hline TMM 41229-13168 & $1 \mathrm{e}$ & $55-60$ & upper P3 & right & -9.56 & 0.019 & -0.53 & 0.032 & 4074.4 \\
\hline TMM 41229-13169 & $1 \mathrm{e}$ & $60-65$ & upper P4 or M1 & left & -8.32 & 0.014 & -0.18 & 0.049 & 4452.5 \\
\hline TMM 41229-13170 & $1 \mathrm{e}$ & $60-65$ & upper P4 or M1 & left & -6.51 & 0.018 & -1.31 & 0.036 & 4452.5 \\
\hline TMM 41229-13171 & $1 \mathrm{e}$ & $60-65$ & upper P4 or M1 & right & -9.20 & 0.009 & -2.04 & 0.035 & 4452.5 \\
\hline TMM 41229-13172 & $1 d$ & $65-70$ & upper P4 or M1 & right & -10.92 & 0.016 & -3.77 & 0.033 & 4813.05 \\
\hline TMM 41229-13173 & $1 d$ & $65-70$ & upper M2 & left & -6.95 & 0.014 & 2.12 & 0.034 & 4813.05 \\
\hline TMM 41229-13174 & $1 d$ & $65-70$ & upper P4 or M1 & right & -9.89 & 0.022 & -1.97 & 0.018 & 4813.05 \\
\hline TMM 41229-13176 & $1 d$ & $70-75$ & upper P3 & left & -7.38 & 0.012 & 1.32 & 0.023 & 5236.85 \\
\hline TMM 41229-13177 & 1 & $70-75$ & upper P4 or M1 & left & -9.85 & 0.007 & -0.26 & 0.013 & 5236.85 \\
\hline TMM 41229-13178 & $1 b$ & $75-80$ & upper P3 & left & -7.95 & 0.023 & 1.05 & 0.033 & 5776.3 \\
\hline TMM 41229-13179 & $1 b$ & $75-80$ & upper P4 or M1 & left & -8.24 & 0.023 & 3.11 & 0.021 & 5776.3 \\
\hline TMM 41229-13180 & $1 \mathrm{a}$ & $75-80$ & upper P4 or M1 & right & -7.30 & 0.014 & -1.69 & 0.016 & 5776.3 \\
\hline TMM 41229-13181 & $1 d$ & $80-85$ & upper P4 or M1 & right & -12.66 & 0.013 & -1.95 & 0.032 & 6043.6 \\
\hline
\end{tabular}


Table S1 (continued)

\begin{tabular}{|c|c|c|c|c|c|c|c|c|c|}
\hline $\begin{array}{c}\text { Specimen } \\
\text { Number }\end{array}$ & Pit & $\begin{array}{l}\text { Depth } \\
\text { (cm) }\end{array}$ & Tooth & Side & $\begin{array}{l}\delta^{13} \mathrm{C} \\
(\% \circ) \\
\end{array}$ & $\begin{array}{c}\delta^{13} \mathrm{C} \\
\operatorname{stdev}(\%)\end{array}$ & $\begin{array}{c}\delta^{18} \mathrm{O} \\
(\%)\end{array}$ & $\begin{array}{c}\delta^{18} O \\
\text { stdev (\%o) }\end{array}$ & $\begin{array}{c}\text { Age (Cal. } \\
\text { yr BP) }\end{array}$ \\
\hline TMM 41229-13182 & $1 d$ & $80-85$ & upper P4 or M1 & right & -7.83 & 0.009 & 2.09 & 0.037 & 6043.6 \\
\hline TMM 41229-13183 & $1 d$ & $80-85$ & upper P4 or M1 & right & -4.51 & 0.014 & 3.21 & 0.046 & 6043.6 \\
\hline TMM 41229-13184 & $1 d$ & $85-90$ & upper P3 & right & -7.82 & 0.010 & -1.64 & 0.026 & 6216.6 \\
\hline TMM 41229-13185 & $1 \mathrm{~d}$ & $85-90$ & upper P4 or M1 & left & -9.48 & 0.015 & -1.84 & 0.027 & 6216.6 \\
\hline TMM 41229-13186 & $1 d$ & $85-90$ & upper M2 & left & -8.74 & 0.010 & -2.11 & 0.029 & 6216.6 \\
\hline TMM 41229-13187 & $1 d$ & $90-95$ & upper P4 or M1 & left & -8.51 & 0.015 & -2.33 & 0.021 & 6338.5 \\
\hline TMM 41229-13188 & $1 d$ & $90-95$ & upper P4 or M1 & left & -6.52 & 0.017 & 1.24 & 0.032 & 6338.5 \\
\hline TMM 41229-13189 & $1 d$ & $90-95$ & upper P4 or M1 & left & -9.10 & 0.021 & 2.42 & 0.064 & 6338.5 \\
\hline TMМ 41229-13190 & $1 \mathrm{~d}$ & $95-100$ & upper P4 or M1 & right & -10.06 & 0.020 & -0.75 & 0.011 & 6556.85 \\
\hline TMM 41229-13191 & $1 \mathrm{~d}$ & $95-100$ & upper P3 & left & -8.82 & 0.014 & 0.18 & 0.034 & 6556.85 \\
\hline TMM 41229-13192 & $1 d$ & $95-100$ & upper P3 & left & -10.34 & 0.008 & -2.72 & 0.023 & 6556.85 \\
\hline TMM 41229-13132 & $1 \mathrm{~d}$ & $100-105$ & upper P4 or M1 & left & -8.63 & 0.013 & -0.41 & 0.056 & 7176.15 \\
\hline TMM 41229-13138 & $1 d$ & $100-105$ & upper P4 or M1 & right & -9.21 & 0.010 & -1.00 & 0.025 & 7176.15 \\
\hline TMM 41229-13139 & $1 \mathrm{~d}$ & $100-105$ & broken upper cheek tooth & left & -3.36 & 0.012 & 2.26 & 0.030 & 7176.15 \\
\hline TMМ 41229-13193 & $1 \mathrm{~d}$ & $105-110$ & upper M2 & left & -7.47 & 0.017 & 2.60 & 0.027 & 8309.55 \\
\hline TMM 41229-13194 & $1 d$ & $105-110$ & upper cheek tooth & right & -12.35 & 0.013 & -0.19 & 0.021 & 8309.55 \\
\hline TMM 41229-13195 & $1 \mathrm{~d}$ & $105-110$ & upper M2 & right & -11.16 & 0.018 & -0.36 & 0.026 & 8309.55 \\
\hline TMM 41229-13196 & $1 d$ & $110-115$ & broken upper cheek tooth & left & -5.54 & 0.008 & 1.02 & 0.023 & 8792.55 \\
\hline TMM 41229-13197 & $1 d$ & $110-115$ & upper P4 or M1 & left & -6.58 & 0.007 & -1.07 & 0.017 & 8792.55 \\
\hline TMМ 41229-13198 & $1 \mathrm{~b}$ & $110-115$ & upper P4, M1, or M2 & right & -10.63 & 0.010 & -1.71 & 0.018 & 8792.55 \\
\hline TMM 41229-13199 & $1 d$ & $115-120$ & upper P4 or M1 & left & -12.77 & 0.016 & 1.83 & 0.027 & 9269.8 \\
\hline TMM 41229-13200 & $1 d$ & $115-120$ & upper P4 or M1 & left & -8.62 & 0.012 & -2.01 & 0.025 & 9269.8 \\
\hline TMM 41229-13201 & $1 d$ & $115-120$ & upper P4 or M1 & right & -10.62 & 0.016 & 2.11 & 0.028 & 9269.8 \\
\hline TMM 41229-13202 & 1 & $120-125$ & upper P3 & left & -8.41 & 0.013 & 2.88 & 0.030 & 9607.6 \\
\hline TMM 41229-13203 & 1 & $120-125$ & upper M2 & right & -7.45 & 0.010 & -2.24 & 0.021 & 9607.6 \\
\hline
\end{tabular}


Table S1 (continued)

\begin{tabular}{|c|c|c|c|c|c|c|c|c|c|}
\hline $\begin{array}{c}\text { Specimen } \\
\text { Number } \\
\end{array}$ & Pit & $\begin{array}{c}\begin{array}{c}\text { Depth } \\
\text { (cm) }\end{array} \\
\end{array}$ & Tooth & Side & $\begin{array}{l}\delta^{13} \mathrm{C} \\
(\% \circ) \\
\end{array}$ & $\begin{array}{c}\delta^{13} \mathrm{C} \\
\text { stdev (\%o) } \\
\end{array}$ & $\begin{array}{c}\delta^{18} O \\
(\% o) \\
\end{array}$ & $\begin{array}{c}\delta^{18} O \\
\text { stdev (\%o) } \\
\end{array}$ & $\begin{array}{c}\text { Age (Cal. } \\
\text { yr BP) } \\
\end{array}$ \\
\hline TMM 41229-13204 & 1 & $120-125$ & upper P4 or M1 & left & -7.66 & 0.011 & 0.10 & 0.033 & 9607.6 \\
\hline TMM 41229-13205 & $1 d$ & $125-130$ & upper P4 or M1 & right & -12.44 & 0.005 & 0.89 & 0.036 & 10136.75 \\
\hline TMM 41229-13206 & $1 d$ & $125-130$ & upper P3 & right & -10.08 & 0.016 & -3.08 & 0.034 & 10136.75 \\
\hline TMM 41229-13207 & $1 d$ & $125-130$ & upper P3 & left & -3.06 & 0.013 & 5.14 & 0.022 & 10136.75 \\
\hline TMM 41229-13208 & $1 d$ & $130-135$ & upper P4 or M1 & right & -10.00 & 0.012 & -2.69 & 0.014 & 11077.95 \\
\hline TMM 41229-13209 & $1 d$ & $130-135$ & upper P3 & right & -8.12 & 0.015 & 0.42 & 0.025 & 11077.95 \\
\hline TMM 41229-13210 & $1 d$ & $130-135$ & upper P4 or M1 & left & -4.31 & 0.016 & 1.57 & 0.032 & 11077.95 \\
\hline TMM 41229-13211 & 1e & $135-140$ & upper P4 or M1 & left & -8.78 & 0.013 & 1.47 & 0.038 & 11312.1 \\
\hline TMM 41229-13212 & $1 \mathrm{e}$ & $135-140$ & upper $\mathrm{P} 3, \mathrm{P} 4$, or $\mathrm{M} 1$ & right & -10.82 & 0.018 & -0.98 & 0.020 & 11312.1 \\
\hline TMM 41229-13213 & $1 \mathrm{e}$ & $135-140$ & upper P4 or M1 & right & -12.14 & 0.010 & -1.10 & 0.016 & 11312.1 \\
\hline TMM 41229-13214 & $1 \mathrm{e}$ & $140-145$ & upper P4 or M1 & right & -10.58 & 0.020 & 3.00 & 0.031 & 11657.7 \\
\hline TMM 41229-13215 & $1 \mathrm{e}$ & $140-145$ & upper P4 or M1 & left & -10.68 & 0.010 & -1.54 & 0.034 & 11657.7 \\
\hline TMM 41229-13216 & $1 \mathrm{e}$ & $140-145$ & upper P4 or M1 & right & -11.35 & 0.012 & -0.95 & 0.021 & 11657.7 \\
\hline TMM 41229-13133 & $1 \mathrm{e}$ & $145-150$ & upper P4 or M1 & left & -8.83 & 0.015 & -1.78 & 0.023 & 11981.25 \\
\hline TMM 41229-13140 & $1 \mathrm{e}$ & $145-150$ & upper P4 or M1 & left & -3.74 & 0.015 & 4.43 & 0.028 & 11981.25 \\
\hline TMM 41229-13141 & $1 \mathrm{e}$ & $145-150$ & upper P4 or M1 & right & -12.06 & 0.018 & 0.58 & 0.031 & 11981.25 \\
\hline TMM 41229-13217 & $1 d$ & $152-155$ & upper P4 or M1 & left & -7.52 & 0.016 & -2.12 & 0.021 & 12651.55 \\
\hline TMM 41229-13218 & $1 d$ & $152-155$ & upper P4 or M1 & left & -10.88 & 0.025 & -0.13 & 0.029 & 12651.55 \\
\hline TMM 41229-13219 & $1 d$ & $152-155$ & upper P3 & left & -6.04 & 0.018 & -0.69 & 0.022 & 12651.55 \\
\hline TMM 41229-13220 & $1 d$ & $155-160$ & upper P4 or M1 & right & -10.48 & 0.009 & -6.39 & 0.028 & 12899.75 \\
\hline TMM 41229-13221 & $1 d$ & $155-160$ & upper P4 or M1 & right & -11.73 & 0.013 & -3.41 & 0.025 & 12899.75 \\
\hline TMM 41229-13222 & $1 d$ & $155-160$ & upper P3 & right & -10.64 & 0.013 & -5.73 & 0.027 & 12899.75 \\
\hline TMM 41229-13223 & $1 \mathrm{e}$ & $160-165$ & upper P4 or M1 & left & -10.79 & 0.010 & -4.52 & 0.019 & 13231.6 \\
\hline TMM 41229-13224 & $1 \mathrm{e}$ & $160-165$ & upper M1 or M2 & left & -9.05 & 0.017 & -3.91 & 0.032 & 13231.6 \\
\hline TMM 41229-13225 & $1 \mathrm{e}$ & $160-165$ & upper $\mathrm{P} 4$ or M1 & right & -9.33 & 0.009 & -5.47 & 0.015 & 13231.6 \\
\hline
\end{tabular}


Table S1 (continued)

\begin{tabular}{|c|c|c|c|c|c|c|c|c|c|}
\hline $\begin{array}{c}\text { Specimen } \\
\text { Number } \\
\end{array}$ & Pit & $\begin{array}{c}\begin{array}{c}\text { Depth } \\
\text { (cm) }\end{array} \\
\end{array}$ & Tooth & Side & $\begin{array}{l}\delta^{13} \mathrm{C} \\
(\% \circ) \\
\end{array}$ & $\begin{array}{c}\delta^{13} \mathrm{C} \\
\text { stdev (\%o) } \\
\end{array}$ & $\begin{array}{c}\delta^{18} O \\
(\% o) \\
\end{array}$ & $\begin{array}{c}\delta^{18} O \\
\text { stdev (\%o) } \\
\end{array}$ & $\begin{array}{c}\text { Age (Cal. } \\
\text { yr BP) } \\
\end{array}$ \\
\hline TMM 41229-13226 & $1 \mathrm{e}$ & $165-170$ & upper M2 & left & -10.81 & 0.013 & -3.63 & 0.044 & 13385.3 \\
\hline TMM 41229-13227 & $1 \mathrm{e}$ & $165-170$ & upper P4 or M1 & right & -3.73 & 0.010 & 0.84 & 0.016 & 13385.3 \\
\hline TMM 41229-13228 & $1 \mathrm{e}$ & $165-170$ & upper M2 & left & -5.74 & 0.009 & -0.02 & 0.028 & 13385.3 \\
\hline TMM 41229-13229 & $1 \mathrm{e}$ & $170-175$ & upper M2 & left & -12.25 & 0.014 & -0.87 & 0.019 & 13435.9 \\
\hline TMM 41229-13230 & $1 \mathrm{e}$ & $170-175$ & upper P3 & left & -7.75 & 0.017 & -1.83 & 0.042 & 13435.9 \\
\hline TMM 41229-13231 & $1 \mathrm{e}$ & $170-175$ & upper P4 or M1 & left & -6.95 & 0.018 & -0.65 & 0.028 & 13435.9 \\
\hline TMM 41229-13232 & $1 \mathrm{~d} / \mathrm{e}$ & $175-180$ & upper P3 & right & -14.33 & 0.016 & -3.16 & 0.025 & 13524.1 \\
\hline TMM 41229-13233 & $1 \mathrm{~d} / \mathrm{e}$ & $175-180$ & upper P4 or M1 & left & -12.87 & 0.014 & -3.21 & 0.020 & 13524.1 \\
\hline TMM 41229-13234 & $1 \mathrm{~d} / \mathrm{e}$ & $175-180$ & upper M2 & right & -13.80 & 0.012 & -3.54 & 0.020 & 13524.1 \\
\hline TMM 41229-13235 & $1 \mathrm{e}$ & $180-185$ & upper P3 & left & -7.18 & 0.013 & -1.73 & 0.023 & 13654.45 \\
\hline TMM 41229-13236 & $1 \mathrm{e}$ & $180-185$ & upper M2 & left & -2.98 & 0.018 & -1.90 & 0.033 & 13654.45 \\
\hline TMM 41229-13237 & $1 \mathrm{c}$ & $180-185$ & upper P4 or M1 & right & -11.87 & 0.008 & -2.84 & 0.012 & 13654.45 \\
\hline TMM 41229-13239 & $1 \mathrm{c}$ & $190-195$ & broken upper cheek tooth & right & -6.41 & 0.013 & -2.58 & 0.019 & 13998.65 \\
\hline TMM 41229-5223 & $1 \mathrm{c}$ & $195-200$ & upper P4 or M1 & right & -11.76 & 0.014 & -3.73 & 0.024 & 14319.55 \\
\hline TMM 41229-4780 & $1 \mathrm{c}$ & $200-205$ & upper P3 & left & -6.20 & 0.012 & -1.80 & 0.012 & 14479.5 \\
\hline TMM 41229-13142 & $1 b$ & $200-205$ & upper P4 or M1 & right & -6.44 & 0.006 & 2.37 & 0.022 & 14479.5 \\
\hline TMM 41229-4782 & $1 \mathrm{c}$ & $200-205$ & lower P4, M1, or M2 & right & -8.85 & 0.011 & -3.05 & 0.017 & 14479.5 \\
\hline TMM 41229-13240 & $1 \mathrm{c}$ & $205-210$ & upper P4 or M1 & right & -8.11 & 0.012 & -1.23 & 0.038 & 14766.25 \\
\hline TMM 41229-13241 & $1 \mathrm{~d} / \mathrm{e}$ & $210-215$ & upper M2 & right & -11.34 & 0.008 & -3.70 & 0.023 & 15202.6 \\
\hline TMM 41229-13242 & $1 \mathrm{~d} / \mathrm{e}$ & $210-215$ & upper P4 or M1 & left & -10.09 & 0.014 & -2.19 & 0.026 & 15202.6 \\
\hline TMM 41229-13243 & $1 \mathrm{~d} / \mathrm{e}$ & $210-215$ & upper P4 or M1 & left & -9.22 & 0.016 & 0.71 & 0.023 & 15202.6 \\
\hline TMM 41229-13244 & $1 \mathrm{~d} / \mathrm{e}$ & $215-220$ & upper P4 or M1 & left & -7.62 & 0.016 & -1.04 & 0.017 & 15406.2 \\
\hline TMM 41229-13245 & $1 \mathrm{~d} / \mathrm{e}$ & $215-220$ & upper P3 & left & -5.55 & 0.016 & -1.19 & 0.027 & 15406.2 \\
\hline TMM 41229-13246 & $1 \mathrm{~d} / \mathrm{e}$ & $220-225$ & upper P4 or M1 & right & -9.58 & 0.016 & -1.26 & 0.031 & 15708.65 \\
\hline TMM 41229-13247 & $1 \mathrm{~d} / \mathrm{e}$ & $220-225$ & upper P3 & right & -9.33 & 0.009 & -1.83 & 0.032 & 15708.65 \\
\hline
\end{tabular}


Table S1 (continued)

\begin{tabular}{|c|c|c|c|c|c|c|c|c|c|}
\hline $\begin{array}{c}\text { Specimen } \\
\text { Number } \\
\end{array}$ & Pit & $\begin{array}{c}\text { Depth } \\
(\mathrm{cm}) \\
\end{array}$ & Tooth & Side & $\begin{array}{l}\delta^{13} \mathrm{C} \\
(\% \circ) \\
\end{array}$ & $\begin{array}{c}\delta^{13} \mathrm{C} \\
\text { stdev (\%o) } \\
\end{array}$ & $\begin{array}{l}\delta^{18} \mathbf{O} \\
(\% 0) \\
\end{array}$ & $\begin{array}{c}\delta^{18} O \\
\text { stdev (\%o) } \\
\end{array}$ & $\begin{array}{c}\text { Age (Cal. } \\
\text { yr BP) } \\
\end{array}$ \\
\hline TMM 41229-13248 & $1 \mathrm{~d} / \mathrm{e}$ & $220-225$ & upper P4 or M1 & left & -7.55 & 0.010 & -0.72 & 0.021 & 15708.65 \\
\hline TMM 41229-13249 & $1 \mathrm{~d} / \mathrm{e}$ & $225-230$ & upper M2 & right & -11.55 & 0.017 & -0.45 & 0.019 & 15919.6 \\
\hline TMM 41229-13250 & $1 \mathrm{~d} / \mathrm{e}$ & $225-230$ & upper P4 or M1 & left & -9.38 & 0.017 & -1.91 & 0.024 & 15919.6 \\
\hline TMM 41229-13251 & $1 \mathrm{~d} / \mathrm{e}$ & $225-230$ & upper P4 or M1 & right & -12.13 & 0.011 & -0.83 & 0.027 & 15919.6 \\
\hline TMM 41229-13252 & $1 \mathrm{~d} / \mathrm{e}$ & $230-235$ & upper P4 or M1 & right & -10.99 & 0.016 & -1.70 & 0.035 & 16144.35 \\
\hline TMM 41229-13253 & $1 \mathrm{~d} / \mathrm{e}$ & $230-235$ & upper P3 & left & -7.26 & 0.009 & -0.13 & 0.018 & 16144.35 \\
\hline TMM 41229-13254 & $1 \mathrm{~d} / \mathrm{e}$ & $230-235$ & upper P3 & right & -10.88 & 0.011 & -4.35 & 0.030 & 16144.35 \\
\hline TMM 41229-13255 & d & $235-240$ & upper P4 or M1 & left & -11.31 & 0.013 & -4.07 & 0.019 & 16769.75 \\
\hline TMM 41229-13256 & d & $240-245$ & upper P4 or M1 & left & -10.03 & 0.016 & -3.41 & 0.025 & 17139.9 \\
\hline TMM 41229-13257 & d & $245-250$ & upper P4 or M1 & left & -11.22 & 0.016 & -1.35 & 0.036 & 17758 \\
\hline TMM 41229-13264 & d & $250-255$ & upper P4 or M1 & right & -9.18 & 0.012 & -1.75 & 0.035 & 17948.95 \\
\hline TMM 41229-13258 & $1 d$ & $255-260$ & upper P4 or M1 & right & -8.42 & 0.013 & -1.18 & 0.030 & 18214.65 \\
\hline TMM 41229-13262 & $\mathrm{d}$ & $260-265$ & upper P3 & right & -7.61 & 0.022 & 1.37 & 0.041 & 18400.25 \\
\hline TMM 41229-13263 & d & $260-265$ & upper P4 or M1 & right & -8.34 & 0.017 & 1.71 & 0.027 & 18400.25 \\
\hline TMM 41229-13259 & $1 d$ & $280-285$ & upper P4 or M1 & right & -8.97 & 0.013 & -0.86 & 0.033 & 18971.55 \\
\hline TMM 41229-13260 & $1 d$ & $285-290$ & upper P4 or M1 & left & -11.03 & 0.012 & -2.90 & 0.018 & 19150.05 \\
\hline TMM 41229-13261 & $1 \mathrm{e}$ & $295-300$ & upper M2 & right & -9.18 & 0.023 & -2.05 & 0.033 & 19571.45 \\
\hline
\end{tabular}


Table S2: Bulk organic carbon isotope data. Carbon isotope values are reported relative to VPDB. $\% \mathrm{C}_{4}$ is calculated using $\mathrm{C}_{3}$ and $\mathrm{C}_{4}$ end-members of $-27 \%$ and $-13 \%$, respectively.

\begin{tabular}{cccccc}
\hline \hline $\begin{array}{c}\text { Depth } \\
(\mathbf{c m})\end{array}$ & $\begin{array}{c}\text { Corrected } \\
\text { Depth }(\mathbf{c m})\end{array}$ & \% C & $\boldsymbol{\delta}^{\mathbf{1 3}} \mathbf{C} \mathbf{( \% )}$ & $\mathbf{\%} \mathbf{C}_{\mathbf{4}}$ & $\begin{array}{c}\text { Age } \\
\text { (Cal. yr bp) }\end{array}$ \\
\hline $0-1$ & -7.26285 & 0.070544 & -18.6991 & 0.592922 & -48.2685 \\
$1-2$ & -6.24275 & 0.076682 & -20.3999 & 0.471436 & -47.5285 \\
$2-3$ & -5.22265 & 0.077705 & -18.5713 & 0.602051 & -46.7885 \\
$3-4$ & -4.20255 & 0.070889 & -20.3958 & 0.471726 & -46.0485 \\
$4-5$ & -3.18245 & 0.064934 & -19.751 & 0.517782 & -45.3085 \\
$5-6$ & -2.16235 & 0.081728 & -20.267 & 0.480926 & -44.5686 \\
$6-7$ & -1.14225 & 0.085622 & -21.5933 & 0.386193 & -43.8286 \\
$7-8$ & -0.12215 & 0.074729 & -21.441 & 0.397068 & -43.0886 \\
$8-9$ & 0.89795 & 0.072134 & -21.437 & 0.397357 & 10.24844 \\
$9-10$ & 1.91805 & 0.063991 & -21.5578 & 0.388731 & 70.74037 \\
$10-11$ & 2.93815 & 0.079427 & -20.6818 & 0.451297 & 131.2323 \\
$11-12$ & 3.95825 & 0.06677 & -19.9134 & 0.506189 & 191.6284 \\
$12-13$ & 4.97835 & 0.06141 & -17.2191 & 0.698638 & 322.3617 \\
$13-14$ & 5.99845 & 0.063249 & -19.6364 & 0.525975 & 455.997 \\
$14-15$ & 7.01855 & 0.061751 & -18.8913 & 0.579193 & 589.6319 \\
$15-16$ & 8.03865 & 0.074992 & -16.6793 & 0.737194 & 722.9612 \\
$16-17$ & 9.05875 & 0.066958 & -17.3915 & 0.68632 & 845.9853 \\
$17-18$ & 10.07885 & 0.06817 & -17.4313 & 0.683477 & 969.0093 \\
$18-19$ & 11.09895 & 0.070968 & -19.5865 & 0.529535 & 1092.033 \\
$19-20$ & 12.11905 & 0.06066 & -18.1372 & 0.633056 & 1203.593 \\
$20-21$ & 13.13915 & 0.060526 & -16.596 & 0.743143 & 1228.367 \\
$21-22$ & 14.15925 & 0.054659 & -16.5682 & 0.745126 & 1253.054 \\
$22-23$ & 15.17935 & 0.054428 & -16.6046 & 0.742527 & 1277.74 \\
$23-24$ & 16.19945 & 0.04672 & -16.0535 & 0.781894 & 1305.758 \\
$24-25$ & 17.21955 & 0.038924 & -15.8161 & 0.798848 & 1347.502 \\
$25-26$ & 18.23965 & 0.038038 & -19.2213 & 0.555624 & 1389.326 \\
$26-27$ & 19.25975 & 0.037612 & -19.0406 & 0.568529 & 1431.15 \\
$27-28$ & 20.27985 & 0.040873 & -13.0076 & 0.999461 & 1482.545 \\
$28-29$ & 21.29995 & 0.026026 & -19.9127 & 0.506232 & 1559.256 \\
$29-30$ & 22.32005 & 0.033829 & -19.3195 & 0.548605 & 1635.968 \\
$30-31$ & 23.34015 & 0.026678 & -19.6833 & 0.522624 & 1712.679 \\
$31-32$ & 24.36025 & 0.027906 & -20.5494 & 0.460756 & 1818.211 \\
$32-33$ & 25.38035 & 0.025947 & -20.2341 & 0.483282 & 1976.53 \\
& & & & &
\end{tabular}


Table S2 (continued)

\begin{tabular}{|c|c|c|c|c|c|}
\hline $\begin{array}{c}\text { Depth } \\
(\mathbf{c m})\end{array}$ & $\begin{array}{c}\text { Corrected } \\
\text { Depth }(\mathrm{cm})\end{array}$ & $\% \mathrm{C}$ & $\delta^{13} \mathrm{C}(\% \%)$ & $\% \mathrm{C}_{4}$ & $\begin{array}{c}\text { Age } \\
\text { (Cal. yr bp) }\end{array}$ \\
\hline $33-34$ & 26.40045 & 0.029554 & -20.7995 & 0.442893 & 2134.85 \\
\hline $34-35$ & 27.42055 & 0.031849 & -18.9993 & 0.57148 & 2293.169 \\
\hline $35-36$ & 28.44065 & 0.029933 & -20.4182 & 0.470132 & 2424.565 \\
\hline $36-37$ & 29.46075 & 0.025627 & -16.472 & 0.752004 & 2520.557 \\
\hline $37-38$ & 30.48085 & 0.029357 & -18.62 & 0.598573 & 2616.548 \\
\hline $38-39$ & 31.50095 & 0.029678 & -16.559 & 0.745789 & 2712.539 \\
\hline $39-40$ & 32.52105 & 0.029328 & -17.4115 & 0.68489 & 2789.565 \\
\hline $40-41$ & 33.54115 & 0.027458 & -13.7114 & 0.949186 & 2848.424 \\
\hline $41-42$ & 34.56125 & 0.035299 & -14.6 & 0.885712 & 2907.284 \\
\hline $42-43$ & 35.58135 & 0.029864 & -16.4646 & 0.752531 & 2966.202 \\
\hline $43-44$ & 36.60145 & 0.027727 & -16.9444 & 0.718254 & 3016.142 \\
\hline $44-45$ & 37.62155 & 0.026765 & -14.8587 & 0.867237 & 3059.802 \\
\hline $45-46$ & 38.64165 & 0.029595 & -13.2767 & 0.980237 & 3103.463 \\
\hline $46-47$ & 39.66175 & 0.026449 & -14.2992 & 0.907203 & 3147.189 \\
\hline $47-48$ & 40.68185 & 0.027574 & -16.0809 & 0.779932 & 3197.429 \\
\hline $48-49$ & 41.70195 & 0.026765 & -12.4026 & 1.042669 & 3250.812 \\
\hline $49-50$ & 42.72205 & 0.030339 & -13.7589 & 0.945793 & 3304.235 \\
\hline $50-51$ & 43.74215 & 0.026575 & -15.197 & 0.843069 & 3357.689 \\
\hline $51-52$ & 44.76225 & 0.024113 & -16.4019 & 0.757006 & 3383.93 \\
\hline $52-53$ & 45.78235 & 0.02142 & -12.3986 & 1.042959 & 3400.965 \\
\hline $53-54$ & 46.80245 & 0.023751 & -16.2711 & 0.766351 & 3418.001 \\
\hline $54-55$ & 47.82255 & 0.030079 & -14.8974 & 0.86447 & 3434.954 \\
\hline $55-56$ & 48.84265 & 0.041218 & -12.2747 & 1.051808 & 3447.253 \\
\hline $56-57$ & 49.86275 & 0.025802 & -10.88 & 1.151429 & 3458.49 \\
\hline $57-58$ & 50.88285 & 0.038755 & -12.976 & 1.001711 & 3469.711 \\
\hline $58-59$ & 51.90295 & 0.031185 & -14.1544 & 0.91754 & 3481.023 \\
\hline $59-60$ & 52.92305 & 0.032001 & -13.9887 & 0.929376 & 3582.343 \\
\hline $60-61$ & 53.94315 & 0.023693 & -11.6205 & 1.098535 & 3693.22 \\
\hline $61-62$ & 54.96325 & 0.025252 & -12.0242 & 1.0697 & 3804.105 \\
\hline $62-63$ & 55.98335 & 0.026042 & -12.8227 & 1.012661 & 3914.99 \\
\hline $63-64$ & 57.00345 & 0.027819 & -13.5894 & 0.9579 & 4022.262 \\
\hline $64-65$ & 58.02355 & 0.025268 & -12.144 & 1.061146 & 4129.375 \\
\hline $65-66$ & 59.04365 & 0.032628 & -12.7011 & 1.021351 & 4236.588 \\
\hline $66-67$ & 60.06375 & 0.031858 & -13.7214 & 0.948473 & 4340.045 \\
\hline $67-68$ & 61.08385 & 0.027625 & -15.0976 & 0.850168 & 4387.165 \\
\hline $68-69$ & 62.10395 & 0.023331 & -13.0525 & 0.99625 & 4434.202 \\
\hline $69-70$ & 63.12405 & 0.030844 & -13.912 & 0.934854 & 4481.319 \\
\hline
\end{tabular}


Table S2 (continued)

\begin{tabular}{|c|c|c|c|c|c|}
\hline $\begin{array}{c}\text { Depth } \\
(\mathrm{cm}) \\
\end{array}$ & $\begin{array}{c}\text { Corrected } \\
\text { Depth }(\mathrm{cm})\end{array}$ & $\% \mathrm{C}$ & $\delta^{13} \mathrm{C}(\%$ ) & $\% \mathrm{C}_{4}$ & $\begin{array}{c}\text { Age } \\
\text { (Cal. yr bp) }\end{array}$ \\
\hline $70-71$ & 64.14415 & 0.030817 & -13.7048 & 0.949657 & 4533.708 \\
\hline $71-72$ & 65.16425 & 0.031429 & -14.0195 & 0.927182 & 4618.666 \\
\hline $72-73$ & 66.18435 & 0.022315 & -12.5899 & 1.029295 & 4703.538 \\
\hline $73-74$ & 67.20445 & 0.027374 & -15.546 & 0.818143 & 4788.431 \\
\hline $74-75$ & 68.22455 & 0.02839 & -15.324 & 0.833998 & 4872.26 \\
\hline $75-76$ & 69.24465 & 0.028354 & -15.0866 & 0.850957 & 4952.032 \\
\hline $76-77$ & 70.26475 & 0.025635 & -11.3819 & 1.115576 & 5031.803 \\
\hline $77-78$ & 71.28485 & 0.025636 & -12.4993 & 1.035766 & 5111.575 \\
\hline $78-79$ & 72.30495 & 0.029931 & -10.8789 & 1.151504 & 5209.797 \\
\hline $79-80$ & 73.32505 & 0.030868 & -11.7423 & 1.089836 & 5351.284 \\
\hline $80-81$ & 74.34515 & 0.02553 & -9.94725 & 1.218054 & 5492.772 \\
\hline $81-82$ & 75.36525 & 0.033643 & -11.1504 & 1.132116 & 5634.297 \\
\hline $82-83$ & 76.38535 & 0.032439 & -10.9688 & 1.145084 & 5736.234 \\
\hline $83-84$ & 77.40545 & 0.027431 & -12.0865 & 1.065251 & 5772.896 \\
\hline $84-85$ & 78.42555 & 0.025557 & -9.89965 & 1.221454 & 5809.62 \\
\hline $85-86$ & 79.44565 & 0.028466 & -12.2914 & 1.050618 & 5846.343 \\
\hline $86-87$ & 80.46575 & 0.030527 & -13.4541 & 0.967564 & 5899.322 \\
\hline $87-88$ & 81.48585 & 0.031598 & -12.4736 & 1.037598 & 5971.647 \\
\hline $88-89$ & 82.50595 & 0.026994 & -10.5033 & 1.178338 & 6044.022 \\
\hline $89-90$ & 83.52605 & 0.033335 & -12.4229 & 1.041223 & 6116.397 \\
\hline $90-91$ & 84.54615 & 0.032779 & -13.7726 & 0.944814 & 6160.377 \\
\hline $91-92$ & 85.56625 & 0.034861 & -12.0264 & 1.069545 & 6179.759 \\
\hline $92-93$ & 86.58635 & 0.026072 & -10.6984 & 1.164402 & 6199.199 \\
\hline $93-94$ & 87.60645 & 0.028348 & -11.2267 & 1.126667 & 6218.623 \\
\hline $94-95$ & 88.62655 & 0.022872 & -10.5828 & 1.172659 & 6241.764 \\
\hline $95-96$ & 89.64665 & 0.030358 & -11.8884 & 1.079397 & 6267.266 \\
\hline $96-97$ & 90.66675 & 0.028686 & -8.33483 & 1.333227 & 6292.769 \\
\hline $97-98$ & 91.68685 & 0.027412 & -10.981 & 1.144214 & 6318.271 \\
\hline $98-99$ & 92.70695 & 0.028529 & -11.9212 & 1.07706 & 6343.632 \\
\hline $99-100$ & 93.72705 & 0.028084 & -11.8867 & 1.079523 & 6368.931 \\
\hline $100-101$ & 94.74715 & 0.022317 & -11.3081 & 1.120852 & 6394.155 \\
\hline $101-102$ & 95.76725 & 0.026399 & -12.6776 & 1.023026 & 6419.428 \\
\hline $102-103$ & 96.78735 & 0.035891 & -11.7205 & 1.091393 & 6494.329 \\
\hline $103-104$ & 97.80745 & 0.040265 & -10.3726 & 1.187672 & 6583.813 \\
\hline $104-105$ & 98.82755 & 0.023159 & -9.94166 & 1.218453 & 6673.276 \\
\hline $105-106$ & 99.84765 & 0.023885 & -11.0629 & 1.138364 & 6762.739 \\
\hline 106-107 & 100.8678 & 0.034686 & -9.6206 & 1.241386 & 6914.94 \\
\hline
\end{tabular}


Table S2 (continued)

\begin{tabular}{|c|c|c|c|c|c|}
\hline $\begin{array}{c}\text { Depth } \\
(\mathrm{cm})\end{array}$ & $\begin{array}{c}\text { Corrected } \\
\text { Depth }(\mathrm{cm})\end{array}$ & $\% \mathrm{C}$ & $\delta^{13} \mathrm{C}(\% \circ)$ & $\% \mathrm{C}_{4}$ & $\begin{array}{c}\text { Age } \\
\text { (Cal. yr bp) }\end{array}$ \\
\hline $107-108$ & 101.8879 & 0.039095 & -10.4831 & 1.179781 & 7078.156 \\
\hline 108-109 & 102.908 & 0.026665 & -9.34315 & 1.261203 & 7241.463 \\
\hline $109-110$ & 103.9281 & 0.021523 & -10.7091 & 1.163634 & 7404.688 \\
\hline $110-111$ & 104.9482 & 0.020644 & -11.6532 & 1.096198 & 7658.168 \\
\hline $111-112$ & 105.9683 & 0.020728 & -12.8962 & 1.007412 & 7918.594 \\
\hline $112-113$ & 106.9884 & 0.017886 & -11.4338 & 1.111872 & 8178.927 \\
\hline $113-114$ & 108.0085 & 0.018896 & -13.1098 & 0.992156 & 8437.851 \\
\hline $114-115$ & 109.0286 & 0.019356 & -13.1798 & 0.987158 & 8516.501 \\
\hline $115-116$ & 110.0487 & 0.033294 & -10.4769 & 1.180218 & 8595.156 \\
\hline $117-118$ & 112.0889 & 0.03293 & -10.9085 & 1.149392 & 8754.025 \\
\hline 118-119 & 113.109 & 0.025547 & -11.7171 & 1.091639 & 8849.598 \\
\hline $119-120$ & 114.1291 & 0.035465 & -13.0207 & 0.998521 & 8945.092 \\
\hline $120-121$ & 115.1492 & 0.032238 & -10.2563 & 1.195975 & 9040.66 \\
\hline $121-122$ & 116.1693 & 0.036496 & -15.1704 & 0.844968 & 9137.174 \\
\hline $122-123$ & 117.1894 & 0.04007 & -9.24721 & 1.268057 & 9238.859 \\
\hline $123-124$ & 118.2095 & 0.031315 & -11.9594 & 1.074328 & 9340.482 \\
\hline $124-125$ & 119.2296 & 0.020104 & -10.9386 & 1.147242 & 9442.163 \\
\hline $125-126$ & 120.2497 & 0.020755 & -11.8109 & 1.084935 & 9527.763 \\
\hline $126-127$ & 121.2698 & 0.019409 & -12.6954 & 1.021759 & 9563.976 \\
\hline $127-128$ & 122.2899 & 0.025568 & -12.2264 & 1.055257 & 9600.161 \\
\hline $128-129$ & 123.31 & 0.018522 & -12.0642 & 1.066843 & 9636.303 \\
\hline $129-130$ & 124.3301 & 0.02701 & -10.755 & 1.160358 & 9705.687 \\
\hline $130-131$ & 125.3502 & 0.024774 & -10.7833 & 1.158332 & 9844.42 \\
\hline $131-132$ & 126.3703 & 0.0336 & -8.79922 & 1.300056 & 9983.154 \\
\hline $132-133$ & 127.3904 & 0.026341 & -10.2076 & 1.19946 & 10121.85 \\
\hline 133-134 & 128.4105 & 0.026544 & -9.98524 & 1.21534 & 10292.08 \\
\hline $134-135$ & 129.4306 & 0.036999 & -8.9714 & 1.287757 & 10509.22 \\
\hline $135-136$ & 130.4507 & 0.030654 & -9.34007 & 1.261423 & 10726.3 \\
\hline 136-137 & 131.4708 & 0.02906 & -8.80825 & 1.29941 & 10943.38 \\
\hline $137-138$ & 132.4909 & 0.027488 & -9.61613 & 1.241705 & 11077.55 \\
\hline 138-139 & 133.5258 & 0.03735 & -9.92404 & 1.219712 & 11122.98 \\
\hline $139-140$ & 134.5846 & 0.030263 & -11.4514 & 1.110616 & 11169.52 \\
\hline $140-141$ & 135.6434 & 0.022756 & -11.1506 & 1.132101 & 11216.05 \\
\hline $141-142$ & 136.7022 & 0.029474 & -11.1668 & 1.13094 & 11269.34 \\
\hline $142-143$ & 137.761 & 0.026579 & -13.2098 & 0.985012 & 11326.09 \\
\hline $143-144$ & 138.8198 & 0.024014 & -13.7223 & 0.948404 & 11382.84 \\
\hline $144-145$ & 139.8786 & 0.019912 & -13.2852 & 0.979631 & 11439.59 \\
\hline
\end{tabular}


Table S2 (continued)

\begin{tabular}{|c|c|c|c|c|c|}
\hline $\begin{array}{c}\text { Depth } \\
(\mathrm{cm}) \\
\end{array}$ & $\begin{array}{c}\text { Corrected } \\
\text { Depth }(\mathrm{cm}) \\
\end{array}$ & $\% \mathrm{C}$ & $\delta^{13} \mathrm{C}(\%)$ & $\% \mathrm{C}_{4}$ & $\begin{array}{c}\text { Age } \\
\text { (Cal. yr bp) } \\
\end{array}$ \\
\hline $145-146$ & 140.9374 & 0.02602 & -12.6854 & 1.022469 & 11525.4 \\
\hline $146-147$ & 141.9962 & 0.025836 & -13.3823 & 0.972696 & 11615.08 \\
\hline $147-148$ & 143.055 & 0.019667 & -15.3988 & 0.828657 & 11704.66 \\
\hline $148-149$ & 144.1138 & 0.01911 & -14.8879 & 0.865147 & 11791.08 \\
\hline $149-150$ & 145.1726 & 0.024963 & -13.599 & 0.957214 & 11850.5 \\
\hline $150-151$ & 146.2314 & 0.020541 & -15.571 & 0.816359 & 11910 \\
\hline $151-152$ & 147.2902 & 0.019188 & -16.6456 & 0.739601 & 11969.48 \\
\hline $152-153$ & 148.349 & 0.023107 & -10.9743 & 1.14469 & 12061.3 \\
\hline $153-154$ & 149.4078 & 0.018707 & -16.0801 & 0.779989 & 12219.06 \\
\hline $154-155$ & 150.4666 & 0.019664 & -16.9531 & 0.717639 & 12376.78 \\
\hline $155-156$ & 151.54 & 0.015145 & -17.327 & 0.690927 & 12536.66 \\
\hline $160-161$ & 156.94 & 0.010783 & -14.3686 & 0.902245 & 12835.97 \\
\hline $161-162$ & 158.02 & 0.010243 & -14.807 & 0.870931 & 12958.98 \\
\hline $164-165$ & 161.26 & 0.014405 & -13.7754 & 0.944612 & 13208.29 \\
\hline $165-166$ & 162.34 & 0.020469 & -12.4363 & 1.040266 & 13228.59 \\
\hline $166-167$ & 163.42 & 0.021559 & -12.0534 & 1.067612 & 13248.9 \\
\hline $167-168$ & 164.5 & 0.027973 & -12.3431 & 1.046921 & 13277.75 \\
\hline $168-169$ & 165.58 & 0.018426 & -14.5078 & 0.892302 & 13316.46 \\
\hline $169-170$ & 166.66 & 0.017388 & -15.4115 & 0.827751 & 13355.19 \\
\hline $170-171$ & 167.74 & 0.015323 & -14.8902 & 0.864987 & 13393.89 \\
\hline $172-173$ & 169.9 & 0.011239 & -15.0993 & 0.850051 & 13416.22 \\
\hline $176-177$ & 174.22 & 0.009677 & -15.4328 & 0.826229 & 13454.13 \\
\hline $177-178$ & 175.3 & 0.00892 & -15.7814 & 0.801329 & 13465.58 \\
\hline $178-179$ & 176.38 & 0.009355 & -15.337 & 0.83307 & 13485.96 \\
\hline $179-180$ & 177.46 & 0.008927 & -14.7749 & 0.873222 & 13522.74 \\
\hline 180-181 & 178.54 & 0.007951 & -16.5708 & 0.74494 & 13559.51 \\
\hline 181-182 & 179.62 & 0.007458 & -17.4852 & 0.679627 & 13596.28 \\
\hline $182-183$ & 180.7 & 0.007303 & -17.3819 & 0.687006 & 13621.87 \\
\hline $183-184$ & 181.78 & 0.00645 & -19.7296 & 0.519311 & 13641.42 \\
\hline 184-185 & 182.86 & 0.007406 & -16.2585 & 0.76725 & 13660.97 \\
\hline $185-186$ & 183.94 & 0.008462 & -13.9431 & 0.932637 & 13680.42 \\
\hline $186-187$ & 185.02 & 0.007413 & -17.0598 & 0.710017 & 13715.97 \\
\hline $187-188$ & 186.1 & 0.007339 & -16.448 & 0.753714 & 13752.38 \\
\hline 188-189 & 187.18 & 0.008317 & -14.7398 & 0.87573 & 13788.87 \\
\hline 189-190 & 188.26 & 0.008558 & -14.9138 & 0.863298 & 13825.73 \\
\hline 190-191 & 189.34 & 0.007441 & -17.1435 & 0.704033 & 13864.07 \\
\hline $191-192$ & 190.42 & 0.009667 & -12.6516 & 1.024883 & 13902.45 \\
\hline
\end{tabular}


Table S2 (continued)

\begin{tabular}{|c|c|c|c|c|c|}
\hline $\begin{array}{c}\text { Depth } \\
(\mathrm{cm}) \\
\end{array}$ & $\begin{array}{c}\text { Corrected } \\
\text { Depth }(\mathrm{cm}) \\
\end{array}$ & $\% \mathrm{C}$ & $\delta^{13} \mathrm{C}(\%)$ & $\% \mathrm{C}_{4}$ & $\begin{array}{c}\text { Age } \\
\text { (Cal. yr bp) }\end{array}$ \\
\hline $192-193$ & 191.5 & 0.005925 & -17.431 & 0.683497 & 13940.85 \\
\hline 193-194 & 192.58 & 0.009158 & -12.2884 & 1.050828 & 14005.06 \\
\hline 194-195 & 193.66 & 0.007417 & -14.1004 & 0.921403 & 14091.57 \\
\hline 195-196 & 194.74 & 0.013555 & -9.94068 & 1.218523 & 14178.07 \\
\hline 196-197 & 195.82 & 0.009874 & -10.7106 & 1.16353 & 14264.58 \\
\hline $200-201$ & 200.14 & 0.011555 & -10.2034 & 1.199759 & 14392.37 \\
\hline 204-205 & 204.5 & 0.024539 & -10.133 & 1.204789 & 14567.95 \\
\hline $205-206$ & 205.5 & 0.01975 & -8.71999 & 1.305715 & 14634.05 \\
\hline $206-207$ & 206.5 & 0.017455 & -14.3439 & 0.904006 & 14700.15 \\
\hline $207-208$ & 207.5 & 0.016673 & -8.27072 & 1.337806 & 14766.25 \\
\hline 208-209 & 208.5 & 0.015195 & -8.29802 & 1.335855 & 14846.7 \\
\hline $210-211$ & 210.5 & 0.024718 & -11.7586 & 1.088673 & 15036.3 \\
\hline $211-212$ & 211.5 & 0.03254 & -8.18618 & 1.343845 & 15131.1 \\
\hline $213-214$ & 213.5 & 0.02528 & -11.269 & 1.123641 & 15250.8 \\
\hline $219-220$ & 219.5 & 0.022959 & -6.86601 & 1.438142 & 15452.85 \\
\hline $220-221$ & 220.5 & 0.030662 & -10.1069 & 1.206651 & 15475.25 \\
\hline $221-222$ & 221.5 & 0.028643 & -10.5786 & 1.172958 & 15496.75 \\
\hline $237-238$ & 237.5 & 0.0224 & -8.0859 & 1.351007 & 16769.75 \\
\hline $238-239$ & 238.5 & 0.019887 & -10.1847 & 1.201092 & 16876.4 \\
\hline $239-240$ & 239.5 & 0.020863 & -7.8711 & 1.36635 & 16983.05 \\
\hline $240-241$ & 240.5 & 0.033068 & -8.23339 & 1.340472 & 17057.1 \\
\hline $244-245$ & 244.5 & 0.036261 & -8.08832 & 1.350834 & 17281.5 \\
\hline $245-246$ & 245.5 & 0.04999 & -8.03357 & 1.354745 & 17440.3 \\
\hline $247-248$ & 247.5 & 0.028846 & -8.92846 & 1.290824 & 17758 \\
\hline $248-249$ & 248.5 & 0.042692 & -8.17556 & 1.344603 & 17846.95 \\
\hline $249-250$ & 249.5 & 0.032174 & -10.0026 & 1.214096 & 17866.05 \\
\hline $250-251$ & 250.5 & 0.029406 & -9.35834 & 1.260119 & 17885.2 \\
\hline $252-253$ & 252.5 & 0.028546 & -8.59655 & 1.314532 & 17948.95 \\
\hline $253-254$ & 253.5 & 0.033283 & -9.23393 & 1.269005 & 18019.05 \\
\hline $256-257$ & 256.5 & 0.03796 & -10.2909 & 1.193506 & 18201.15 \\
\hline $258-259$ & 258.5 & 0.027822 & -9.74978 & 1.232159 & 18228.2 \\
\hline $260-261$ & 260.5 & 0.033209 & -10.3357 & 1.19031 & 18278.85 \\
\hline $261-262$ & 261.5 & 0.028841 & -10.1716 & 1.202031 & 18339.55 \\
\hline $262-263$ & 262.5 & 0.030653 & -10.382 & 1.187003 & 18400.25 \\
\hline $263-264$ & 263.5 & 0.031785 & -10.207 & 1.199502 & 18460.95 \\
\hline $264-265$ & 264.5 & 0.025204 & -9.80388 & 1.228294 & 18501.95 \\
\hline $267-268$ & 267.5 & 0.026748 & -7.91248 & 1.363394 & 18565.75 \\
\hline
\end{tabular}


Table S2 (continued)

\begin{tabular}{cccccc}
\hline $\begin{array}{c}\text { Depth } \\
(\mathbf{c m})\end{array}$ & $\begin{array}{c}\text { Corrected } \\
\text { Depth }(\mathbf{c m})\end{array}$ & \% C & $\boldsymbol{\delta}^{\mathbf{1 3}} \mathbf{C}(\mathbf{\% o})$ & $\boldsymbol{\%}_{\mathbf{4}}$ & $\begin{array}{c}\text { Age } \\
\text { (Cal. yr bp) }\end{array}$ \\
\hline $268-269$ & 268.5 & 0.029326 & -10.2238 & 1.198299 & 18592.45 \\
$269-270$ & 269.5 & 0.035657 & -11.0135 & 1.141891 & 18624.5 \\
$272-273$ & 272.5 & 0.047111 & -9.1511 & 1.274921 & 18715.65 \\
$274-275$ & 274.5 & 0.032068 & -10.0791 & 1.208638 & 18759.95 \\
$275-276$ & 275.5 & 0.029886 & -11.2406 & 1.125673 & 18782.05 \\
$279-280$ & 279.5 & 0.028464 & -9.83171 & 1.226306 & 18816.05 \\
$284-285$ & 284.5 & 0.029991 & -8.64668 & 1.310952 & 19075.35 \\
$285-286$ & 285.5 & 0.028113 & -10.2737 & 1.194734 & 19100.25
\end{tabular}


Table S3: Radiocarbon dates as published by Cooke et al. (2003).

\begin{tabular}{cccc}
\hline \hline Depth $(\mathbf{c m})$ & Material & RC $(\mathbf{y B P})$ & stddev \\
\hline \hline $15-20$ & gelatin & 1500 & 60 \\
$25-30$ & gelatin & 2330 & 60 \\
51 & charcoal & 3190 & 70 \\
$60-65$ & gelatin & 4000 & 60 \\
$90-95$ & gelatin & 5320 & 60 \\
$76-78$ & humins & 5400 & 70 \\
$105-110$ & gelatin & 7700 & 80 \\
$120-125$ & gelatin & 8630 & 60 \\
$145-150$ & gelatin & 10310 & 70 \\
$155-160$ & liquefied gelatin & 11310 & 60 \\
$165-170$ & gelatin & 11410 & 70 \\
$185-190$ & gelatin & 11550 & 70 \\
$195-200$ & gelatin & 12110 & 90 \\
$220-225$ & gelatin & 12570 & 80 \\
$270-275$ & gelatin & 13940 & 100 \\
$210-215$ & liquefied gelatin & 14400 & 80 \\
$235-240$ & gelatin & 14700 & 90 \\
260 & humic acid & 15290 & 90 \\
$295-300$ & gelatin & 16240 & 100 \\
$315-320$ & gelatin & 16510 & 100 \\
$338-343$ & humic acid & 16610 & 110 \\
$300-305$ & gelatin & 16620 & 110 \\
$345-350$ & gelatin & 16770 & 100 \\
& & &
\end{tabular}


Table S4: Age-depth model. $95 \%$ probability intervals are in calendar years BP.

\begin{tabular}{|c|c|c|c|c|c|c|c|}
\hline $\begin{array}{c}\text { Depth } \\
(\mathrm{cm})\end{array}$ & $\begin{array}{c}\text { Average Age } \\
\text { (Cal. yr BP) }\end{array}$ & $\begin{array}{c}\text { Lower } \\
95 \%\end{array}$ & $\begin{array}{c}\text { Upper } \\
95 \%\end{array}$ & $\begin{array}{c}\begin{array}{c}\text { Depth } \\
\text { (cm) }\end{array} \\
\end{array}$ & $\begin{array}{c}\text { Average Age } \\
\text { (Cal. yr BP) }\end{array}$ & $\begin{array}{c}\text { Lower } \\
95 \%\end{array}$ & $\begin{array}{c}\text { Upper } \\
95 \% \\
\end{array}$ \\
\hline 0 & $\begin{array}{c}-43 \\
\end{array}$ & -691 & 484 & 35 & 2932.6 & 2353 & 3033 \\
\hline 1 & 16.3 & -505 & 490 & 36 & 2990.4 & 2386 & 3106 \\
\hline 2 & 75.6 & -323 & 542 & 37 & 3033.2 & 2442 & 3142 \\
\hline 3 & 134.9 & -152 & 598 & 38 & 3076 & 2452 & 3227 \\
\hline 4 & 194.1 & -25 & 635 & 39 & 3118.8 & 2508 & 3278 \\
\hline 5 & 325.2 & 18 & 673 & 40 & 3161.7 & 2544 & 3319 \\
\hline 6 & 456.2 & 45 & 800 & 41 & 3214.1 & 2596 & 3336 \\
\hline 7 & 587.2 & 82 & 962 & 42 & 3266.4 & 2671 & 3401 \\
\hline 8 & 718.3 & 114 & 1089 & 43 & 3318.8 & 2718 & 3448 \\
\hline 9 & 838.9 & 260 & 1090 & 44 & 3371.2 & 2745 & 3495 \\
\hline 10 & 959.5 & 374 & 1154 & 45 & 3387.9 & 2821 & 3506 \\
\hline 11 & 1080.1 & 415 & 1225 & 46 & 3404.6 & 2870 & 3550 \\
\hline 12 & 1200.7 & 481 & 1376 & 47 & 3421.3 & 2948 & 3588 \\
\hline 13 & 1225 & 641 & 1386 & 48 & 3437.9 & 2936 & 3646 \\
\hline 14 & 1249.2 & 784 & 1429 & 49 & 3449 & 3091 & 3706 \\
\hline 15 & 1273.4 & 851 & 1456 & 50 & 3460 & 3175 & 3710 \\
\hline 16 & 1297.6 & 955 & 1580 & 51 & 3471 & 3266 & 3736 \\
\hline 17 & 1338.5 & 1148 & 1593 & 52 & 3482.1 & 3313 & 3878 \\
\hline 18 & 1379.5 & 1308 & 1638 & 53 & 3590.7 & 3409 & 3924 \\
\hline 19 & 1420.5 & 1350 & 1770 & 54 & 3699.4 & 3472 & 4057 \\
\hline 20 & 1461.5 & 1366 & 1966 & 55 & 3808.1 & 3491 & 4226 \\
\hline 21 & 1536.7 & 1448 & 2048 & 56 & 3916.8 & 3523 & 4353 \\
\hline 22 & 1611.9 & 1495 & 2135 & 57 & 4021.9 & 3612 & 4387 \\
\hline 23 & 1687.1 & 1550 & 2225 & 58 & 4126.9 & 3675 & 4450 \\
\hline 24 & 1762.3 & 1580 & 2340 & 59 & 4232 & 3725 & 4510 \\
\hline 25 & 1917.5 & 1758 & 2358 & 60 & 4337.1 & 3780 & 4615 \\
\hline 26 & 2072.7 & 1905 & 2395 & 61 & 4383.3 & 3954 & 4699 \\
\hline 27 & 2227.9 & 2012 & 2492 & 62 & 4429.4 & 4154 & 4784 \\
\hline 28 & 2383.1 & 2064 & 2564 & 63 & 4475.6 & 4288 & 4853 \\
\hline 29 & 2477.2 & 2139 & 2679 & 64 & 4521.7 & 4351 & 4951 \\
\hline 30 & 2571.3 & 2179 & 2724 & 65 & 4605 & 4433 & 5073 \\
\hline 31 & 2665.4 & 2214 & 2789 & 66 & 4688.2 & 4449 & 5254 \\
\hline 32 & 2759.5 & 2223 & 2893 & 67 & 4771.4 & 4505 & 5445 \\
\hline 33 & 2817.2 & 2277 & 2922 & 68 & 4854.7 & 4515 & 5675 \\
\hline 34 & 2874.9 & 2305 & 3030 & 69 & 4932.9 & 4604 & 5729 \\
\hline
\end{tabular}


Table S4 (continued)

\begin{tabular}{|c|c|c|c|c|c|c|c|}
\hline $\begin{array}{c}\text { Depth } \\
(\mathrm{cm})\end{array}$ & $\begin{array}{c}\text { Average Age } \\
\text { (Cal. yr BP) }\end{array}$ & $\begin{array}{c}\text { Lower } \\
95 \% \\
\end{array}$ & $\begin{array}{c}\text { Upper } \\
95 \% \\
\end{array}$ & $\begin{array}{c}\text { Depth } \\
(\mathrm{cm})\end{array}$ & $\begin{array}{c}\text { Average Age } \\
\text { (Cal. yr BP) }\end{array}$ & $\begin{array}{c}\text { Lower } \\
95 \% \\
\end{array}$ & $\begin{array}{c}\text { Upper } \\
95 \% \\
\end{array}$ \\
\hline 70 & 5011.1 & 4693 & 5763 & 107 & 8181.9 & 8043 & 8623 \\
\hline 71 & 5089.3 & 4741 & 5866 & 108 & 8437.2 & 8202 & 8722 \\
\hline 72 & 5167.5 & 4796 & 6026 & 109 & 8514.3 & 8314 & 8799 \\
\hline 73 & 5306.2 & 4874 & 6094 & 110 & 8591.4 & 8403 & 8933 \\
\hline 74 & 5444.9 & 4898 & 6158 & 111 & 8668.6 & 8481 & 9091 \\
\hline 75 & 5583.6 & 4921 & 6226 & 112 & 8745.7 & 8520 & 9290 \\
\hline 76 & 5722.4 & 4965 & 6310 & 113 & 8839.4 & 8592 & 9337 \\
\hline 77 & 5758.3 & 5005 & 6355 & 114 & 8933 & 8634 & 9394 \\
\hline 78 & 5794.3 & 5070 & 6405 & 115 & 9026.7 & 8666 & 9521 \\
\hline 79 & 5830.3 & 5180 & 6490 & 116 & 9120.3 & 8693 & 9618 \\
\hline 80 & 5866.3 & 5230 & 6575 & 117 & 9220 & 8803 & 9648 \\
\hline 81 & 5937.2 & 5279 & 6644 & 118 & 9319.6 & 8923 & 9698 \\
\hline 82 & 6008.1 & 5314 & 6709 & 119 & 9419.3 & 8951 & 9796 \\
\hline 83 & 6079.1 & 5359 & 6759 & 120 & 9518.9 & 8971 & 9936 \\
\hline 84 & 6150 & 5409 & 6829 & 121 & 9554.4 & 9190 & 9940 \\
\hline 85 & 6169 & 5457 & 6872 & 122 & 9589.9 & 9339 & 9974 \\
\hline 86 & 6188 & 5521 & 6921 & 123 & 9625.3 & 9477 & 9997 \\
\hline 87 & 6207.1 & 5640 & 7030 & 124 & 9660.8 & 9539 & 10229 \\
\hline 88 & 6226.1 & 5710 & 7055 & 125 & 9796.8 & 9619 & 10299 \\
\hline 89 & 6251.1 & 5812 & 7092 & 126 & 9932.8 & 9645 & 10370 \\
\hline 90 & 6276.1 & 5869 & 7124 & 127 & 10068.8 & 9680 & 10465 \\
\hline 91 & 6301.1 & 5898 & 7183 & 128 & 10204.7 & 9700 & 10675 \\
\hline 92 & 6326.1 & 5920 & 7260 & 129 & 10417.6 & 9789 & 10754 \\
\hline 93 & 6350.9 & 6039 & 7294 & 130 & 10630.4 & 9838 & 10878 \\
\hline 94 & 6375.7 & 6105 & 7335 & 131 & 10843.2 & 9882 & 10982 \\
\hline 95 & 6400.4 & 6167 & 7437 & 132 & 11056 & 9916 & 11196 \\
\hline 96 & 6425.2 & 6175 & 7545 & 133 & 11099.9 & 10035 & 11245 \\
\hline 97 & 6513 & 6315 & 7730 & 134 & 11143.8 & 10115 & 11360 \\
\hline 98 & 6600.7 & 6393 & 7813 & 135 & 11187.8 & 10195 & 11425 \\
\hline 99 & 6688.4 & 6476 & 7911 & 136 & 11231.7 & 10230 & 11575 \\
\hline 100 & 6776.1 & 6512 & 8117 & 137 & 11285.3 & 10422 & 11632 \\
\hline 101 & 6936.1 & 6744 & 8184 & 138 & 11338.9 & 10481 & 11721 \\
\hline 102 & 7096.1 & 6882 & 8282 & 139 & 11392.5 & 10661 & 11841 \\
\hline 103 & 7256.2 & 7091 & 8456 & 140 & 11446.1 & 10736 & 11976 \\
\hline 104 & 7416.2 & 7219 & 8559 & 141 & 11530.7 & 10834 & 12004 \\
\hline 105 & 7671.4 & 7492 & 8552 & 142 & 11615.4 & 10959 & 12029 \\
\hline 106 & 7926.7 & 7756 & 8586 & 143 & 11700 & 11069 & 12174 \\
\hline
\end{tabular}


Table S4 (continued)

\begin{tabular}{|c|c|c|c|c|c|c|c|}
\hline $\begin{array}{c}\text { Depth } \\
\text { (cm) }\end{array}$ & $\begin{array}{c}\text { Average Age } \\
\text { (Cal. yr BP) }\end{array}$ & $\begin{array}{c}\text { Lower } \\
95 \% \\
\end{array}$ & $\begin{array}{c}\text { Upper } \\
95 \% \\
\end{array}$ & $\begin{array}{c}\text { Depth } \\
(\mathbf{c m})\end{array}$ & $\begin{array}{c}\text { Average Age } \\
\text { (Cal. yr BP) }\end{array}$ & $\begin{array}{c}\text { Lower } \\
95 \% \\
\end{array}$ & $\begin{array}{c}\text { Upper } \\
95 \% \\
\end{array}$ \\
\hline 144 & 11784.7 & 11027 & 12262 & 181 & 13627.3 & 13345 & 13980 \\
\hline 145 & 11840.8 & 11328 & 12283 & 182 & 13645.4 & 13328 & 13963 \\
\hline 146 & 11897 & 11482 & 12357 & 183 & 13663.5 & 13392 & 13997 \\
\hline 147 & 11953.2 & 11647 & 12422 & 184 & 13681.5 & 13410 & 14035 \\
\hline 148 & 12009.3 & 11682 & 12517 & 185 & 13715.3 & 13438 & 14078 \\
\hline 149 & 12158.3 & 11864 & 12549 & 186 & 13749 & 13445 & 14090 \\
\hline 150 & 12307.3 & 11957 & 12622 & 187 & 13782.8 & 13474 & 14104 \\
\hline 151 & 12456.2 & 12007 & 12752 & 188 & 13816.5 & 13480 & 14130 \\
\hline 152 & 12605.2 & 12033 & 12868 & 189 & 13852 & 13500 & 14275 \\
\hline 153 & 12636.1 & 12173 & 12903 & 190 & 13887.5 & 13520 & 14195 \\
\hline 154 & 12667 & 12298 & 12973 & 191 & 13923.1 & 13556 & 14426 \\
\hline 155 & 12698 & 12388 & 13053 & 192 & 13958.6 & 13569 & 14374 \\
\hline 156 & 12728.9 & 12453 & 13188 & 193 & 14038.7 & 13635 & 14465 \\
\hline 157 & 12842.8 & 12544 & 13214 & 194 & 14118.8 & 13695 & 14525 \\
\hline 158 & 12956.7 & 12667 & 13257 & 195 & 14198.9 & 13726 & 14681 \\
\hline 159 & 13070.6 & 12744 & 13294 & 196 & 14279 & 13771 & 14746 \\
\hline 160 & 13184.5 & 12797 & 13337 & 197 & 14306 & 13833 & 14823 \\
\hline 161 & 13203.4 & 12846 & 13361 & 198 & 14333.1 & 13896 & 14876 \\
\hline 162 & 13222.2 & 12870 & 13380 & 199 & 14360.1 & 13940 & 14930 \\
\hline 163 & 13241 & 12889 & 13404 & 200 & 14387.2 & 13938 & 14973 \\
\hline 164 & 13259.8 & 12908 & 13448 & 201 & 14424.1 & 14031 & 15086 \\
\hline 165 & 13295.7 & 12964 & 13449 & 202 & 14461 & 14068 & 15073 \\
\hline 166 & 13331.5 & 13006 & 13476 & 203 & 14498 & 14121 & 15196 \\
\hline 167 & 13367.4 & 13032 & 13502 & 204 & 14534.9 & 14158 & 15258 \\
\hline 168 & 13403.2 & 13053 & 13533 & 205 & 14601 & 14236 & 15321 \\
\hline 169 & 13410.1 & 13073 & 13548 & 206 & 14667.1 & 14263 & 15353 \\
\hline 170 & 13416.9 & 13085 & 13570 & 207 & 14733.2 & 14310 & 15430 \\
\hline 171 & 13423.8 & 13119 & 13619 & 208 & 14799.3 & 14347 & 15507 \\
\hline 172 & 13430.6 & 13154 & 13679 & 209 & 14894.1 & 14433 & 15563 \\
\hline 173 & 13441.2 & 13193 & 13703 & 210 & 14988.9 & 14439 & 15629 \\
\hline 174 & 13451.8 & 13203 & 13723 & 211 & 15083.7 & 14475 & 15725 \\
\hline 175 & 13462.4 & 13220 & 13815 & 212 & 15178.5 & 14642 & 15947 \\
\hline 176 & 13473 & 13195 & 13810 & 213 & 15226.7 & 14689 & 15984 \\
\hline 177 & 13507.1 & 13252 & 13827 & 214 & 15274.9 & 14773 & 16048 \\
\hline 178 & 13541.1 & 13274 & 13854 & 215 & 15323 & 14836 & 16141 \\
\hline 179 & 13575.2 & 13281 & 13871 & 216 & 15371.2 & 14909 & 16254 \\
\hline 180 & 13609.2 & 13322 & 13907 & 217 & 15394.5 & 14957 & 16267 \\
\hline
\end{tabular}


Table S4 (continued)

\begin{tabular}{|c|c|c|c|c|c|c|c|}
\hline $\begin{array}{l}\text { Depth } \\
(\mathrm{cm})\end{array}$ & $\begin{array}{c}\text { Average Age } \\
\text { (Cal. yr BP) }\end{array}$ & $\begin{array}{c}\text { Lower } \\
95 \% \\
\end{array}$ & $\begin{array}{c}\text { Upper } \\
95 \% \\
\end{array}$ & $\begin{array}{c}\text { Depth } \\
(\mathbf{c m})\end{array}$ & $\begin{array}{c}\text { Average Age } \\
\text { (Cal. yr BP) }\end{array}$ & $\begin{array}{c}\text { Lower } \\
95 \% \\
\end{array}$ & $\begin{array}{c}\text { Upper } \\
95 \% \\
\end{array}$ \\
\hline 218 & 15417.9 & 14964 & 16359 & 255 & 18124.2 & 16716 & 18406 \\
\hline 219 & 15441.2 & 14996 & 16396 & 256 & 18194.4 & 16813 & 18463 \\
\hline 220 & 15464.5 & 15013 & 16423 & 257 & 18207.9 & 16879 & 18489 \\
\hline 221 & 15486 & 15034 & 16479 & 258 & 18221.4 & 16806 & 18486 \\
\hline 222 & 15507.5 & 15064 & 16529 & 259 & 18235 & 16872 & 18502 \\
\hline 223 & 15529 & 15057 & 16587 & 260 & 18248.5 & 16904 & 18529 \\
\hline 224 & 15550.5 & 15130 & 16695 & 261 & 18309.2 & 16983 & 18543 \\
\hline 225 & 15655.9 & 15173 & 16743 & 262 & 18369.9 & 17091 & 18561 \\
\hline 226 & 15761.4 & 15160 & 16840 & 263 & 18430.6 & 16980 & 18590 \\
\hline 227 & 15866.9 & 15244 & 16929 & 264 & 18491.3 & 17104 & 18649 \\
\hline 228 & 15972.3 & 15272 & 17117 & 265 & 18512.6 & 17160 & 18690 \\
\hline 229 & 15998.7 & 15478 & 17148 & 266 & 18533.8 & 17081 & 18691 \\
\hline 230 & 16025.1 & 15631 & 17166 & 267 & 18555.1 & 17112 & 18727 \\
\hline 231 & 16051.5 & 15695 & 17220 & 268 & 18576.4 & 17262 & 18747 \\
\hline 232 & 16077.9 & 15724 & 17344 & 269 & 18608.5 & 17402 & 18767 \\
\hline 233 & 16210.8 & 15776 & 17451 & 270 & 18640.5 & 17413 & 18808 \\
\hline 234 & 16343.8 & 15839 & 17429 & 271 & 18672.6 & 17303 & 18833 \\
\hline 235 & 16476.8 & 15897 & 17522 & 272 & 18704.6 & 17393 & 18988 \\
\hline 236 & 16609.8 & 15950 & 17665 & 273 & 18726.7 & 17503 & 18883 \\
\hline 237 & 16716.4 & 15855 & 17715 & 274 & 18748.9 & 17479 & 18909 \\
\hline 238 & 16823.1 & 16009 & 17819 & 275 & 18771 & 17539 & 18924 \\
\hline 239 & 16929.7 & 15987 & 17877 & 276 & 18793.1 & 17585 & 19050 \\
\hline 240 & 17036.4 & 16125 & 17920 & 277 & 18799.7 & 17657 & 18982 \\
\hline 241 & 17077.8 & 16094 & 17944 & 278 & 18806.2 & 17801 & 19036 \\
\hline 242 & 17119.2 & 16060 & 17980 & 279 & 18812.8 & 17699 & 19109 \\
\hline 243 & 17160.6 & 16160 & 18005 & 280 & 18819.3 & 17883 & 19193 \\
\hline 244 & 17202.1 & 16186 & 18096 & 281 & 18880.2 & 18053 & 19223 \\
\hline 245 & 17360.9 & 16307 & 18097 & 282 & 18941.1 & 18097 & 19232 \\
\hline 246 & 17519.7 & 16352 & 18247 & 283 & 19002 & 18111 & 19291 \\
\hline 247 & 17678.6 & 16406 & 18161 & 284 & 19062.9 & 18169 & 19339 \\
\hline 248 & 17837.4 & 16499 & 18189 & 285 & 19087.8 & 18206 & 19366 \\
\hline 249 & 17856.5 & 16474 & 18194 & 286 & 19112.7 & 18281 & 19406 \\
\hline 250 & 17875.6 & 16510 & 18235 & 287 & 19137.6 & 18287 & 19427 \\
\hline 251 & 17894.8 & 16552 & 18252 & 288 & 19162.5 & 18327 & 19462 \\
\hline 252 & 17913.9 & 16598 & 18323 & 289 & 19217 & 18378 & 19488 \\
\hline 253 & 17984 & 16638 & 18378 & 290 & 19271.4 & 18468 & 19523 \\
\hline 254 & 18054.1 & 16638 & 18383 & 291 & 19325.9 & 18523 & 19558 \\
\hline
\end{tabular}


Table S4 (continued)

\begin{tabular}{|c|c|c|c|c|c|c|c|}
\hline $\begin{array}{c}\text { Depth } \\
\text { (cm) }\end{array}$ & $\begin{array}{c}\text { Average Age } \\
\text { (Cal. yr BP) }\end{array}$ & $\begin{array}{c}\text { Lower } \\
95 \% \\
\end{array}$ & $\begin{array}{c}\text { Upper } \\
95 \% \\
\end{array}$ & $\begin{array}{c}\text { Depth } \\
(\mathrm{cm})\end{array}$ & $\begin{array}{c}\text { Average Age } \\
\text { (Cal. yr BP) }\end{array}$ & $\begin{array}{c}\text { Lower } \\
95 \% \\
\end{array}$ & $\begin{array}{c}\text { Upper } \\
95 \% \\
\end{array}$ \\
\hline 292 & 19380.4 & 18568 & 19593 & 321 & 19907.2 & 19663 & 20438 \\
\hline 293 & 19417.1 & 18671 & 19611 & 322 & 19933.5 & 19693 & 20493 \\
\hline 294 & 19453.8 & 18764 & 19634 & 323 & 19959.8 & 19694 & 20514 \\
\hline 295 & 19490.5 & 18868 & 19668 & 324 & 19986.1 & 19715 & 20560 \\
\hline 296 & 19527.2 & 18912 & 19707 & 325 & 19993.1 & 19731 & 20586 \\
\hline 297 & 19556.7 & 18961 & 19721 & 326 & 20000 & 19762 & 20622 \\
\hline 298 & 19586.2 & 19007 & 19727 & 327 & 20006.9 & 19763 & 20653 \\
\hline 299 & 19615.7 & 19038 & 19748 & 328 & 20013.8 & 19804 & 20729 \\
\hline 300 & 19645.1 & 19061 & 19776 & 329 & 20028.4 & 19828 & 20763 \\
\hline 301 & 19663.3 & 19124 & 19799 & 330 & 20043 & 19827 & 20827 \\
\hline 302 & 19681.4 & 19140 & 19835 & 331 & 20057.5 & 19831 & 20811 \\
\hline 303 & 19699.6 & 19156 & 19881 & 332 & 20072.1 & 19855 & 20865 \\
\hline 304 & 19717.7 & 19187 & 19932 & 333 & 20093.4 & 19895 & 20900 \\
\hline 305 & 19724.5 & 19204 & 19964 & 334 & 20114.6 & 19910 & 20950 \\
\hline 306 & 19731.3 & 19215 & 19985 & 335 & 20135.9 & 19923 & 20973 \\
\hline 307 & 19738.1 & 19244 & 20014 & 336 & 20157.1 & 19931 & 21016 \\
\hline 308 & 19744.8 & 19279 & 20069 & 337 & 20183.6 & 19955 & 21045 \\
\hline 309 & 19756.2 & 19300 & 20100 & 338 & 20210.1 & 19966 & 21116 \\
\hline 310 & 19767.5 & 19319 & 20134 & 339 & 20236.6 & 19977 & 21142 \\
\hline 311 & 19778.8 & 19386 & 20176 & 340 & 20263.1 & 19987 & 21182 \\
\hline 312 & 19790.1 & 19397 & 20202 & 341 & 20275.8 & 20031 & 21206 \\
\hline 313 & 19791.7 & 19432 & 20222 & 342 & 20288.6 & 20048 & 21308 \\
\hline 314 & 19793.3 & 19431 & 20261 & 343 & 20301.3 & 20064 & 21349 \\
\hline 315 & 19794.8 & 19496 & 20291 & 344 & 20314 & 20084 & 21364 \\
\hline 316 & 19796.4 & 19510 & 20315 & 345 & 20330.5 & 20098 & 21398 \\
\hline 317 & 19817.5 & 19556 & 20336 & 346 & 20347 & 20161 & 21426 \\
\hline 318 & 19838.6 & 19591 & 20361 & 347 & 20363.4 & 20176 & 21456 \\
\hline 319 & 19859.7 & 19610 & 20380 & 348 & 20379.9 & 20184 & 21494 \\
\hline 320 & 19880.9 & 19642 & 20422 & & & & \\
\hline
\end{tabular}




\section{APPENDiX B: MATlab Modeling SCRIPTS}

\section{Script 1: Distribution change with relative season length}
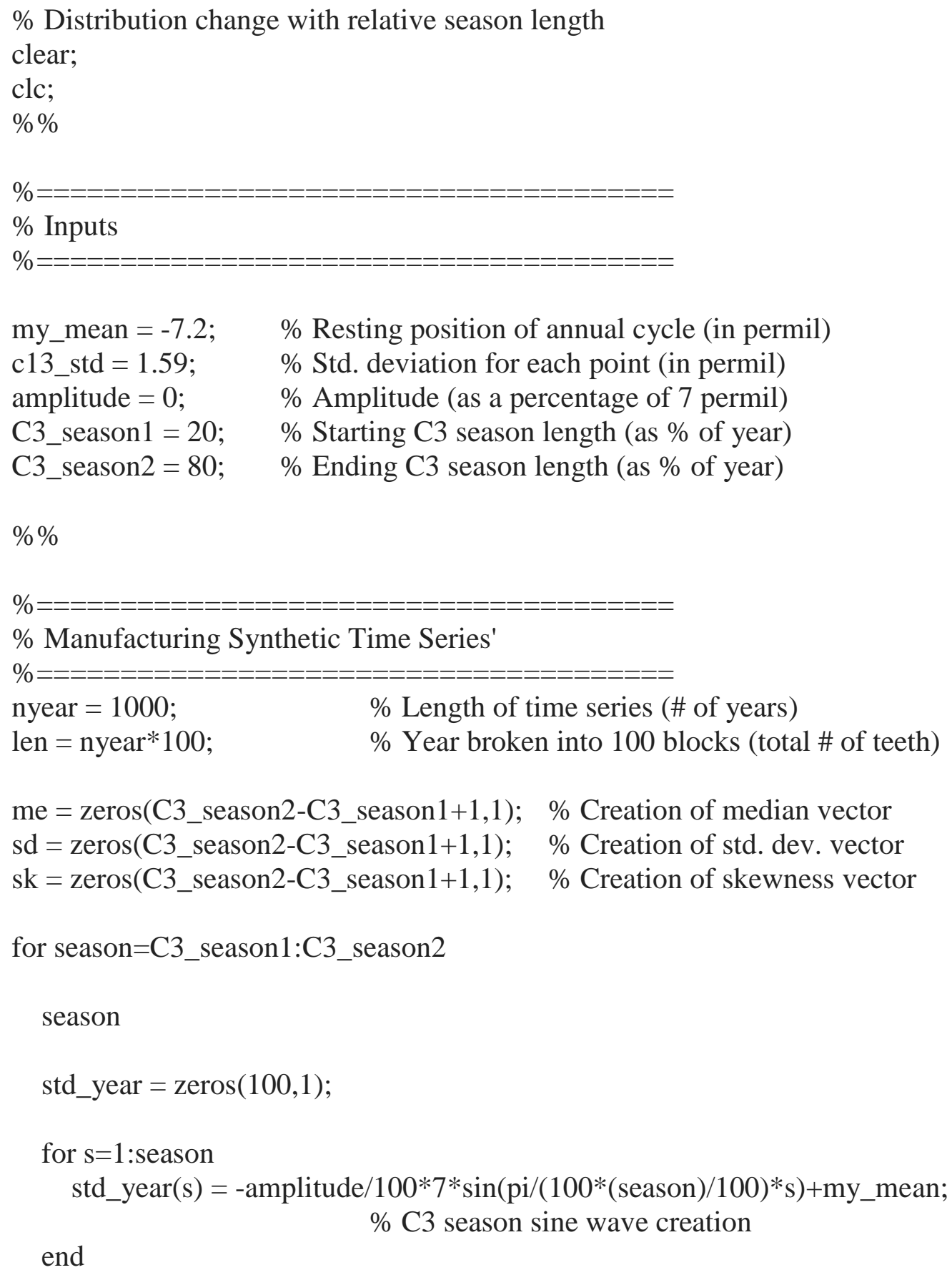


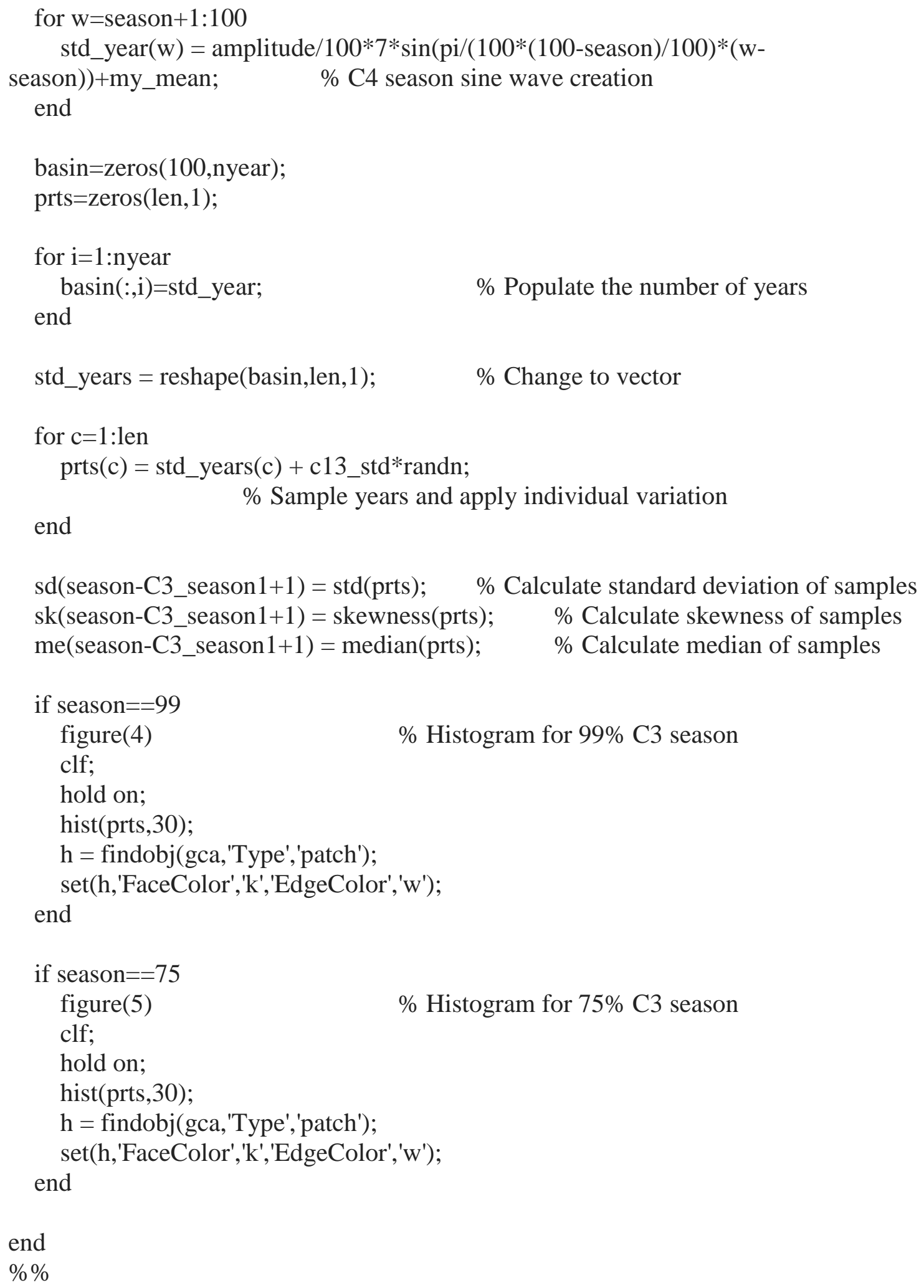




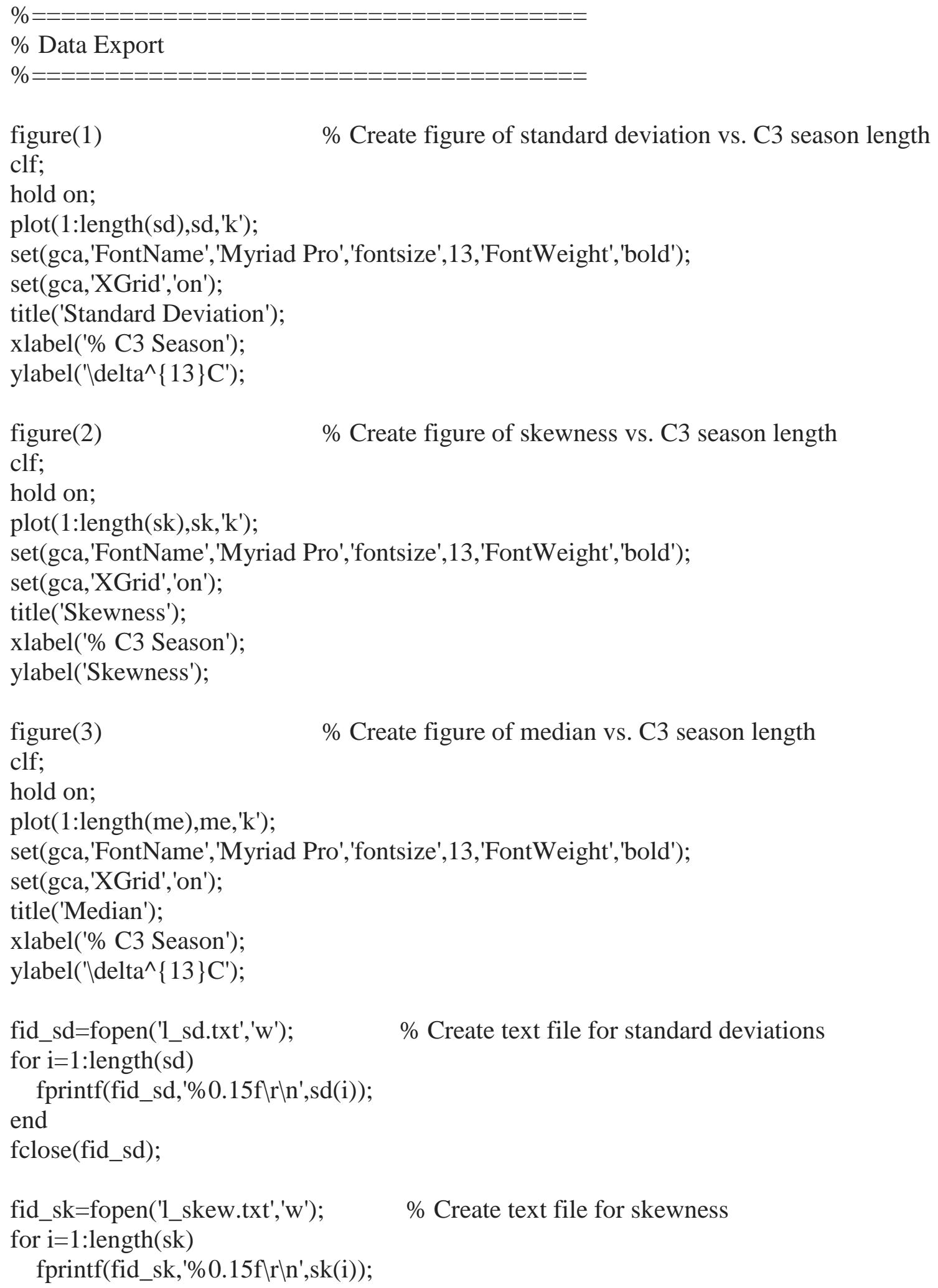


end

fclose(fid_sk);

fid_me=fopen('1_medi.txt','w'); $\quad \%$ Create text file for median

for $\mathrm{i}=1$ :length(me)

fprintf(fid_me,'\%0.15fไr\n',me(i));

end

fclose(fid_me); 


\section{Script 2: Distribution change with amplitude}
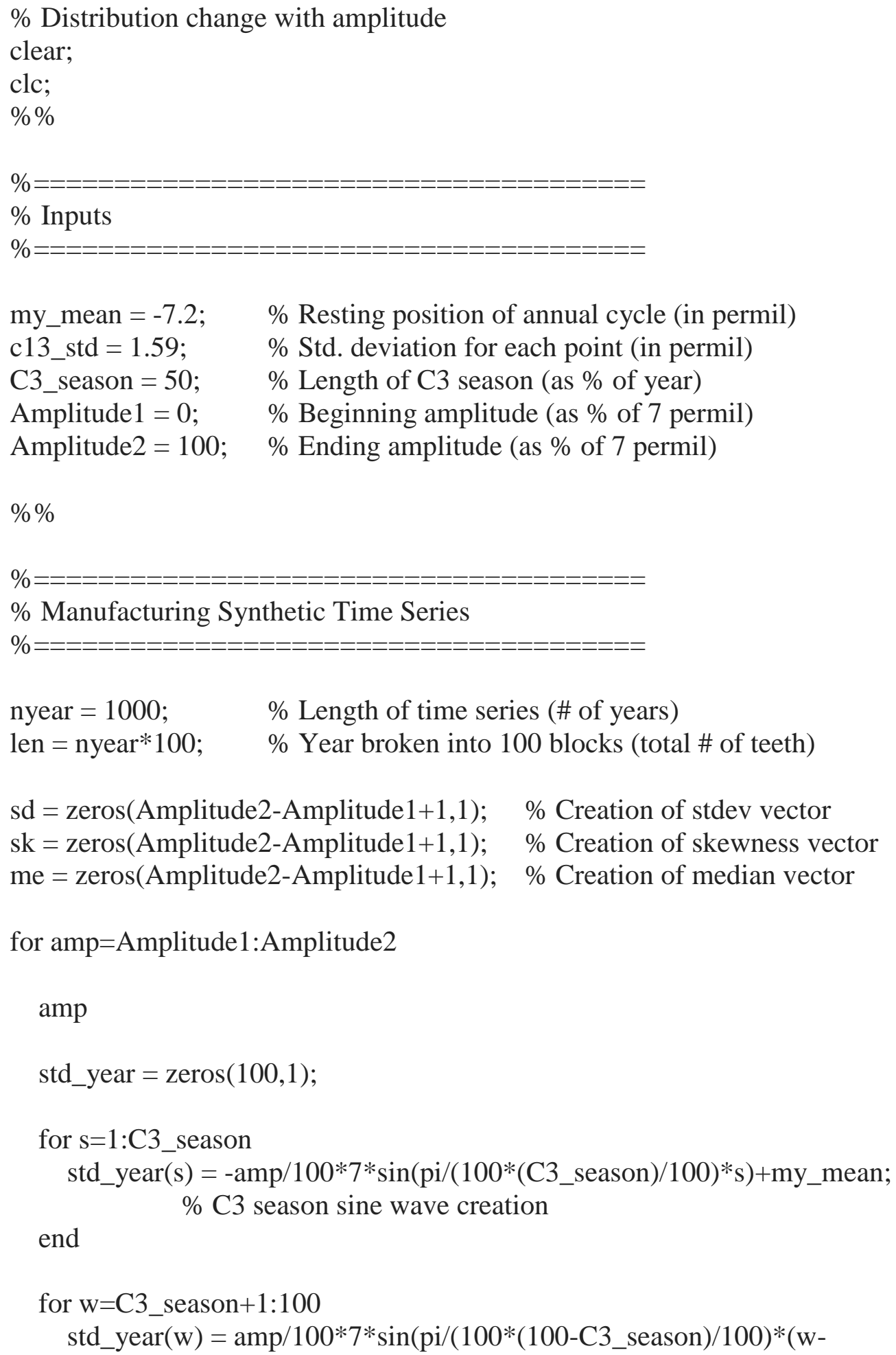


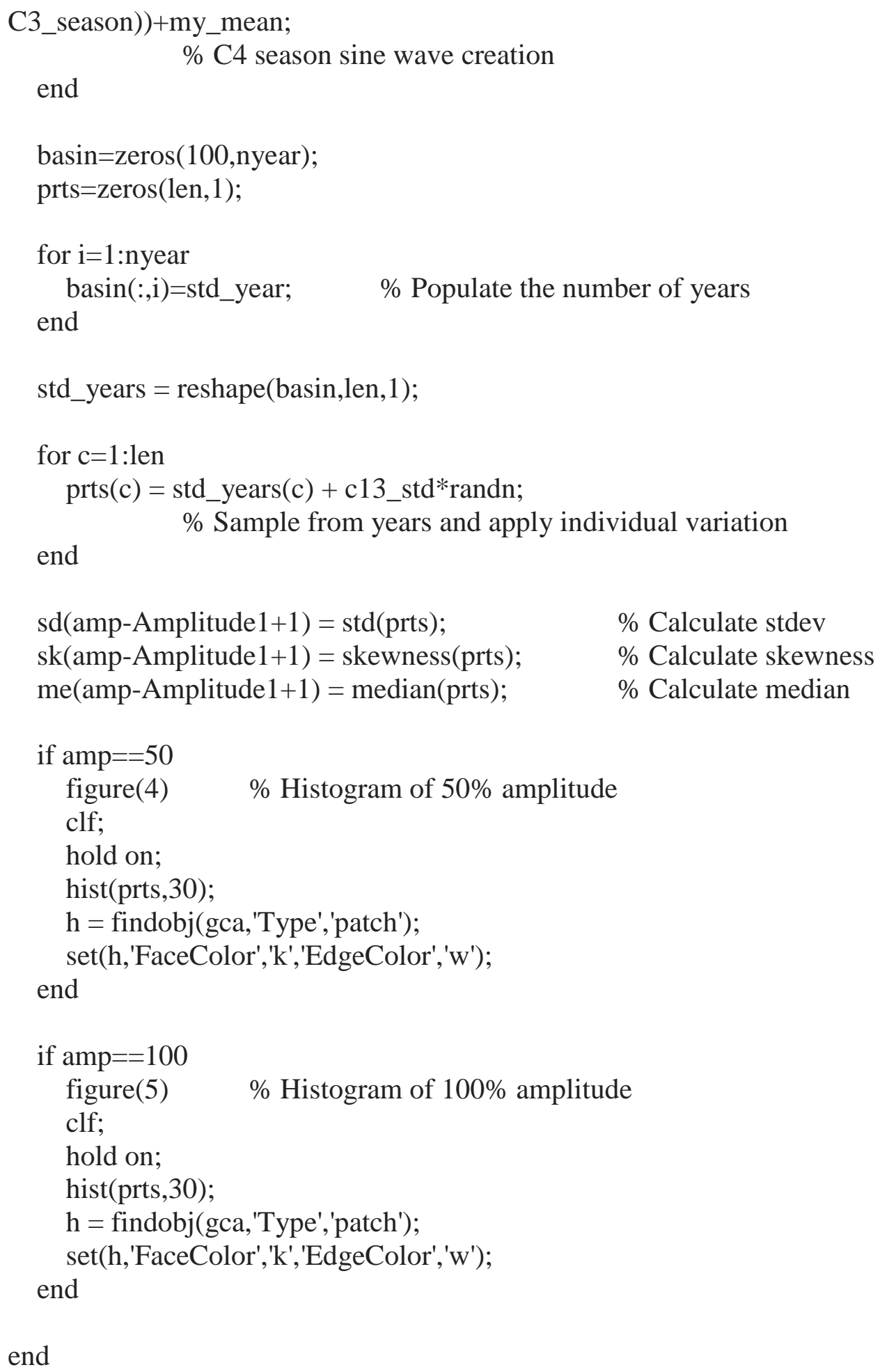




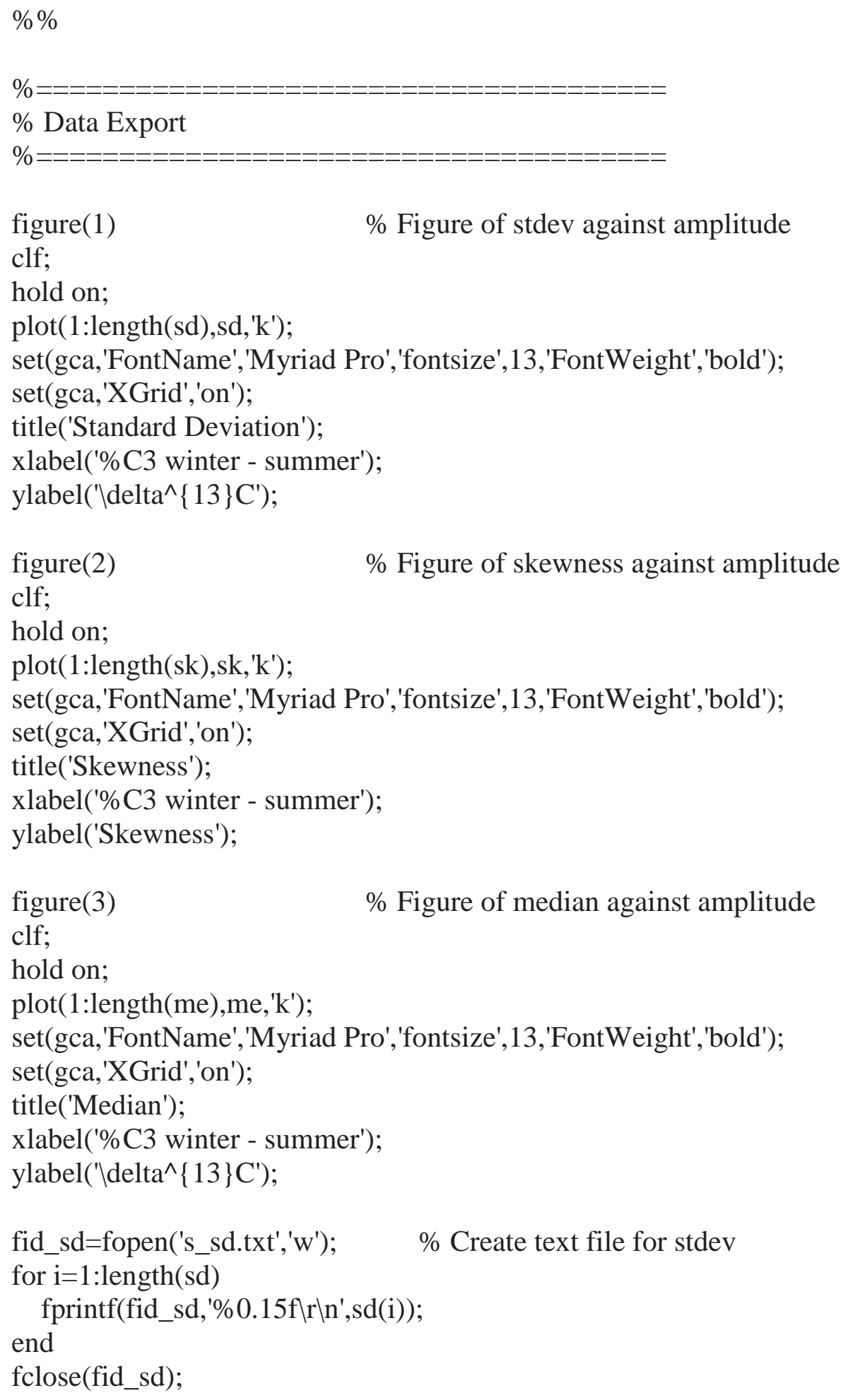


fid_sk=fopen('s_sk.txt','w'); $\quad \%$ Create text file for skewness

for $\mathrm{i}=1$ :length(sk)

fprintf(fid_sk,'\%0.15fไrın',sk(i));

end

fclose(fid_sk);

fid_me=fopen('s_me.txt','w'); $\quad \%$ Create text file for median

for $\mathrm{i}=1$ :length(me)

fprintf(fid_me,'\%0.15f \r\n',me(i));

end

fclose(fid_me); 
Script 3: Precision change with sample size

$\%$ Sample size and precision

clear;

clc;

$\% \%$

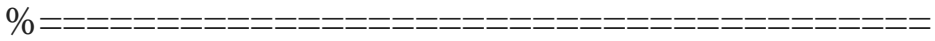

$\%$ Input

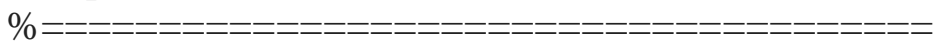

my_mean $=-7.2 ; \quad \%$ Resting position of annual cycle (in permil)

c13_std $=1.59 ; \quad \%$ Std. deviation of individual points (in permil)

amplitude $=16 ; \quad \%$ Amplitude (as \% of 7)

C3_season $=20 ; \quad \%$ C3 Season length (as \% of year)

tooth $1=3 ; \quad \%$ Minimum number of teeth (needs to be at least 3 )

tooth2 $=100 ; \quad \%$ Maximum number of teeth

$\% \%$

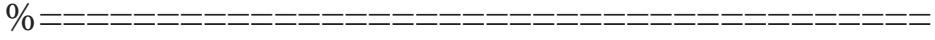

$\%$ Manufacturing Synthetic Time Series

$\%=================================$

nyear $=1000 ; \quad \%$ Number of years

len $=$ nyear* $100 ; \quad \%$ Number of total teeth in population

std_year1 = zeros $(100,1)$;

for $\mathrm{w}=1$ :C3_season

std_year1 $(\mathrm{w})=-\operatorname{amplitude} / 100 * 7 * \sin \left(\mathrm{pi} /\left(100 *\left(\mathrm{C} 3 \_\right.\right.\right.$season $\left.\left.) / 100\right) * \mathrm{w}\right)+$ my_mean;

$\% \mathrm{C} 3$ season sine wave creation

end

for $\mathrm{s}=\mathrm{C} 3$ _season $+1: 100$

std_year1(s) = amplitude/100*7*sin(pi/(100*(100-C3_season $) / 100) *(\mathrm{~s}-$

C3_season))+my_mean;

$\% \mathrm{C} 4$ season sine wave creation

end

basin 1=zeros(100,nyear);

prts1=zeros(len,1); 


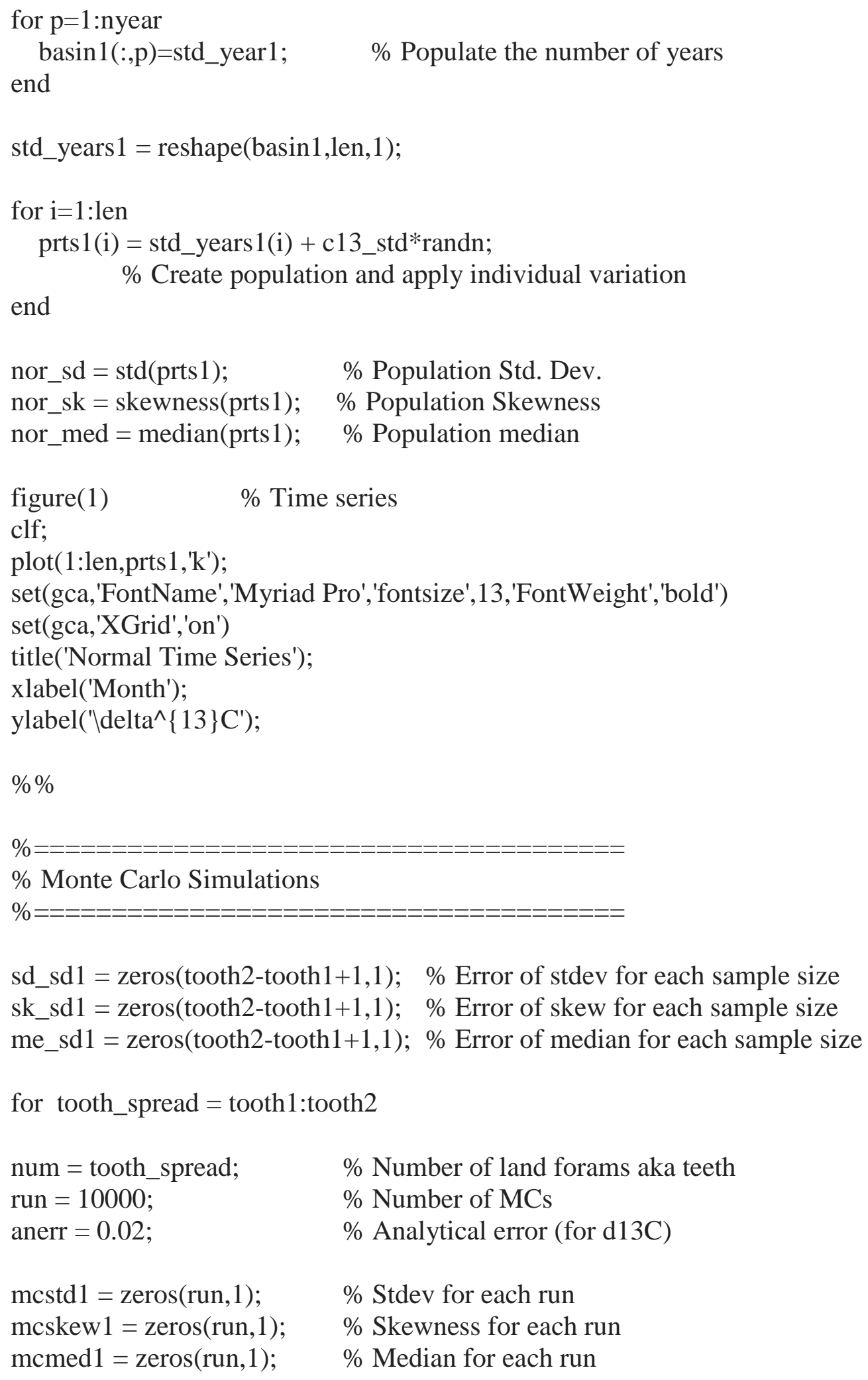




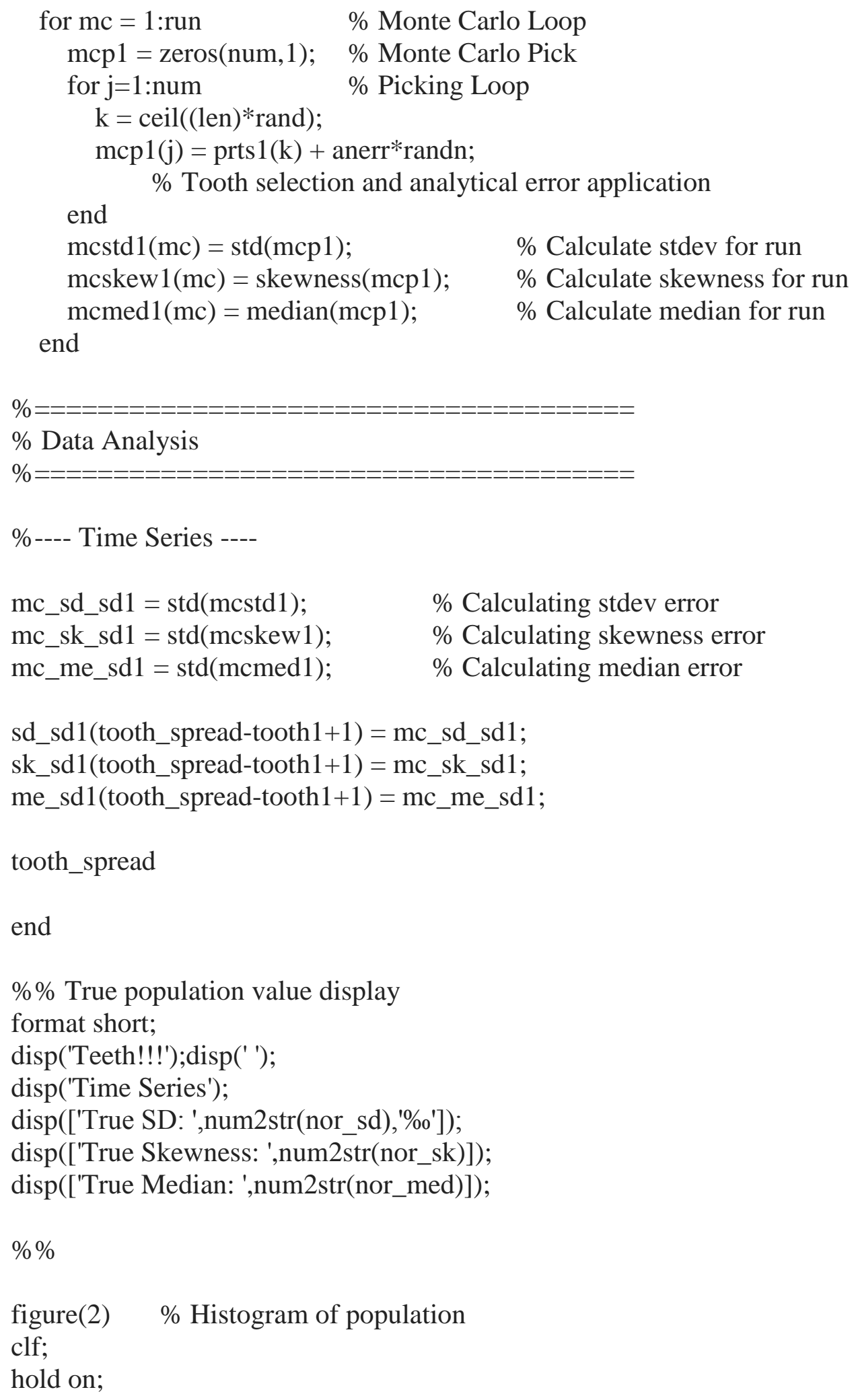




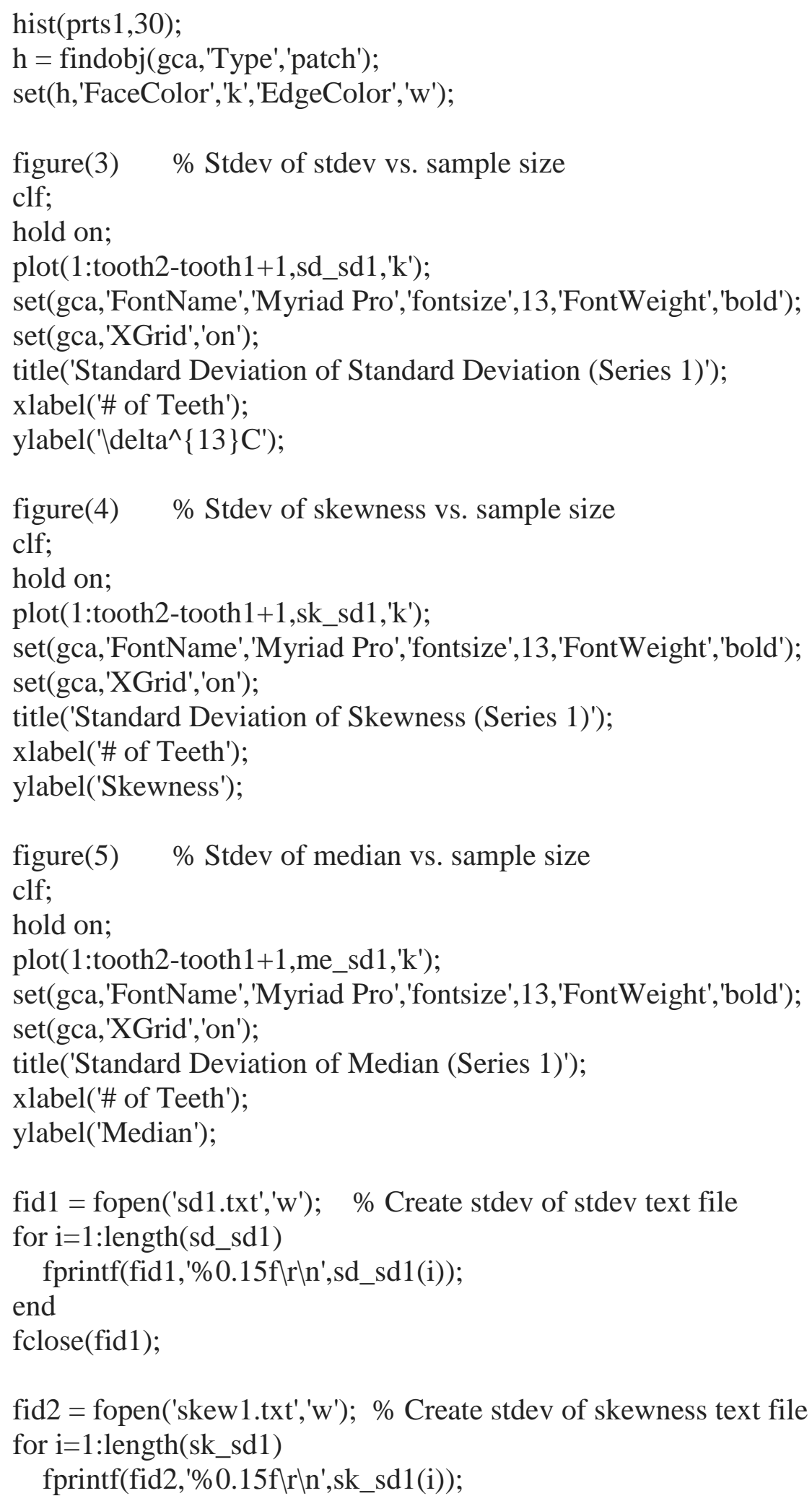


end

fclose(fid2);

fid3 = fopen('medi1.txt','w'); \% Create stdev of median text file

for $\mathrm{i}=1$ :length(me_sd1)

fprintf(fid3,'\%0.15flrın',me_sd1(i));

end

fclose(fid3); 


\section{References}

Abul-Fatih, H. A., and F. A. Bazzaz. 1979. The biology of Ambrosia trifida L. II germination, emergence, growth, and survival. New Phytologist 83:817-827.

Angevine, M. W., and B. F. Chabot. 1979. Seed germination syndromes in higher plants. In: Solbrig, O. T., Jain, S., Johnson, G. B., Raven, P. H. (eds) Topics in Plant Population Biology. Columbia University Press, New York.

Arguez, A., S. Applequist, R. Vose, I. Durre, M. Squires, and X. Yin. 2012. NOAA's 1981-2010 climate normals methodology of temperature-related normals. NCDC Report. 7 pp.

Asmerom, Y., V. J. Polyak, and S. J. Burns. 2010. Variable winter moisture in the southwestern United States linked to rapid glacial climate shifts. Nature Geoscience 3:114-117.

Balesdent, J., C. Girardin, and A. Mariotti. 1993. Site-related $\delta^{13} \mathrm{C}$ of tree leaves and soil organic matter in a temperate forest. Ecology 74:1713-1721.

Bedaso, Z. K., J. G. Wynn, Z. Alemseged, and D. Geraads. 2013. Dietary and paleoenvironmental reconstruction using stable isotopes of herbivore tooth enamel from middle Pliocene Dikika, Ethiopia: implication for Australopithecus afarensis habitat and food resources. Journal of Human Evolution 64:21-38.

Berger, A. L. 1978. Long-term variations of daily insolation and quaternary climatic changes. Journal of the Atmospheric Sciences 35:2362-2367.

Besnard, G., A. M. Muasya, F. Russier, E. H. Roalson, N. Salamin, and P.-A. Christin. 2009. Phylogenomics of $\mathrm{C}_{4}$ photosynthesis in sedges (Cyperaceae): multiple appearances and genetic convergence. Molecular Biology and Evolution 26:19091919.

Blaauw, M., and J. A. Christen. 2011. Flexible paleoclimate age-depth models using an autoregressive gamma process. Bayesian Analysis 6:457-474.

Bomar, G. W. 1995. Texas Weather: Second Edition, Revised. University of Texas Press. Austin, TX. 287 pp.

Bond, W. J. 2008. What limits trees in $\mathrm{C}_{4}$ grasslands and savannas? Annual Review of Ecology, Evolution, and Systematics 39:641-659. 
Boutton, T. W., S. R. Archer, A. J. Midwood, S. F. Zitzer, and R. Bol. 1998. $\delta^{13}$ C values of soil organic carbon and their use in documenting vegetation change in a subtropical savanna ecosystem. Geoderma 82:5-41.

Brewer, N. R. 2006. Biology of the rabbit. Journal of the American Association for Laboratory Animal Science 45:8-24.

Cerling, T. E. 1984. The stable isotopic composition of modern soil carbonate and its relationship to climate. Earth and Planetary Science Letters 71:229-240.

Cerling, T. E., and Z. D. Sharp. 1996. Stable carbon and oxygen isotope analysis of fossil tooth enamel using laser ablation. Palaeogeography, Palaeoclimatology, Palaeoecology 126:173-186.

Cerling, T. E., J. M. Harris, B. J. Macfadden, M. G. Leakey, J. Quadek, V. Eisenmann, and J. R. Ehleringer. 1997. Global vegetation change through the Miocene/Pliocene boundary. Nature 389:153-158.

Cerling, T. E., and J. M. Harris. 1999. Carbon isotope fractionation between diet and bioapatite in ungulate mammals and implications for ecological and paleoecological studies. Oecologia 120:347-363.

Chapman, J. A., and G. R. Willner. 1978. Sylvilagus audubonii. Mammalian Species 106:1-4.

Christin, P.-A., G. Besnard, E. Samaritani, M. R. Duvall, T. R. Hodkinson, V. Savolainen, and N. Salamin. 2008. Oligocene $\mathrm{CO}_{2}$ decline promoted $\mathrm{C}_{4}$ photosynthesis in grasses. Current Biology 18:37-43.

Cooke, M. J., L. A. Stern, J. L. Banner, L. E. Mack, T. W. J. Stafford, and R. S. I. Toomey. 2003. Precise timing and rate of massive late Quaternary soil denudation. Geology 31:853-856.

Correll, D. S., and M. C. Johnston 1970. Manual of the Vascular Plants of Texas. Texas Research Foundation. Renner, TX. 1881 pp.

Dalke, P. D., and P. R. Sime. 1941. Food habits of the eastern and New England cottontails. The Journal of Wildlife Management 5:216-228.

Deniro, M. J., and S. Epstein. 1978. Influence of diet on the distribution of carbon isotopes in animals. Geochimica et Cosmochimica Acta 42:495-506. 
DiMiceli, C. M., M. L. Carroll, R. A. Sohlberg, C. Huang, M. C. Hansen, and J. R. G. Townshend. 2011. Annual Global Automated MODIS Vegetation Continuous Fields (MOD44B) at $250 \mathrm{~m}$ Spatial Resolution for Data Years Beginning Day 65, 2000 2010, Collection 5. University of Maryland, College Park, MD. http://www.landcover.org/data/vcf/

Durre, I., M. F. Squires, R. S. Vose, A. Arguez, S. Applequist, and X. Yin. 2011. Computational procedures for the 1981-2010 normals: precipitation, snowfall, and snow depth. NCDC Report. $11 \mathrm{pp}$.

Ehleringer, J. R., C. B. Field, Z. Lin, and C. Kuo. 1986. Leaf carbon isotope and mineral composition in subtropical plants along an irradiance cline. Oecologia 70:520-526.

Ehleringer, J. R. 1993. Variation in leaf carbon isotope discrimination in Encelia farinosa: implications for growth, competition, and drought survival. Oecologia 95:340-346.

Ehleringer, J. R., T. E. Cerling, and B. R. Helliker. 1997. C 4 photosynthesis, atmospheric $\mathrm{CO}_{2}$, and climate. Oecologia 112:285-299.

Feldhamer, G. A., B. C. Thompson, and J. A. Chapman, eds. 2003. Wild Mammals of North America: Biology, Management, and Conservation. The Johns Hopkins University Press. Baltimore, MD. 1216 pp.

Feranec, R. S., E. A. Hadly, and A. Paytan. 2009. Stable isotopes reveal seasonal competition for resources between late Pleistocene bison (Bison) and horse (Equus) from Rancho La Brea, southern California. Palaeogeography, Palaeoclimatology, Palaeoecology 271:153-160.

Feranec, R. S., E. A. Hadly, and A. Paytan. 2010. Isotopes reveal limited effects of middle Pleistocene climate change on the ecology of mid-sized mammals. Quaternary International 217:43-52.

Forbes, M. S., M. J. Kohn, E. A. Bestland, and R. T. Wells. 2010. Late Pleistocene environmental change interpreted from $\delta^{13} \mathrm{C}$ and $\delta^{18} \mathrm{O}$ of tooth enamel from the Black Creek Swamp Megafauna site, Kangaroo Island, South Australia. Palaeogeography, Palaeoclimatology, Palaeoecology 291:319-327.

Fowler, N. L., and D. W. Dunlap. 1986. Grassland vegetation of the eastern Edwards Plateau. American Midland Naturalist 115:146-155. 
Friedli, H., H. Lötscher, H. Oeschger, U. Siegenthaler, and B. Stauffer. 1986. Leaf carbon isotope and mineral composition in subtropical plants along an irradiance cline. Nature 324:237-238.

Hibbard, C. W. 1949. Techniques of collecting microvertebrate fossils. Contributions from the Museum of Paleontology, University of Michigan 8:7-19

Hobson, K., and J. Sease. 1998. Stable isotope analyses of tooth annuli reveal temporal dietary records : An Example Using Stellar Sea Lions. Marine Mammal Science 14:116-129.

Hoppe, K. A, S. M. Stover, J. R. Pascoe, and R. Amundson. 2004. Tooth enamel biomineralization in extant horses: implications for isotopic microsampling. Palaeogeography, Palaeoclimatology, Palaeoecology 206:355-365.

Hynek, S. A., B. H. Passey, J. L. Prado, F. H. Brown, T. E. Cerling, and J. Quade. 2012. Small mammal carbon isotope ecology across the Miocene-Pliocene boundary, northwestern Argentina. Earth and Planetary Science Letters 321-322:177-188.

Jenkins, S. G., S. T. Partridge, T. R. Stephenson, S. D. Farley, and C. T. Robbins. 2001. Nitrogen and carbon isotope fractionation between mothers, neonates, and nursing offspring. Oecologia 129:336-341.

Johnsgard, P. A. 2002. North American Owls: Biology and Natural History, 2 nd ed. Smithsonian Institution Press, Washington, D. C. 298 pp.

Keeling, C. D., S. C. Piper, R. B. Bacastow, M. Wahlen, T. P. Whorf, M. Heimann, and H. A. Meijer. 2005. Terrestrial biosphere and oceans from 1978 to 2000 : observations and carbon cycle implications; pp. 83-113 in J. R. Ehleringer, T. E. Cerling, and M. D. Dearing (eds.), A History of Atmospheric CO2 and its Effects on Plants, Animals, and Ecosystems. Springer-Verlag, New York, NY.

Koch, P. L., N. Tuross, and M. L. Fogel. 1997. The effects of sample treatment and diagenesis on the isotopic integrity of carbonate in biogenic hydroxylapatite. Journal of Archaeological Science 24:417-429.

Koch, P. L., N. S. Diffenbaugh, and K. A. Hoppe. 2004. The effects of late Quaternary climate and $\mathrm{pCO}_{2}$ change on $\mathrm{C}_{4}$ plant abundance in the south-central United States. Palaeogeography, Palaeoclimatology, Palaeoecology 207:331-357.

Koutavas, A., P. B. DeMenocal, G. C. Olive, and J. Lynch-Stieglitz. 2006. Mid-Holocene El Niño-Southern Oscillation (ENSO) attenuation revealed by individual foraminifera in eastern tropical Pacific sediments. Geology 34:993-996. 
Koutavas, A., and S. Joanides. 2012. El Niño-Southern Oscillation extrema in the Holocene and Last Glacial Maximum. Paleoceanography 27(4; PA4208):1-15.

Lanzante, J. R. 2005. A cautionary note on the use of error bars. Journal of Climate 18:3699-3703.

Larkin, T. J., and G. W. Bomar. 1983. Climatic Atlas of Texas. Texas Department of Water Resources, Austin, Texas, 151 pp.

Larter, N. C., and C. C. Gates. 1994. Home-range size of wood bison: effects of age, sex, and forage availability. Journal of Mammalogy 75:142-149.

Leduc, G., L. Vidal, O. Cartapanis, and E. Bard. 2009. Modes of eastern equatorial Pacific thermocline variability: Implications for ENSO dynamics over the last glacial period. Paleoceanography 24(3; PA3202):1-14.

Lee-Thorp, J. A., and P. B. Beaumont. 1995. Vegetation and seasonality shifts during the late Quaternary deduced from ${ }^{13} \mathrm{C}^{12} \mathrm{C}$ ratios of grazers at Equus Cave, South Africa. Quaternary Research 43:426-432.

MacFadden, B. J., T. E. Cerling, and J. Prado. 1996. Cenozoic terrestrial ecosystem evolution in Argentina: evidence from carbon isotopes of fossil mammal teeth. Palaios 11:319-327.

McLean, B. S., and S. D. Emslie. 2012. Stable isotopes reflect the ecological stability of two high-elevation mammals from the late Quaternary of Colorado. Quaternary Research 77:408-417.

McNab, B. K. 1963. Bioenergetics and the dermination of home range size. The American Naturalist 97:133-140.

Means, L. L. 1952. On thunderstorm forecasting in the central United States. Monthly Weather Review 80:165-189.

Medina, E., G. Montes, E. Guevas, and Z. Rokzandic. 1986. Profiles of $\mathrm{CO}_{2}$ concentration and $\delta^{13} \mathrm{C}$ values in tropical rain forests of the upper Rio Negro Basin, Venezuela. Journal of Tropical Ecology 2:207-217.

Mitchell, M. J., R. W. Arritt, and K. Labas. 1995. A climatology of the warm season Great Plains low-level jet using wind profiler observations. Weather and Forecasting 10:576-591. 
Morgan, R. G. 1980. Bison movement patterns on the Canadian plains: an ecological analysis. Plains Anthropologist 25:143-160.

Ode, D. J., L. L. Tieszen, and J. C. Lerman. 1980. The seasonal contribution of $\mathrm{C}_{3}$ and $\mathrm{C}_{4}$ plant species to primary production in a mixed prairie. Ecology 61:1304-1311.

Overpeck, J. T., R. S. Webb, and T. Webb III. 1992. Mapping eastern North American vegetation change of the past $18 \mathrm{ka}$ : No-analogs and the future. Geology 20:10711074.

Paruelo, J. M., W. K. Lauenroth, S. E. Applications, and N. Nov. 1996. Relative abundance of plant functional types in grasslands and shrublands of North America. Ecological Applications 6:1212-1224.

Passey, B. H., T. F. Robinson, L. K. Ayliffe, T. E. Cerling, M. Sponheimer, M. D. Dearing, B. L. Roeder, and J. R. Ehleringer. 2005. Carbon isotope fractionation between diet, breath $\mathrm{CO}_{2}$, and bioapatite in different mammals. Journal of Archaeological Science 32:1459-1470.

Petit, J. R., J. Jouzel, D. Raynaud, N. I. Barkov, J. M. Barnola, I. Basile, M. Bender, J. Chappellaz, M. Davis, G. Delaygue, C. Ritz, M. Delmotte, V. M. Kotlyakov, M. Legrand, V. Y. Lipenkov, C. Lorius, L. Pepin, E. Saltzman, and M. Stievenard. 1999. Climate and atmospheric history of the past 420,000 years from the Vostok ice core, Antarctica. Nature 399:429-436.

Podlesak, D. W., A.-M. Torregrossa, J. R. Ehleringer, M. D. Dearing, B. H. Passey, and T. E. Cerling. 2008. Turnover of oxygen and hydrogen isotopes in the body water, $\mathrm{CO}_{2}$, hair, and enamel of a small mammal. Geochimica et Cosmochimica Acta 72:19-35.

Probert, R. J. 2000. The role of temperature in the regulation of seed dormancy and germination; pp. 261-292 in M. Fenner (ed.), Seeds: The Ecology of Regeneration in Plant Communities, 2nd ed. CABI Publishing, Oxford, UK.

Rathcke, B., and E. P. Lacey. 1985. Phenological patterns of terrestrial plants. Annual Review of Ecology and Systematics 16:179-214.

Raynal, D. J., and F. A. Bazzaz. 1975. Interference of winter annuals with Ambrosia artemisiifolia in early successional fields. Ecology 56:35-49.

Reimer, P. J., M. G. L. Baillie, E. Bard, A. Bayliss, J. W. Beck, P. G. Blackwell, C. Bronk Ramsey, C. E. Buck, G. S. Burr, R. L. Edwards, M. Friedrich, P. M. Grootes, T. P. Guilderson, I. Hajdas, T. J. Heaton, A. G. Hogg, K. A. Hughen, K. F. Kaiser, 
B. Kromer, F. G. McCormac, S. W. Manning, R. W. Reimer, D. A. Richards, J. R. Southon, S. Talamo, C. S. M. Turney, J. van der Plicht, and C. E. Weyhenmeyer. 2009. IntCal09 and Marine09 radiocarbon age calibration curves, 0-50,000 years cal. BP. Radiocarbon 51:1111-1150.

Rogers, K. L., and Y. Wang. 2002. Stable isotopes in pocket gopher teeth as evidence of a late Matuyama climate shift in the southern Rocky Mountains. Quaternary Research 57:200-207.

Rohde, A., and R. P. Bhalerao. 2007. Plant dormancy in the perennial context. Trends in Plant Science 12:217-223.

Royer, A., C. Lécuyer, S. Montuire, R. Amiot, S. Legendre, G. Cuenca-Bescós, M. Jeannet, and F. Martineau. 2013. What does the oxygen isotope composition of rodent teeth record? Earth and Planetary Science Letters 361:258-271.

Sage, R. F., P.-A. Christin, and E. J. Edwards. 2011. The $\mathrm{C}_{4}$ plant lineages of planet Earth. Journal of Experimental Botany 62:3155-3169.

Sankaran, M., N. P. Hanan, R. J. Scholes, J. Ratnam, D. J. Augustine, B. S. Cade, J. Gignoux, S. I. Higgins, X. Le Roux, F. Ludwig, J. Ardo, F. Banyikwa, A. Bronn, G. Bucini, K. K. Caylor, M. B. Coughenour, A. Diouf, W. Ekaya, C. J. Feral, E. C. February, P. G. H. Frost, P. Hiernaux, H. Hrabar, K. L. Metzger, H. H. T. Prins, S. Ringrose, W. Sea, J. Tews, J. Worden, and N. Zambatis. 2005. Determinants of woody cover in African savannas. Nature 438:846-849.

Schiller, A., U. Mikolajewicz, and R. Voss. 1997. The stability of the North Atlantic thermohaline circulation in a coupled ocean-atmosphere general circulation model. Climate Dynamics 13:325-347.

Schmidly, D. J. 1994. The Mammals of Texas, Revised Edition. University of Texas Press. Austin, TX. 501 pp.

Sherry, R. A., E. Weng, J. A. Arnone III, D. W. Johnson, D. S. Schimel, P. S. Verburg, L. L. Wallace, and Y. Luo. 2008. Lagged effects of experimental warming and doubled precipitation on annual and seasonal aboveground biomass production in a tallgrass prairie. Global Change Biology 14:2923-2936.

Shuman, B., T. Webb, P. Bartlein, and J. W. Williams. 2002. The anatomy of a climatic oscillation : vegetation change in eastern North America during the Younger Dryas chronozone. Quaternary Science Reviews 21:1777-1791. 
Smeins, F. E., T. W. Taylor, and L. B. Merrill. 1976. Vegetation of a 25-year exclosure on the Edwards Plateau, Texas. Journal of Range Management 29:24-29.

Smith, C. S. 2011. Stable carbon isotope analysis of modern leporids to assess their usefulness as fine-grained ecological proxies to reconstruct local paleoecology. University of Texas at San Antonio. Unpublished Master's Thesis. 101 pp.

Steinbeiss, S., V. M. Temperton, and G. Gleixner. 2008. Mechanisms of short-term soil carbon storage in experimental grasslands. Soil Biology and Biochemistry 40:26342642 .

Teeri, J. A., and L. G. Stowe. 1976. Climatic patterns and the distribution of $\mathrm{C}_{4}$ grasses in North America. Oecologia 23:1-12.

Tieszen, L. L., D. J. Ode, P. W. Barnes, and P. M. Bultsma. 1980. Seasonal variation in $\mathrm{C}_{3}$ and $\mathrm{C}_{4}$ biomass at the Ordway Prairie and selectivity by bison and cattle; $\mathrm{pp}$. 165-174 in C. L. Kucera (ed.), Proceedings of the 7th North American Prairie Conference. Southwest Missouri State University. Springfield, Missouri.

Toomey, R. S. I. 1993. Late Pleistocene and Holocene faunal and environmental changes at Hall's Cave, Kerr County, Texas. The University of Texas at Austin. Unpublished doctoral dissertation. $560 \mathrm{pp}$.

Turkowski, F. J. 1975. Dietary Adaptability of the Desert Cottontail. The Journal of Wildlife Management 39:748-756.

Ugan, A., and J. Coltrain. 2011. Variation in collagen stable nitrogen values in blacktailed jackrabbits (Lepus californicus) in relation to small-scale differences in climate, soil, and topography. Journal of Archaeological Science 38:1417-1429.

Ungar, P. S. 2010. Mammal Teeth. The Johns Hopkins University Press. Baltimore, MD. 304 pp.

Van Auken, O. W. 1997. Germination requirements of aerial chasmogamous florets and seeds of Nassella leucotricha (Poaceae). The Southwestern Naturalist 42:194-200.

Vander Wall, S. B. 1990. Food Hoarding in Animals. The University of Chicago Press. Chicago, IL. 445 pp.

Volaire, F., and M. Norton. 2006. Summer dormancy in perennial temperate grasses. Annals of Botany 98:927-933. 
Whitlock, M. C. and D. Schluter. 2009. The Analysis of Biological Data. Roberts and Company Publishers. Greenwood Village, CO. 700 pp.

Yu, Z., and H. E. W. Jr. 2001. Response of interior North America to abrupt climate oscillations in the North Atlantic region during the last deglaciation. Earth-Science Reviews 52:333-369.

Zimmerman, J. K., and J. R. Ehleringer. 1990. Carbon isotope ratios are correlated with irradiance levels in the Panamanian orchid Catasetum viridiflavum. Oecologia 83:247-249. 